Florida International University FIU Digital Commons

$11-10-2008$

\title{
Municipal accountability : should regulations similar to the Sarbanes-Oxley Act apply to the local sector?
}

Douglas Ray Fink

Florida International University

DOI: $10.25148 /$ etd.FI15101401

Follow this and additional works at: https://digitalcommons.fiu.edu/etd

Part of the Public Affairs, Public Policy and Public Administration Commons

\section{Recommended Citation}

Fink, Douglas Ray, "Municipal accountability : should regulations similar to the Sarbanes-Oxley Act apply to the local sector?" (2008). FIU Electronic Theses and Dissertations. 3325.

https://digitalcommons.fiu.edu/etd/3325 


\section{FLORIDA INTERNATIONAL UNIVERSITY}

Miami, Florida

\section{MUNICIPAL ACCOUNTABILITY: SHOULD REGULATIONS SIMILAR TO THE SARBANES-OXLEY ACT APPLY TO THE LOCAL SECTOR?}

A dissertation submitted in partial fulfillment of the

requirements for the degree of

DOCTOR OF PHILOSOPHY

in

PUBLIC MANAGEMENT

by

Douglas Ray Fink

2008 


\section{To: Dean Kenneth Furton}

College of Arts and Sciences

This dissertation, written by Douglas Ray Fink, and entitled Municipal Accountability: Should Regulations Similar to the Sarbanes-Oxley Act Apply to the Local Sector?, having been approved in respect to style and intellectual content, is referred to you for judgment.

We have read this dissertation and recommend that it be approved.

Sukumar Ganapati

Eric F. Wagner

Keith D. Revell

Date of Defense: November 10, 2008

The dissertation of Douglas Ray Fink is approved.

Dean Kenneth Furton College of Arts and Sciences

Dean George Walker University Graduate School

Florida International University, 2008 
C Copyright 2008 by Douglas Ray Fink

All rights reserved. 


\section{DEDICATION}

This dissertation is dedicated to my wife Patricia, who encouraged me to complete this life long goal and supported me throughout the arduous process. To my mother and children who always believed in my ability to succeed. To my late father who encouraged me to complete my journeys. 


\section{ACKNOWLEDGMENTS}

I would like to thank all of my committee members for their time and effort in guiding me through the dissertation effort. I would especially like to thank Dr. Howard Frank for his patience, understanding, and guidance. Without his constant persistence this research would never have been completed. 


\section{ABSTRACT OF THE DISSERTATION}

MUNICIPAL ACCOUNTABILITY: SHOULD REGULATIONS SIMILAR TO THE SARBANES-OXLEY ACT APPLY TO THE LOCAL SECTOR?

Douglas Ray Fink

Florida International University, 2008

Miami, Florida

Professor Howard A. Frank, Major Professor

As America moved into the $21^{\text {st }}$ century financial scandals associated with large publicly traded corporations brought widespread concern about the reliability of financial reporting. In response the U.S. Congress adopted the Sarbanes-Oxley Act of 2002 (SOX). Undergirding SOX was the belief that improvements in the reliability of an organization's financial disclosures would lead to increased trust in the issuing organization.

While SOX is aimed at publicly traded private sector organizations, the value of adopting SOX-like practices in the public and the nonprofit sectors have been recognized. Although SOX-like auditing practices have not at the time of this research become part of the auditing regime for municipalities, the results of this research provide a baseline "read" of municipal finance officers' perceptions of the value and obstacles associated with adoption of two major components of SOX: Principal Officer(s) Certification (POC) and the Independent Audit Committee (IAC) requirements.

The author mailed surveys to all finance officers of municipalities in Florida and Ohio with populations of 10,000 or greater which did not contract out the operation of 
their finance departments. Post-survey "elite" interviews were conducted in an effort to obtain a deeper understanding of revealed issues and contradictions found in the analysis of the results of the mails survey.

The findings suggest municipal finance officers are willing to adopt POC but have reservations about implementing IAC. With both POC and IAC the respondents appeared to consider intangible, non-pecuniary consequences as much or more than tangible, pecuniary consequences. Consistent with prior research, attitudes regarding POC and IAC were found to be unrelated to prior adoptive behavior, or personal and organizational demographic variables. Although accounting and auditing are inexorably intertwined, views of the recently implemented GASB 34 reporting model were found to be unrelated to the willingness to adopt POC or IAC.

Findings dovetail with current discourse in public sector accounting suggesting local finance professionals may see benefits - - both tangible and intangible - to some but not all accounting practices adopted in the private sector. This is consistent with the commonly accepted belief that public sector accounting maintains fundamental differences from its private counterpart. 
TABLE OF CONTENTS

CHAPTER

PAGE

I. INTRODUCTION ................................................... 1

II. CONCEPTUAL FRAMEWORK HYPOTHESES AND QUESTIONS.... 22

III. METHODOLOGY................................................. 36

IV. ANALYSIS AND PRESENTATION OF FINDINGS BASIC QUANTITATIVE FINDINGS AND FACTOR ANALYSIS.............. 44

V. PRELIMINARY CAUSAL FINDINGS ELITE INTERVIEWS........... 77

VI. DISCUSSION OF THE STUDY AND SUMMARY OF FINDINGS...... 96

REFERENCES........................................................ 108

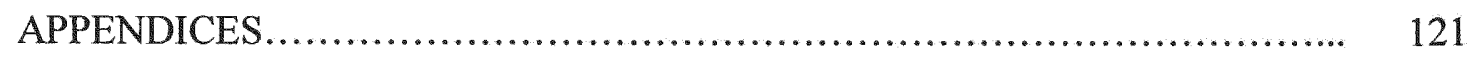

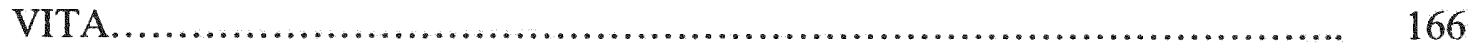




\section{LIST OF TABLES}

TABLE

PAGE

4-1 Responses by State ............................................... 45

4-2 Responses by City Size ............................................ 45

4-3 Should POC be implemented as a required practice? ............................... 46

4-4 If your City was required, or voluntarily adopted, Principal Officer(s) Certifications, who should sign and attest to the accuracy and completeness?....

4-5 Potential benefits associated with a municipality either being required or voluntarily adopting Principal Officer(s) Certification.................

4-6 Potential implementation issues (costs) associated with a municipality adopting Principal Officer(s) Certification.

4-7 Attitudes toward implementing mandatory Independent Audit Committee: Need for implementation by size of community.

4-8 Support for Independent Audit Committee implementation by respondent's community size

4-9 Benefits associated with a municipality either being required or voluntarily adopting an Independent Audit Committee....

4-10 Implementation issues (costs) associated with a municipality adopting an Independent Audit Committee.

4-11 Attitudes toward orientation of government accounting................ 59

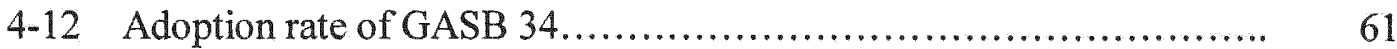

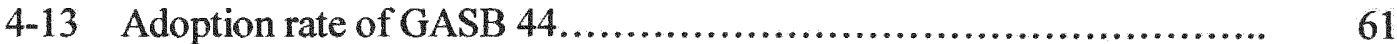

4-14 Gender.......................................................... 62

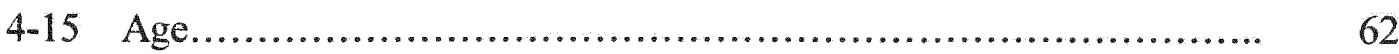

4-16 Education......................................................... 63

4-17 Certified Public Accountants......................................... 63 
4-18 State Location....................................................... 63

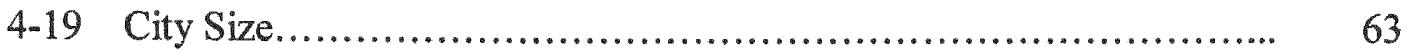

4-20 Chief administrative officer of municipality.......................... 64

4-21 Selection of chief financial officer................................... 64

4-22 Chief financial officer directly reports to whom........................ 64

4-23 Communalities: Principal Axis Method - No Rotation................. 67

4-24 Factor loadings equal to or greater than 10.401 value: Principal axis method - no rotation...................................................

4-25 Alternative factor extraction models: principal axis method - varimax rotation.

4-26 Comparison of factor structure of 2-factor model vs. 3-factor model: 23 observed variables - varimax rotation.

4-27 2-Factor model: factor loadings $\geq|0.40|$ : principal axis method varimax rotation.

5-1 Consequences specifically related to POC: Factor loadings $\geq|0.40|$ :

Principal axis method - varimax rotation.

5-2 Consequences specifically related to IAC: Factor loadings $\geq|0.40|$ :

Principal axis method - varimax rotation.

5-3 POC regressed upon factor scores: Multiple regression................ 80

5-4 IAC regressed upon factor scores: Multiple regression.................. 80

5-5 Ordinary least squares regression of POC on associated consequences: Full model and reduced model.

5-6 Ordinary least squares regression of IAC on associated consequences: Full model and reduced model.

5-7 Logistic regression: Strongly agree/agree vs. disagree/strongly disagree: "In general, I believe principal officer(s) certification similar to SOX should be required of the principal officer(s) of municipalities.". 
5-8 Logistics regression: Strongly agree/agree vs. disagree/strongly disagree: "Should municipalities be required to have an independent audit committee with responsibilities similar to the requirement of Sarbanes-Oxley?" 


\section{LIST OF ABBREVIATIONS AND ACRONYMS}

AAA American Accounting Association

AICPA American Institute of Certified Public Accountants

CAFR Comprehensive Annual Financial Report

CEO Chief Executive Officer

CFO Chief Financial Officer

CM Convergence Model

COSO Committee of Sponsoring Organizations of the Treadway Commission

CPA Certified Public Accountant

FASB Financial Accounting Standards Board

GAAP Generally Accepted Accounting Principles

GAAS Generally Accepted Auditing Standards

GAGAS Generally Accepted Government Auditing Standards

GAO U.S. Government Accountability Office

GASB Governmental Accounting Standards Board

GFOA Government Finance Officers Association

IA Theory of Innovation Acceptance

IAC Independent Audit Committee

NCGA National Council of Governmental Accounting

NPM New Public Management

OMB U.S. Office of Management and Budget

PAFR Popular Annual Financial Report

PCAOB Public Company Accounting Oversight Board 
POC Principal Officer(s) Certification

SEC U.S. Securities and Exchange Commission

SOX Sarbanes-Oxley Act of 2002

TID Theory of Innovation Diffusion

TPB Theory of Planned Behavior 


\section{CHAPTER I}

\section{INTRODUCTION}

As America moved into the $21^{\text {st }}$ century financial scandals associated with Enron, Adelphia, Tyco, and WorldCom brought about widespread concern about the reliability of financial reporting in the publicly-traded private sector (Grumet, 2007, p. 7). To calm the raging crisis of confidence in American capitalism the U.S. Congress adopted the Sarbanes-Oxley Act of 2002 ("A price worth paying," 2005, p. 83). Undergirding the SOX legislation was the belief that improvements in the reliability of an organization's financial disclosures will lead to increased trust in the organization. In an effort to increase the reliability of financial reporting the framers of SOX focused on greater independence of those involved in the auditing-assurance process and specific assignment of responsibility for accurate reporting.

Because SOX was implemented to correct problems in the private sector "there is a great inclination for those in government service, whether local, state, or federal, to view the problems as relating only to the private sector and as not really impacting or having implications for the governmental sector" (Brown, 2005, p. 20). In contrast, those concerned with regulating and guiding public sector and nonprofit financial auditing practices have taken a different view. Federal agencies have already come under SOXlike regulations (Duquette, 2005; George, 2005; Hawkins \& Hardwick, 2005). Several state legislatures have either passed or are considering proposals imposing SOX-like requirements on nonprofit entities ${ }^{1}$ (Mulligan, 2007; Holt, 2006; Vermeer, Raghunandan, \& Forgione, 2006). At the state and local level SOX-like requirements have not yet been

\footnotetext{
${ }^{1}$ California, Connecticut, Kansas, Maine, New Hampshire, and West Virginia have passed acts codifying some SOX-like reforms for nonprofits. New York and Massachusetts have proposed bills (Mulligan, 2007).
} 
imposed, but the latest version of the Government Finance Officers Association's (GFOA) Recommended Practice for Audit Committees (2006) captures essential ingredients of the structure and operation of audit committees as required by SOX (Gauthier, 2007a). Whether SOX-like practices for the nonprofit and government sectors will be imposed regulations or be expressed as recommendations of "best practices;" SOX-like principles appear to be coming to the local government sector.

The broad question of this study is whether SOX-like regulations should apply to municipalities? It is acknowledged that whether SOX-like regulations should apply to municipalities will be influenced by future events, many actors, and institutional-political forces. Both regulators and those regulated will influence the decision. One of the key actors which will influence whether SOX-like regulations should apply to the municipal sector is the municipal finance officer.

The views of the municipal finance officers are important because they are the administrative officers with the technical expertise who generally would have the responsibility for interpreting and implementing any new audit requirements (Del Vecchio, Johnson, \& Magner, 2007). Their collective views have the potential to impact the shaping of SOX-like requirements for the municipal sector. In short, the municipal finance officers are at the nexus of the regulation and how it is implemented.

The focus of this study is on the willingness of municipal finance officers to have their municipalities being required to adopt new SOX-like auditing requirements. The study considers the municipal finance officers' perception of the consequences and obstacles related to acceptance of two major components of SOX: Principal Officer 
Certification (POC) and Independent Audit Committee (IAC) requirements, as well as other factors that may influence their views.

Why a Study of Whether Enhanced Audit Requirements Should Come to the Municipal Sector?

This study is being undertaken at a time when actions taken in the U.S. and internationally are aimed at improving the relevance and reliability of governmental financial reporting. Relevance is related basically to what is measured, how it is measured, and the form of reporting the financial information in the organization's financial statements. Reliability of accounting information can be thought of as the processes and procedures which provide assurance that what is reported in the financial statements is accurate and not misleading. Both relevance and reliability are "primary qualities that make accounting information useful for decision making" (FASB Concept Statement No. 2, 1980, p. 5).

Accounting information can be used in service to different informational needs. One form is the budget which has been recognized as "the most important financial document in government" (Cote \& Herron, 2000, p. 32). The budget serves the important role of providing information about how the government intends to spend the taxpayers' money (Rubin, 2000). Another use of accounting information involves the use of managerial accounting techniques, such as activity based costing, which can be "tailored to the individual needs of a jurisdiction [that can] make a local government more efficient and effective" (McCue, Gianakis, \& Frank, 2007, p. 156). A final major use of accounting information is in the preparation of the audited financial statements. While 
the budget provides a prospective view of the financial activities of the government, the audited financial statements provides a retrospective view.

Budgeting, management accounting, and audited financial statements all serve the larger important public administration issues of accountability and trust in government. Recognizing that both accountability and trust in government are broad concepts which are multi-faceted and complex, there is a general recognition that enhanced accountability can facilitate greater trust in government (Fard \& Anvary Rostamy, 2007). Acknowledging there are many factors which affect accountability and trust, the growing importance of financial accounting and auditing for serving governmental accountability has been recognized both in the U.S. and internationally (Staats, 1996). As Andersen (1997) from the World Bank stated:

Financial accountability is a broad concept which embraces accounting and auditing as fundamental elements of stewardship. Stewardship requires integrity and an attitude of responsiveness and responsibility, which in turn leads to good governance.... Without financial accountability, good governance is impaired (Para. 3).

The enactment of the SOX legislation by the U.S. Congress supports the view that financial accounting and auditing serve accountability and trust. Although SOX was aimed at restoring trust in corporate America (Raxaee \& Crumbly, 2007), adoption of SOX-like regulations for increasing trust in government has been recognized (Walker, 2005; Brown, 2005). The possibility of SOX-like enhanced auditing regulations coming to the municipal sector is what inspired this study. 
What is Sarbanes-Oxley?

President George W. Bush characterized SOX as "the most far reaching reform of American business practices since the time of Franklin Delano Roosevelt" (cited in "The Laws," 2005, para. 21). Yuji Ijiri (2005) refers to SOX as "the most important legislation on securities transactions and accounting issues since the establishment of the SEC" (p. 256-257). SOX mandates a number of reforms intended to facilitate the reliability of financial reporting and transfer the risk for "honest reporting" from the external stakeholders (e.g. citizenry, investors, legislative and oversight bodies, and creditors) to primarily the organization's management (Ijiri, 2005, p. 266).

SOX has not been without its critics. Its implementation has been timeconsuming and expensive. ("A price worth paying," 2005; Feldman, 2005; Levisohn, 2005). Many have argued the additional financial reporting assurances called for under SOX have done little to make the average shareholder or other stakeholder more comfortable with corporate behavior or more immune to insider manipulation. Some have even argued that SOX implementation has deterred corporate start-ups, driven publicly-traded firms off the exchanges, or sent American capital overseas. In short, these critics see SOX as well-intended but a form of "overkill" that adds additional costs to the financial reporting process for the corporation with little tangible payoff to stakeholders (shareholders, managers, and the public).

Notwithstanding these criticisms, SOX's repeal seems remote, but relaxation of some provisions, especially Section $404^{2}$, is probable (Barlas, 2007). Meanwhile,

\footnotetext{
${ }^{2}$ Section 404 requires the management and the external auditor to report on the company's internal control over financial reporting. It is often described as the most costly and controversial provision of the SOX legislation requiring a great deal of documentation and testing (Levisohn, 2005; Grumet, 2007; Bedard, Graham, Hoitash, \& Hoitash, 2007).
} 
corporate America has accepted — albeit grudgingly — the additional time, expense, and effort needed to improve the reliability of their financial disclosures. On a related front, the Securities and Exchange Commission and others in the Securities arena have implemented the SOX requirements while performing their own "clean-ups" of the mutual fund industry, and even the New York Stock Exchange itself. In short, the drive toward more reliable financial statements and responsible corporate behaviors are a tandem that will not soon disappear from the financial landscape. The recent large bankruptcies and bail-outs of financial institutions underscore the continuing need for more reliable financial information and responsible corporate behavior.

SOX reforms, which are intended to improve "the accuracy and reliability of corporate disclosures" (SOX, Preamble), can be classified into two general groups. First are those reforms which deal with the external parties who are involved in the assurance process and marketing of the securities (Parles, O’Sullivan, \& Shannon, 2005, p. 38). For example, SOX has changed the relationship of corporations with their external auditors, brought the establishment of auditing standards and oversight of the auditing profession under Federal control through the Public Company Accounting Oversight Board ${ }^{3}$ (PCAOB), and affected the standards and rules of stock market exchanges.

The second other general classification includes those provisions which are directed at the management and directors of the corporation. These are provisions specifically addressed to issues of individual responsibility, independence of the audit committee and the design and review of the internal controls. Generally they are

\footnotetext{
${ }^{3}$ It should be noted that while the SOX legislation allowed for the SEC to have control over accounting standards, the PCAOB chose to continue having the accounting profession determine accounting standards. As stated by Boster (2007), "there does not seem to be in compelling explanation for why the ' $A$ ' in PCAOB stands for 'Accounting' rather than the more descriptive 'Auditing,' given the statutory mission" (p. 131).
} 
provisions which deal with "who is accountable for what" with implications for what constitutes good governance.

The two major provisions included in this study are the "Principal Officer(s) Certification" (POC) and "Independent Audit Committee" (IAC) requirements. In short, POC requires the Chief Executive Officer (CEO) and the Chief Financial Officer (CFO) to take "personal responsibility for financial statements" with failure to do so possibly resulting in criminal penalties (Williams, 2005, p. 255). The essence of IAC is the requirement for companies to have an audit committee comprised of independent directors with at least one member being a "financial expert" (Parles et al, 2007, p. 39).

Principal Officer(s) Certification (POC) and Independent Audit Committee (IAC)

POC and IAC reflect basic tenets of SOX which address the involvement and participation of top management and directors in the assurance (auditing) process. They are intended to enhance the reliability of what is reported in the financial statements. Perhaps most importantly, from a research perspective, both POC and IAC are not totally foreign to the municipal accounting/auditing process. This should allow the respondents to the research instrument to more reliably relate to questions regarding these components (Neuman, 1997, p. 236).

An attenuated form of POC currently exists with municipal financial reporting when the Comprehensive Annual Financial Report (CAFR) includes a "letter of transmittal" and the external auditor has been provided with a "management representation letter." The letter of transmittal is typically addressed to the citizens of the community and signed by executive officers of the city. It refers to how the financial 
statements are, to the best of the signing officers' knowledge and belief, accurate. The management representation letter is addressed to the external auditor, signed by the executive officers of the city, and basically assures the external auditors that all material financial information concerning the city has been provided to the auditors. Neither letter legally assigns personal responsibility to the signing officers and allows for them to have "plausible deniability" regarding any uncovered misrepresentations in the financial statements (see for example the Enron case).

The thrust of POC is in assigning legal and personal accountability to the signing officers. If nothing else, the POC provision makes it clear the top management of an organization are ultimately responsible for the audited financial statements. Attesters can no longer simply claim "unawareness" of any misrepresentation. The signing officers are certifying the financial statements do not contain any untrue statements or omit any statements of a material fact which would make the report misleading. The certifying officers are assuring the users that the financial statements fairly present in all material respect the financial condition and results of operations of the issuer. The signing officers, along with other management, are assigned responsibility for the establishment, maintenance, and effectiveness of the internal controls and that any material weaknesses are reported to the issuer's external auditors. Failure to comply with these requirements can subject the signing officers to criminal penalties (SOX, 2002, Sections $302,404, \&$ 906). The responsibilities assigned to the principal officers are significantly greater than existing requirements and key components of POC were explained in the survey instrument (Appendix A), 
Although the Government Finance Officers Association (GFOA) has recommended the use of an audit committee since 1997, anecdotal evidence suggests wide-spread adoption of audit committees by municipalities has not occurred. Even if wide-spread adoption had occurred, the requirements of IAC significantly change the structure and operation of audit committees. Nevertheless, as a result of the efforts of GFOA, the general concept of an audit committee should not be totally foreign to municipal finance officers.

As explained in the survey instrument (Appendix A), the IAC emphasizes the independence of the members and assigns them responsibility for selecting, overseeing, communicating, and employing the external auditors. The IAC is required to have at least one member who is an "expert" in accounting. The IAC provisions imply the members of the committee should be knowledgeable of financial accounting and auditing and should understand the operations and operating environment of the organization, especially financial risks that may be threats to the organization (SOX, 2002, Sections 202, 301, \& 407; Beasley, Carcello, \& Hermanson, 1999).

\section{Could SOX-like Practices be Coming to Municipalities?}

SOX-like practices such as POC and IAC are enhanced auditing standards. In the U.S. the source of auditing standards for municipalities is a complex interrelated network of state law ${ }^{4}$, federal regulation, and the auditing profession. In addition there are professional associations, such as the Government Finance Officers Association (GFOA), which can recommend "best practices." From the perspective of nation-wide auditing

\footnotetext{
${ }^{4}$ In the U.S. federalist system the individual states have authority over the accounting and auditing procedures and practices of municipalities.
} 
standards for municipalities there are currently two primary sources. The American Institute of Certified Public Accountants (AICPA) publishes what is referred to as Generally Accepted Auditing Standards (GAAS). For those municipalities receiving grants from the federal government their audits must also conform to the Generally Accepted Government Auditing Standards (GAGAS) published by the U.S. Government Accountability Office (GAO). In addition, the Securities and Exchange Commission (SEC) has limited authority if fraud is indicated in the financial statements of municipalities which issue municipal securities ${ }^{5}$ (SEC 2007). At the time of this study neither POC nor IAC are auditing standards applicable to the municipal sector. Nevertheless, there have been signals that indicate POC and IAC may become requirements for the municipal sector.

The recognition of the importance of SOX-like regulations in the public sector first occurred at the federal level. The federal agencies came under the influence of SOX-like requirements through revisions of the Office of Management and Budget (OMB) Circular A-123, Management's Responsibility for Internal Controls. Hawkins and Hardwick (2005) described the revisions to Circular A-123 as mirroring "the spirit of SOX" (p. 57). These revisions, which became effective in 2006, require federal agencies to follow the Treadway Commission's Committee of Sponsoring Organizations (COSO) ${ }^{6}$ guidance on internal control called Internal Control-Integrated Framework (which also serves as the grounding for the independent audit committee and internal control

\footnotetext{
${ }^{5}$ Municipal securities is a term which refers to bonds, notes, and other debt instruments issued by states, local governments, or their agencies and instrumentalities (Cox, 2007).

${ }^{6} \mathrm{COSO}$ is an independent private sector committee formed in 1985 and sponsored by the American Accounting Association (AAA), The American Institute of Certified Public Accountants (AICPA), Financial Executive International (FEI), the Institute of Internal Auditors (IIA), and the Institute of Management Accountants (IMA).
} 
requirements of SOX). These COSO provisions were also referenced in the so-called "Yellow Book," published by the GAO, which governs internal control and auditor standards applied to federal and local entities under its regulatory domain (Marcia Buchanan, personal communication, January 12,2006 ). The revisions to OMB Circular A-123 and recommendations of the "Yellow Book" require federal agencies to follow requirements which are similar to SOX, but modified to accommodate the different environment of the federal government sector. As David Walker, former Comptroller General and head of the GAO stated, "the GAO continues to monitor the implementation of the major accountability provisions in SOX and, when appropriate, to promote their application in government" (Walker, 2005, p. 270).

In the nonprofit sector there is a movement to incorporate certain aspects of SOX as best practices (Smith \& Richmond, 2007; Holt, 2006). SOX-like reforms have been proposed in New York and Massachusetts and have been enacted in California, Connecticut, Kansas, Maine, and New Hampshire (Mulligan, 2007). Generally these statutes have focused on POC and IAC (Mulligan, 2007).

At the state and local level SOX is not yet a requirement. However, there is some evidence that SOX-like regulations may be on the horizon. The 2006 version of the Government Finance Officers Association's (GFOA) Recommended Practice for Audit Committees reflects some of the basic ingredients regarding the structure and operation of audit committees similar to the IAC requirement (Gauthier, 2007a). In addition, during 2007 the Securities and Exchange Commission (SEC) requested changes to the current regulatory environment of municipal securities (Gaffney, 2007). While the white paper sent to Congress by the SEC did not specifically suggest that SOX should be required for 
municipalities which issue municipal bonds, the SEC did speak to its need to have additional authority "To provide investors in municipal securities with access to full, accurate, and timely information like that enjoyed by investors in many other U.S. capital markets" (SEC, 2007, p. 4).

These "signals" illustrate the recognition by regulators and professional associations of the value of POC and IAC to the public and nonprofit sectors. Nonetheless, to bring SOX-like POC and IAC as regulations to the municipal sector important issues need to be resolved; perhaps the most important being the issue of who would author and enforce the regulations. Another question is what changes in state law, such as "Sunshine" provisions, are necessary. These are issues beyond the scope of this study.

The focus of this study is on the willingness of municipal finance officers to have their municipalities be required to adopt new auditing requirements similar to $\mathrm{POC}$ and IAC. Because auditing and accounting are so inexorably intertwined, exploring the municipal finance officers' views of the recently implemented Governmental Accounting Standards Board ${ }^{7}$ (GASB) 34 reporting model are considered because they may influence the finance officers' intentions to adopt or oppose POC and IAC. The background of the development of the GASB 34 reporting model is important to this study because it provides insight into why financial reporting has become a more important topic in public administration financial management.

\footnotetext{
${ }^{7}$ The Governmental Accounting Standards Board (GASB) is not a governmental entity. The GASB is a component of the professional accounting structure. The GASB publishes standards, referred to as Generally Accepted Accounting Principles (GAAP) for state and local governments. Although the states have the authority to set accounting principles, most states have recognized the GASB as the official source for GAAP.
} 


\section{Convergence Model and New Public Management}

The importation of SOX-like practices into the governmental sector can be viewed as part of a broader mosaic of imposing business-like accounting practices onto the public sector which has been occurring in the U.S. and elsewhere. The importation of business-like accounting practices and reporting into the government sectors, herein referred to as a Convergence Model $(\mathrm{CM})$, has received substantial coverage in the literature (Christiaens \& Rommel, 2008). The CM plays a central role in the New Public Management (NPM) and has led to what some view as a new era of financial management under the rubric of the New Public Financial Management (NPFM) (Vinnari and Nasi, 2008).

From a global perspective the conceptual support and involvement of the NPM movement has been important and substantial. Under the broad umbrella of the NPM movement there has been recognition of how accounting can be utilized as an "instrument of change" for re-inventing government and impacting management practices (Lapsley \& Pallot, 2000). As Peter Smith (1996) stated, "Much of the impetus behind the new public sector management arises from a conviction that the methods of accounting applied to the corporate sector can be transferred to the public sector" ( $p$ xi). Coincident with the goals of the NPM many countries have embraced adopting privatesector accounting techniques in the public sector. As June Pallot (1999) noted, "Accounting has been a key element in supporting the removal of public/private sector distinctions and the imposition of explicit and measurable standards of performance" ( $p$. 419). 
Although the impact of the NPM movement is more evident in the accounting practices outside the U.S. ${ }^{8}$, the NPM movement and its counterpart the "reinventing government" (REGO) movement, illustrate public administration perspectives that endorse a greater role for private-sector accounting practices in the public sector. In the U.S. an "official" adoption of business-like accounting practices by the local public sector has been a result of actions taken by the Governmental Accounting Standards Board (GASB).

Formation and Rise of the GASB

Unlike the private sector where Generally Accepted Accounting Principles (GAAP) for accounting have existed on a nation-wide basis for some time, up until the 1980s "all 50 states had different accounting procedures" (Icerman \& Simson, 1996, p. 75). During the 1970 s the financial crisis of several major cities, especially the New York default, brought the problems of a lack of national standards for municipal reporting and enforcement to the forefront. Several bodies, including the National Committee on Governmental Accounting (NCGA), the Financial Accounting Standards Board (FASB), and U.S. Senate became involved in the debate about who should have control over the reporting standards and enforcement of state and local governmental accounting (Burton, 1980, p. 13-14). There were perceived weaknesses with each of the candidates; finally in 1984 a compromise was reached with the establishment of the Governmental Accounting Standards Board (GASB).

\footnotetext{
${ }^{8}$ For example, in New Zealand and Australia there has been almost a wholesale importation of businesslike accounting measurements into the governmental sector (Karan, 2003; Carnegie \& West, 2005).
} 
The GASB was empowered to establish accounting standards for state and local governments and enforce them when a Certified Public Accountant (CPA) audited the financial statements. Although individual states continued to have ultimate authority over the standards of financial accounting and reporting for municipalities located within their jurisdiction, most of the states chose to require municipalities to follow the GAAP determined by the GASB. In addition, many cities elected to have their annual financial report audited by CPAs. For the first time in American history the GASB provided a single authority for determining the proper accounting and reporting for municipalities on a national basis?

In the formative years the actions of GASB did not make substantial changes to basic municipal accounting procedures and practices. The first signs of a significant change in municipal accounting occurred when the GASB completed its work on a new reporting model that had been on its agenda from the inception (Foltin, 2008). The new reporting model was introduced in 1999 with the issuance of GASB Statement 34, Basic Financial Statements- and Management's Discussion and Analysis-for State and Local Governments (GASB 34). Depending upon the size of the municipality, implementation occurred in the fiscal years ending in 2002 through 2004.

Significance of GASB 34

Similar to the recognition of SOX as "the most important legislation on securities transactions and accounting issues since the establishment of the SEC" (Ijiri, 2005);

\footnotetext{
${ }^{9}$ It should be noted that while most of the states have required municipalities to adopt the GAAP as determined by GASB there remain some states which have not required GASB compliance (e.g. New Jersey) and recently some states have rejected more recent pronouncements related to retirement benefits other than pensions (e.g. Texas).
} 
GASB 34 has been described as "the most significant change in the history of governmental accounting" (Allen, 1999). The statement requires the "flow of economic resources measurement focus" and "accrual basis of accounting" for the newly required government-wide financial statements. In short, these new business-like reporting and measurements make the financial information provided by municipalities more like private sector financial accounting and reporting. The most controversial aspect of the new requirements was the recognition of long-term assets and long-term liabilities in the new entity-wide "balance sheet-like" Statement of Net Assets and the recognition of depreciation expense on the capital assets (including infrastructure) in the new entitywide "income statement-like" Statement of Activities (Foltin, 2008).

While GASB 34 did require adoption of business-like practices such as accrual accounting and entity-wide reporting (which are consistent with practices in other nations), it also retained a set of the traditional reports and accounting. The practical impact of this dual approach is that it allows municipalities to continue to use traditional fund accounting ${ }^{10}$ in their daily operations. At the same time users of the annual financial statements have reports related to both "fiscal accountability" and "operational accountability" (GASB 34).

Fiscal accountability serves the important traditional role of governmental accounting by providing information about the government's current period legal compliance in "raising and spending of public moneys" (GASB 34, 1999, para. 203). Operational accountability has the goal of providing information in the financial statements which assist users in assessing the municipality's "operating results; cost of

\footnotetext{
${ }^{10}$ Traditional fund accounting includes recognition of the legislative adopted budget, encumbrances, and expenditures.
} 
services; economy, efficiency, and effectiveness; and interperiod equity" (GASB 34, 1999, para. 234). The accounting profession recognizes that operational accountability is complex and very difficult to measure in the public sector ${ }^{11}$. In releasing GASB 34 the GASB acknowledged the required government-wide financial statements would contribute to operational accountability, but that additional information and standards would be needed (GASB 34, 1999, para. 234).

As currently constituted the GASB 34 reporting model is complex and difficult to read (Chase \& Phillips, 2004, p. 27) and as the accounting profession has stated: "Information cannot be useful to decision makers who cannot understand it" (FASB Concept Statement 2, 1980, p. 5). Neither has the model resolved the difficult issues surrounding the measurement of program effectiveness and performance reporting. In spite of these shortcomings and some controversy, the GASB 34 reporting "appears to be firmly embedded in contemporary public financial management" and "knowledge of the standard is sine qua non for new graduates of public administration programs" (Frank, Gianakis, \& McCue, 2005, p. 558-559).

The significance of the GASB 34 reporting model to this study is whether the municipal finance officers experiences with implementing the GASB 34 reporting model influences their intentions to adopt or oppose POC and IAC. Although POC and IAC are auditing standards which are different from accounting principles, accounting and auditing are so inexorably intertwined it is possible the experiences with implementing the GASB 34 reporting model may influence the municipal finance officers' intentions to adopt or oppose POC and IAC. As a result, consideration of the municipal finance

\footnotetext{
${ }^{11}$ See for example the American Accounting Association's 1972 release of the Report of the Committee on Concepts of Accounting Applicable to the Public Sector, 1970-71.
} 
officers' assessment of the value and appropriateness of the GASB 34 reporting model is included in the survey instrument (Appendix A).

\section{Controversial Issues}

This study is conducted at a time when there are some important issues surrounding U.S. municipal financial accounting and auditing. Although most of the states have required compliance with the GASB GAAP, it is still a voluntary act by each state. The basic tenet of federalism gives the power to each state to set accounting and auditing standards for themselves and their municipalities. Recent actions have raised questions about whether individual states will continue requiring municipalities to comply with GASB GAAP ${ }^{12}$. Another stream of discord has come from the much respected GFOA. The GFOA has stated it is reassessing its support for GASB and perhaps opting for the Financial Accounting Standards Board (FASB) to become the authoritative accounting body for state and local governments (GFOA, 2007).

Partially in response to the dissension from GASB GAAP, the SEC has indicated an interest in having legislation which would allow the SEC to designate the GASB as the official body for designating GAAP for municipalities (SEC, 2007). In the same document the SEC expressed concern that "issuers of municipal securities may lack policies and procedures adequate to ensure accurate and full disclosure in their offering documents and are not legally required to certify the accuracy of their disclosures" (SEC,

\footnotetext{
${ }^{12}$ Municipalities in New Jersey must use statutory accounting methods other than GASB GAAP. Texas has allowed their municipalities to opt-out of complying with GASB 45. Connecticut passed a bill that would have allowed the state to set accounting standards different than GASB, but the bill was vetoed by the Governor.
} 
2007, p. 9). While SOX was not specifically mentioned by the SEC, there was clearly the implication of an interest in imposing SOX-like requirements, especially POC.

If the SEC does receive authority to regulate municipal accounting and auditing, this would be a significant change from the existing municipal financial reporting regime. From a public policy perspective this would represent a shift in power from the states to the federal government. Using the current implementation of SOX in the private sector as a guide, the authority for establishing accounting would remain with the accounting profession (GASB) but auditing standards would come under the direct control of the SEC. The impact for municipal finance directors would be similar to the private sector. Those municipalities which issue bonds through regulated markets would have to conform to an expanded set of auditing standards beyond those municipalities which do not issue such bonds.

Could it happen? The short answer is yes. The total size of the municipal securities market ${ }^{13}$ is enormous, hovering around $\$ 2.5$ trillion. The municipal securities routinely provide financing for the public goods such as roads, parks, schools, and other government provided infrastructure. As Chistopher Cox, Chairman of the SEC commented: "Investors, analysts, investment advisers, and broker-dealers deserve the same level of current, high-quality disclosure and protection in the municipal market as they do in the corporate market" (Cox, 2007). In the same speech, Chairman Cox spoke to how both citizens and taxpayers pay the price "when municipal finance isn't conducted properly."

\footnotetext{
${ }^{13}$ Municipal securities are those bonds, notes, and other debt instruments that are issued by states, municipalities, and other local governmental entities (Cox, 2007).
} 


\section{Significance of Study}

The topic of enhanced auditing standards for the public sector raises important policy issues for public administration and public finance, e.g., federal authority versus states rights, the imposition of private-sector practices onto the public sector, and the role of audited financial reports in serving accountability and trust in government. It is acknowledged that whether SOX-like enhanced auditing standards will be applied to municipalities will be influenced by future events, many actors, and institutional-political forces. The broad question of this study is whether SOX-like enhanced auditing standards should apply to municipalities. Regulators and professional associations have indicated their interest in having both POC and IAC apply to the public sector. The research question of this study is the willingness of municipal finance officers to have their municipality being required to adopt SOX-like POC and IAC.

SOX-like POC and IAC regulations enjoin the leadership and management of the municipality to participate in the assurance (auditing) processes and practices which surround what is reported in the audited financial statements. POC assigns legal and personal responsibility to the signing officers for the accuracy and completeness of the information contained in the audited financial statements. The IAC provides additional oversight of the municipality's auditing processes and practices by an "independent" body.

Research exploring the factors which influence municipal finance officers' willingness to have their municipalities required to adopt new audit requirements is largely unexplored. To fill the gap in this largely unexplored area, this study offers a baseline "read" of municipal finance officers" willingness to embrace POC and IAC and 
identify possible drivers of support or opposition to such requirements. The study considers the municipal finance officer' perception of the consequences and obstacles related to acceptance of POC and IAC, as well as the possible modifying affect of their views toward the GASB 34 reporting model. Intervening events, such as gaining more information about the details of the requirements or how important others view the requirements, may alter the municipal financial officers' views obtained from this study. Nonetheless, this examination of the willingness of financial officers to embrace required POC and IAC and their perception of associated benefits and obstacles will provide preliminary information useful to further studies by public administration researchers, practitioners and others involved in the process.

The research objectives of this study include:

1. Determining the willingness of municipal finance officers to accept required adoption of POC and IAC.

2. Identifying the determinants of the revealed intentions and test the relationship that exists between the determinants and the intention.

3. Uncovering any potential benefits and obstacles associated with required $P O C$ and IAC perceived by the municipal finance officers.

4. Exploring the municipal finance officers' views of the GASB 34 reporting model and whether these views influence their intentions to adopt or oppose POC and IAC. 


\section{CHAPTER II \\ CONCEPTUAL FRAMEWORK \\ HYPOTHESES AND QUESTIONS}

This study is an exploratory effort to discern how municipal finance officers view the imposition of two SOX-like (audit) regulations onto the municipal sector: "principal officer(s) certification" (POC) and an "independent audit committee" (IAC). To the author's knowledge this study is the first to examine the pre-regulation views of municipal finance officers as well as factors that may be influencing their views toward the potential imposition of POC and IAC regulations upon municipalities. In endeavoring to identify the possible drivers of municipal finance officers' support for or opposition to these potentially "new" audit requirements in the municipal sector, the research objectives include: 1) uncovering perceived potential benefits and obstacles associated with required POC and IAC, and 2) exploring how the municipal finance officers' views the new reporting requirements of GASB 34 and whether these views might influence their intention to support or oppose POC and IAC regulation.

Researching the factors which influence a municipal finance officer's support for or opposition to having a "new" auditing requirement imposed upon their municipality is largely unexplored. This is not to say that pre-regulation views of those who would be subject to a new audit regulation are ignored. When a new audit requirement is under consideration by a regulator ${ }^{14}$, an exposure draft is sent to potential regulatees and other interested parties soliciting their views on the audit requirements. Those views are then

\footnotetext{
${ }^{14}$ Regulators of audit requirements on a national basis include the American Institute of Certified Public Accountants, (AICPA), the Government Accountability Office (GAO), and the Public Company Accounting Oversight Board (PCAOB). Of course, individual States can also add additional audit requirements to municipalities within their jurisdiction.
} 
considered by the regulator in revising the exposure draft and releasing a final audit requirement. This "due process ${ }^{15}$ " is basically a process of determining audit requirements from a consensus of "expert" opinions. The importance of expert consensus to the formation of audit regulations is not denied. However, the due process does not provide information about what factors influenced the municipal finance officers' views toward new audit requirements.

Although public sector financial audit regulations are highly technical, from the broader perspective taken in this study they represent administrative processes (Gianakis \& McCue, 1997). Research exploring the factors which influence municipal finance officers' willingness to have their municipalities required to adopt new audit requirements should be of interest to scholars and practitioners in public administration, public finance, accounting, and auditing. To fill the gap in this largely unexplored area, this study is offered as an initial indication of municipal finance officers' perception of the consequences and obstacles related to having their municipality embrace heightened audit committee requirements and specific assignment of personal responsibility for the integrity of the published financial statements. To the author's knowledge, there is no "Unified Theory of Audit Innovation Adoption in the Public Sector" to build upon. Nonetheless, there are several strains of thought that inform this study.

Findings from Accounting Innovation Adoption

Because accounting and auditing are inexorably intertwined the author reviewed recent studies of accounting innovation acceptance in the public sector. Jackson and

\footnotetext{
${ }^{15}$ See for example the discussion of the "due process" in Government Accountability Office's (GAO) exposure draft on proposed revisions to the Generally Accepted Government Auditing Standards (GAGAS) for 2006.
} 
Lapsley (2003) found "the most important reason for accounting innovation in public sector organizations is statute, regulation, or other external pressure.... it overwhelms all other reasons" (p. 366-367). Several scholars have recognized the importance of legislative action, statute, funding sources, and professional interests as external influences on accounting innovation adoption by local governments (Geiger \& Ittner, 1996; Brignall \& Modell, 2000; Cavalluzzo \& Ittner, 2004). That an innovation will be adopted if required by an external body that has authority is certainly not surprising. However, as observed by Mohr (1969) the adoption of an innovation does not necessarily signify the acceptance of an innovation. An organization or individual may adopt an innovation then discontinue it for some reason or maintain it only on a token level (Mohr, 1969, p. 113). In the present study the focus is on the dimension of acceptance of POC and IAC, not on whether POC and IAC will be implemented or adopted if required.

Researchers have found the acceptance of a new accounting innovation to be related to the organizational factors of political leadership, senior management acceptance, organizational culture and norms (Lapsley \& Pallot, 2000; Chia \& Koh, 2007; Cavalluzzo \& Ittner, 2004; Kloot \& Martin, 2007). These findings are supported by similar findings regarding innovation acceptance by public sector entities for innovations other than accounting and will be considered in the present study (VigodaGadot, Shoham, Schwabsky, 2005; Bernier \& Hafsi, 2007; Moon, 1999; Durst \& Newell, 1999; Watson, 1997; Kamal, 1996).

Endorsements by leaders and managers, as well as compatibility with existing organizational norms, have been recognized within the broader findings of diffusion innovation (Rogers, 2003). Diffusion of innovation is one of the most studied of all social 
science topics, although some researchers have argued that innovation research has not emerged as a major theme in public administration (Vigoda-Gadot, Shoham, Schwabsky, \& Ruvio, 2005; see also Rogers, 2003, p. 45). While it may be true that changes in the way things are done in the public sector have not been studied extensively under the rubric of innovation, the extensive literature on public sector reforms suggests public administration has long had an interest in innovation. To assist in the development of a conceptual framework for this study, components of the general theory of innovation diffusion are considered.

\section{Diffusion of Innovations}

Many scholars from disparate disciplines have studied innovation diffusion. Rogers' (2003) reported that when he wrote his first edition of Diffusion of Innovation published in 1962 there existed 405 publications about the topic, by the time he published his fifth edition in 2003 he estimated that publications had grown to 5200 (p. xviii). Perhaps as a result of the diversity of disciplines which have studied innovation with differing goals, different concepts and measures, and diverse methodologies; the findings have often been non-comparable or inconsistent and tend to not be cumulative (Kimberly \& Evansko, 1981, p. 689; Bingham, 1978, p. 179). To at least partially mitigate the diverse findings, scholars have noted distinctions among innovation research.

Early research of innovations often grappled with the distinction between invention and innovation. Mohr (1969) distinguished them as follows: "Invention implies bringing something new into being; innovation implies bring something new into use" (p. 63). Contemporary research has come to define an innovation as "an idea, 
practice, or object perceived as new by an individual or other unit of adoption" (Rogers, 2003, p. 36). As Daft (1978) explained an innovation "can be old to other organizations so long as the idea has not been previously been used by the adopting organization" ( $p$. 197). Required POC and IAC fit the definition of innovations because they are new "administrative innovations" to the municipal sector even though they are existing requirements in the private sector.

The scope of innovation research is wide. It includes the decision to begin research on a recognized or potential problem, to development of an innovation, commercialization, diffusion, to the decision to adopt and implement (Damanpour \& Wischnevsky, 2006; Rogers, 2003). Researchers have recognized the difference in the factors which influence the generation of an innovation and the adoption of an innovation (Damanpour \& Wischnevsky, 2006, p. 271). In the present study the focus is innovation adoption or more specifically on innovation acceptance. As Mohr (1969) has discussed innovation adoption and innovation acceptance may not be synonymous (p. 113). Because the adoption of POC and IAC on a sector-wide basis will most likely occur after they have become a requirement, Malmi (1999) has suggested that motives for an organization facing a "forced selection" will play no role in the adoption or rejection of an innovation (p. 653). The perspective of this research is that understanding the organizational motives, obstacles, and availability of resources for overcoming the obstacles prior to being required to adopt an innovation may facilitate what Mohr (1969) refers to as a "successful" adoption of an innovation.

It has been suggested that distinguishing different types of innovations is necessary for understanding and identifying the factors which influence the decision to 
accept an innovation (Downs \& Mohr, 1976; Damanpour, 1991). Classifications have included "product" innovations versus "process" innovations (Walker, 2006), "technical" versus "administrative" (Damanpour, 1991), "radical" versus "incremental" (Damanpour \& Wischnevsky, 2006), "amenity" versus "need” (Bingham, 1976), etc. Recent research has revealed problems with developing contingency theories of innovation based upon innovation type. For example, Walker (2006) has suggested the distinction between product and process innovations may be inappropriate because they are more "conceptually and operationally alike" than research had assumed (p. 313). Damanpour and Wischnevsky (2006) commented on how "the aggregated results of past empirical studies do not support the theories of organizational innovation based on differences between innovation type" (p. 270). While the importance of distinguishing innovation research by innovation type is arguable, it is acknowledged the findings of this study may be limited in generality to administrative type innovations. Classifying POC and IAC as administrative innovations reflects their close relationship with management processes and procedures (Kimberly \& Evansko, 1981).

Another distinction which is made in the literature is that between the public sector and the private sector. True competition, which is viewed as a fundamental root cause for motivating innovation in the business sector, is non-existent or at best simulated through "quasi-markets" in the governmental sector. Nonetheless, efficiency and effectiveness have generally been cited as the goal for adopting innovations in both sectors (Damanpour, 1991, p. 556). The public sector adoption of private sector management accounting techniques, e.g., Balanced Scorecard, Activity Based Costing, are representative of innovation adoption studies concerned with increasing efficiency 
and effectiveness (McCue, Gianakis, \& Frank, 2007). However, POC and IAC are administrative innovations that have the goal of increasing trust in the financial statements. Unlike innovations which are intended to increase efficiency and effectiveness, POC and IAC would seem to fit within the notion of "legitimacy-seeking" and may be subject to influence by different factors than efficiency and effectiveness (Brignall \& Modell, 2000)

In sum, the findings of this research are limited to public sector innovation acceptance of administrative innovations which are intended to increase trust in the published financial statements. This classification of the study limits the generalizability of the findings. On the other hand, the concentration on this "type" of innovation can assist this exploratory research by helping to identify and isolate factors that can be tested in confirmatory studies (Kimberly \& Evanisko, 1981, p. 691). In addition, there have been some generalizations, or broad consistencies, which emerge from innovation research.

One basic concept which has received general support over the last four decades of innovation research is that individuals and organizations will innovate when the benefits outweigh the costs (Mansfield, 1961; Rogers, 2003, p. 233). The benefits and costs may be of an economic nature or they may be related to intangible factors. The implication is the decision to accept or decline an innovation is directed by some form of a rational action (Rogers, 2003, p. 232; Malmi, 1999).

Another general guideline is that the influence of organizational and personal characteristics may be idiosyncratic variables that have different impacts in different contexts (Gianankis \& McCue, 1997). As moderating variables they may be found to 
have a direct relationship, interactive relationship, or no discernable relationship to the innovation acceptance decision (Venkatesh, Morris, Davis, \& Davis, 2003). In the present study the interest is to determine whether these variables have a significant direct relationship to the acceptance decision of the municipal finance officers in Florida and Ohio.

One broad finding which has been acknowledged in innovation research is that perceived characteristics of the innovation have been found to be most predictive of the innovation acceptance (To \& Ngai, 2007; Rogers, 2003). Several models utilizing the perceived characteristics of the innovation have been offered in the literature: attributes of innovation (Rogers, 2003), the theory of planned behavior (Ajzen, 1988) and its predecessor the theory of reasoned action (Ajzen \& Fishbein, 1980), and the technology acceptance model (Davis, 1989) which was built upon the theory of reasoned action model. The multiple models of innovation acceptance (IA) reflect the research interest of their author, but they all basically focus on how consequences, resources, and obstacles perceived to be related to a specific innovation are major determinants of user acceptance. To inform this study the Theory of Planned Behavior (TPB) was selected because it has been found to be a tightly specified model which has been found useful in multiple contexts, including accounting research (Sutton, 1998; Conner \& Armitage, 1998; Davis, Bagozzi, \& Warshaw, 1989).

Theory of Planned Behavior(TPB)

TPB and its antecedent theory of reasoned action (TRA) were developed in the social-psychology literature by Icek Ajzen and Martin Fishbein. In brief, TRA considers 
"attitude" and "subjective norms" as the constructs for determining the construct "behavioral intention" (Fishbein \& Ajzen, 1975; Ajzen \& Fishbein, 1980). The TPB extends the number of determinates of the TRA by adding "perceived behavioral control" (Ajzen, 1985, 1988, 1991).

Attitude reflects the individual's personal evaluation of the favorable and unfavorable consequences associated with the target behavior (e.g., having additional police on the streets will enhance the "safety image" of the community). Subjective norms are the individual's perception of the expectations of important others to perform or not perform the target behavior (e.g., my city council would support the decision to voluntarily provide greater disclosure of the city's pension obligations). Perceived behavioral control refers to the individual's perception of his ability to perform the target behavior. Perceived ability to perform includes non-motivational factors such as time, money, skills, and cooperation of others (Ajzen, 1991, p. 182). An example of a control belief would be - it would be difficult to find a part of my community which would agree to the development of a landfill.

As Ajzen and Fishbein (1980) stated the general proposition of TPB is consistent with "common sense" (p. 6). If an individual perceives the consequences of an act are on the whole favorable (behavioral beliefs); that others important to him would support the decision (normative beliefs); and if there sufficient resources available and minimal obstacles (control beliefs); the individual is likely to have a favorable intention to perform the act (Ajzen, 1991; Ajzen, 1988). The theory postulates that absent any intervening events, favorable intention together with accommodating perceived behavioral control would then be highly predictive of performing the act. 
TPB is tightly specified by postulating that in most contexts there are only three determinants of an individual's intentions ${ }^{16}$ : attitude, subjective norms, and perceived behavioral control. The relative importance of the three determinates have been found to vary across situations (Ajzen, 1991, p. 188). For example, at the time the research instrument of this study was administered, the SOX-like POC and IAC requirements for municipalities had received little attention. Persons whom the municipal finance officer might consider as "important others" were unlikely to have formed or communicated their opinions to the municipal finance officers. As a result, the expectations of important others (normative beliefs) were not included in the study.

The model further specifies the measures of behavior, intention, and underlying beliefs must "correspond" or be "compatible" (Ajzen \& Fishbein, 1977; Ajzen, 1988). The essence of correspondence is that the level of specificity of the beliefs measured should correspond to the level of specificity of the intention measured. The "principle of compatibility" also postulates that general beliefs (in this study the views toward GASB 34) would not be influential to the support for or opposition to POC and IAC requirements (Ajzen, 1988, pp. 92-111).

An example of following the principle of compatibility in an accounting context which utilized TPB is Weidman's (2002) dissertation. Her dependent variable was the respondents" "general attitude towards disclosure of environmental liabilities." She then asked the respondents to rate the following consequences on a 7-point Likert scale ranging from very undesirable to very desirable.

\footnotetext{
${ }^{16}$ Ajzen (1991) does suggest that with respect to behaviors which include a dimension of ethical or moral behavior a measure of perceived moral obligation could add predictive power to the TPB model.
} 
Illustration 2-1

Consequences measured in a

TPB based accounting study

\begin{tabular}{|l|}
\hline \multicolumn{1}{|c|}{ Consequence } \\
\hline Creating a reserve for future utilization. \\
\hline Adversely affecting share prices and/or borrowing costs. \\
\hline $\begin{array}{l}\text { Having company viewed as acting responsibility in managing environmental } \\
\text { issues. }\end{array}$ \\
\hline $\begin{array}{l}\text { Having questions raised about the accuracy of estimates in the financial } \\
\text { statements. }\end{array}$ \\
\hline Fulfilling the obligation to fully inform users of financial statements. \\
\hline Increasing the risk of lawsuits. \\
\hline Adversely affecting profits in the current period. \\
\hline Showing a conservative approach to financial reporting. \\
\hline Increasing regulatory oversight of the company. \\
\hline Drawing management attention to environmental issues. \\
\hline
\end{tabular}

In summary, the TPB is a widely applied general model of the attitudes-behavior relationships for an individual "which has met with some degree of success in predicting a variety of behaviors" (Conner \& Armitage, 1998, p. 1429; see also Elliot, Armitage, \& Baughan, 2003, p. 964). That TPB has been found to explain intentions better than behaviors fits well with the objectives of this study (Sutton, 1998, p. 1317). In this study the interest is to determine the acceptability (intentions) to municipal finance officers of having their municipality subject to required POC and IAC, not their actual adoption by the municipality (behavior).

TPB will be used in this study to examine the perceived attributes of required POC and IAC; however it does have some limitations. Several of the independent variables of interest to this study (prior innovation adoption rates, organizational variables, and personal variables) are treated as external or peripheral variables, rather than an integral part of TPB theory (Ajzen \& Fishbein, 1980, p. 9; Davis, Bagozzi, \& Warshaw, 1989, p. 984). From Ajzen and Fishbein's (1980) point of view, external 
variables may have a direct influence on the beliefs a person holds but only an indirect influence on intentions (p. 83). These external variables which are basically ignored by the TPB model will be included in the study using guidance provided by the general innovation acceptance model and prior studies of innovation acceptance in the governmental sector previously discussed.

TPB is a general model and does not specify the consequences, obstacles, or resources that are operative for municipal finance officers when assessing the acceptability of POC or IAC (Davis, Bagozzi, \& Warshaw, 1989). To identify these items for the present study, ideas were obtained from previous studies in accounting, the reported responses to SOX in the private-sector, and Rogers (2003) attributes of innovation model. The items were then reviewed by practitioners, regulators, and academics prior to administering the survey instrument.

\section{Hypotheses and Questions}

The most basic proposition of TPB is that beliefs about perceived attributes which the decision-maker associates with POC and IAC are evaluated by the decision-maker in forming a favorable or unfavorable intention to accept POC and IAC (Ajzen, 1991). Attributes include the consequences the municipal finance officer associates with POC and IAC, as well as his perception of the resources available and obstacles impeding the municipality's ability to perform the act (Ajzen \& Fishbein, 1988; Ajzen, 1991). In this study the perceived attributes were categorized in four groupings:

1. Potential favorable outcomes associated with the adoption of POC.

2. Reservations or concerns associated with the adoption of POC. 
3. Potential favorable outcomes associated with the adoption of IAC.

4. Reservations or concerns associated with the adoption of IAC.

According to TPB theory the overall assessment by the municipal finance officers of the perceived attributes will act as determinates of their intention to accept or oppose POC and IAC regulations for his community. This relationship results in the following hypotheses:

H1: The intention to favor or oppose adoption of POC requirements results from the municipal finance officer's evaluation of the associated perceived attributes of adopting required POC.

$\mathrm{H} 2$ : The intention to favor or oppose adoption of IAC requirements results from the municipal finance officer's evaluation of the associated perceived attributes of adopting required IAC.

One of the research objectives of this study is to explore the municipal finance officers' views of the reporting requirements of GASB 34. The municipal finance officers' views toward GASB 34 are considered as general beliefs about externally imposed accounting requirements. Based upon the TPB "principle of compatibility" these general beliefs about GASB 34 should not be influential to the formation of municipal finance officers' intentions toward POC or IAC (Ajzen, 1988, p. 39). This results in two additional hypotheses:

H3: General beliefs about GASB 34 will not be influential to the formation of municipal finance officers' intention to accept or oppose required POC.

H4: General beliefs about GASB 34 will not be influential to the formation of municipal finance officers' intention to accept or oppose required IAC. 
That past behavior influences future behavior is a well accepted maxim in psychology (Ouellette \& Wood, 1998, p. 54; Ajzen, 1991, p. 202). Several researchers have suggested that past behavior be added as a substantive construct to the TPB model (Ajzen, 1991, p. 202-203; Ajzen, 2002, p. 45-46; Elliot, Armitage, \& Baughan, 2003, p. 965). Ajzen has in general been opposed to the inclusion of past behavior as an additional construct in the TPB model, although he does concede that measurement of past behavior can, in certain situations, be helpful (Ajzen, 2002, p. 120).

In this study past behavior is measured as the municipality's prior adoptive behavior (early to late) with regard to accounting statements GASB 34 and GASB 44 . It is acknowledged the rate of adoption of accounting statements, which often require significant changes in the accounting computing software, may not be the same as willingness to support or oppose POC and IAC. Nonetheless, it was thought to be worthwhile to question whether there was any relationship between prior adoptive behavior of GASB 34 and GASB 44 and support for or opposition to POC and IAC.

The remaining independent variables considered in the current study were personal demographics of the municipal finance officers and the organizational demographics of the municipalities. Innovation research has had mixed results regarding their importance to the acceptance decision and TPB research has either not discussed them or reported little or no significance. In the present study the effort is to explore whether there is any significant relationship between any of the personal demographics or organization variables and the municipal finance officers' support for or opposition to POC or IAC. 


\section{CHAPTER III}

\section{METHODOLOGY}

\section{Introduction}

This study deployed multiple steps in collecting and analyzing the data. Data from the U.S. Census Bureau was used to identify municipalities, their state of location, and population. A mail survey was used to collect quantifiable data of interest. The data was analyzed using descriptive statistics, exploratory factor analysis, multiple regression and logistic regression. A post-survey elite electronic interview was utilized to obtain a deeper understanding of revealed issues and contradictions found in the analysis of the results of the mail survey.

\section{Mail Survey}

The mail survey methodology has often been used to learn about individual attitudes and beliefs, demographics, and behavior (Creswell, 2002; Neuman, 2006). Mail surveys are recognized as a methodology for obtaining a large amount of data from a large group that is geographically dispersed at a relatively low cost. The methodology can provide respondent anonymity and allows respondents time to answer the questions. The methodology allows for consistently structured questions for which responses can be easily quantified.

\section{Target Population}

The target population was the universe of finance officers of municipalities with populations of 10,000 or greater in the States of Florida and Ohio. These two states were selected based upon both similarities and differences. The two major similarities are: 1 ) 
both states require municipalities to prepare audited financial statements in conformity with the GASB 34 reporting model, and 2) both states contain a comparable number of municipalities with populations of 10,000 or greater. The differences are several and may facilitate a greater generalizability to the study. Ohio is one of the "rust belt" states and Florida is one of the "sun belt" states ${ }^{17}$. These contrasting regional socio-economic conditions have caused municipalities to face differing problems. While both Ohio and Florida require their municipalities to produce audited financial statements, however in Ohio the financial audits are overwhelmingly performed by state employed auditors ${ }^{18}$ rather than private sector Certified Public Accountants (CPA). Ohio has municipal chief financial officers which are elected (especially in the northeast section) and Florida does not. Ohio requires their municipalities to provide their financial statements for publication on a state sponsored website and Florida does not. In addition, in an effort to increase response rates, Florida was included as the domicile of Florida International University and Ohio was included because it is the "home state" of the author of this study where he served in an elected capacity.

Survey Recipients - Constructing the Mailing List

Identification of the targeted municipalities was provided by the U.S. Census Bureau in electronically digitized format. The capabilities of Microsoft Access® relational database permitted capturing the data from the U.S. Census Bureau in unaltered

\footnotetext{
17 "Rust belt" and "sun belt" are terms used to classify regions of the U.S. which have and are experiencing contrasting socio-economic conditions. The "rust belt" refers to those states primarily located in the upper Midwest with a declining manufacturing employment base and an overall decline in socio-economic conditions. In contrast, the "sun belt" refers to those states primarily located in the South which have experienced growth related to increased employment opportunities and attractive "living conditions."

${ }^{18}$ In Ohio the municipality may choose to have their financial statements audited by private sector Certified Public Accountants, but the majority rely upon the state auditors.
} 
form, eliminating the possibility of data entry error. The database is located on a personal computer to insure confidentiality. A filtered query of the U.S Census Bureau data provided the name of the municipality, state location, and population of the 147 municipalities in Florida and 168 municipalities in Ohio which had populations of 10,000 or greater.

To personalize the cover letter and to reduce "coverage error" (Dillman, 2007, pp. 198-204) compilation of the names and addresses for the finance officers in the sampling frame was captured utilizing several sources. In Ohio, each municipality is required to submit their annual financial report for publication on the state auditor's website. Information regarding the name and address of the municipality's finance officer and address is typically provided in the annual financial report. The information obtained from the electronically published financial statements was verified from the websites for the individual cities. For those Ohio municipalities which did not have a recent financial statement posted to the state auditor's website, a search was conducted for a website for the municipality. Finally, if the name and address of the finance officer was not published on the state auditor's website or a website for the individual municipality, a phone call was placed to the respective city offices.

Florida does not require municipalities to provide their annual financial statements for publication at a state sponsored website. As an alternative the name and address for finance officer was acquired from the individual websites of the municipalities. For those Florida municipalities which did not have a website, a phone call was placed to the respective city offices. Two Florida municipalities were eliminated 
from further processing because they "contracted out" the operation of their finance departments.

All of the data regarding the names and addresses of the finance officers was entered into the Access database and verified by an independent party to assure data entry errors were minimized. The database of 145 municipalities from Florida and 168

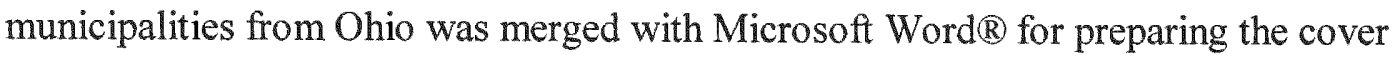
letters and survey questionnaires mailed to the targeted population of 313 . There were no undeliverable mailings returned as a result of incorrect addresses.

\section{Survey Instrument Design, Processes, and Procedures}

The literature acknowledges a declining response rate to mailed surveys. Cycyota and Harrison (2006) found that reported response rates to surveys mailed to executives in widely cited journals in management for the period of 1992 through 2003 had an average response rate of $34 \%$ and had significantly declined during the period. Larson (2005) reported similar findings regarding the response rates of professionals in logistics with a high of $39.6 \%$ in 1990 to $14.1 \%$ in 2003 . Nonresponse gives rise to concern about the generaliazability of the results of research and the general recommendation to reduce nonresponse is to follow best practices (Blair \& Zinkhan, 2006).

Acknowledging that chief financial officers of municipalities are executives that may have "less time and energy to spend on pro bono, low-priority behaviors such as survey completion" as well as possibly having some reservations about lack of confidentiality as a result "sunshine laws," an effort was made to utilize "response rate enhancement techniques" (Cycyota \& Harrison, 2006, p. 135). In the current study the 
following techniques were utilized (see Dillman, 2007; Larson, 2005; Greer, Chuchinprakarn, \& Seshadri, 2000; Cycyota \& Harrison, 2006) :

1. First mailing of cover letter and questionnaire was made on June 27, 2005 and a second follow-up mailing to non-respondents was made on July 25, 2005.

2. Each mailing was sent to the municipality address and included the cover letter, questionnaire, and pre-addressed and pre-paid return envelope. The return envelopes were addressed to a post office box to mitigate the loss of any responses.

3. Each cover letter was on FIU letterhead and included an inside address, personal salutation, and was individually signed. The body of the cover letter explained what was being requested, why the respondent was selected, usefulness of the survey, statement of confidentiality, token of appreciation, willingness to answer any questions the recipient may have, and a thank you.

4. The questionnaire was a two page document printed on both sides (total of four pages).

A copy of the cover letters and questionnaire are provided in Appendix A.

\section{Questionnaire Development}

When the questionnaire was sent to the target population in the summer of 2005 , it was recognized that municipal finance officers might not be conversant with the key components of SOX or what the requirements of POC and IAC would include when applied to the public sector. In addressing this particular challenge the survey instrument included an explanation of major provisions of both POC and IAC. This was done to 
minimize any discrepancy between the researcher's and respondents' concept of POC and IAC (Fowler, 1998, 1992). Although the survey instrument included these explanations, there was still an expectation that a certain number of respondents would either not have an opinion or would still be uncertain of their opinion. To allow for those without an opinion or uncertain of their opinion, the item responses included neutral or no opinion as the middle alternative.

It was challenging to develop specific survey questions for a topic previously unexplored. The goals of the research provided a general framework for the categories of survey questions, but did not provide guidance on specific questions. To facilitate development of the survey questions, the author reviewed prior research in similar areas, and literature regarding responses to SOX in the private sector. With the help of an assistant finance officer from Ohio and an assistant finance officer from Florida, as well as advice from the dissertation committee, a questionnaire for pre-testing was developed.

The questionnaire was pretested on individuals who would have similar knowledge and experience as a municipal finance officer, but were not part of the target population. The pre-testing group included: assistant chief financial officers, an assistant city manager with an accounting background, a researcher with GASB, and faculty members. The pre-test group provided recommendations which were incorporated into the questionnaire and were asked to provide feedback on the amount of time to complete the questionnaire. 
Response Recording and Control

After confirming the questionnaire was completed the responses were recorded in an Access ${ }^{\circledR}$ database. The database remained under the sole control of the researcher. The data in the Access $(8)$ database was electronically transferred to NCSS $(\mathbb{R}$ statistical package program for analysis.

\section{Elite Post-Survey Interviews}

In order to add more clarity to some of the findings of the analysis of the results of the interviews were arranged with "elite experts" from the government accountingauditing field. A "snowballing" sampling process was used to identify potential interviewees. The respondents included practitioners from Florida (2) and Ohio (3), as well as Academics (2), and a representative from the GASB (1).

The geographic dispersion of the interviewees did not permit personal meetings. To interview the individuals an interactive web-based system was designed specifically for this research project. This methodology provided a convenient and secure process for the interviewee to participate in the interview at his/her convenience. The process allowed for reviewing the responses and contacting the interviewee by telephone if necessary.

Potential interviewees were sent a request asking for their participation. Although the request was tailored to each potential interviewee, the general format of the request included statements regarding: 1) what the research project was about, 2) why their interview was important, 3) who recommended contacting them (see example, Appendix 
B, p. B1). Each request had an attachment which provided the major findings of the survey and some demographic information (Appendix B, p. B2-B3).

The request provided the link to the interview questions and a personalized log-in and password. The interviewee was assured their responses would be held in strict confidence and never disclosed as his/her response. The interactive format allowed for each interviewee to access the interview questions at their convenience. The interview consisted of twelve open-ended questions, with number ten being different for those interviewees from Ohio (Appendix B). 


\section{CHAPTER IV}

\section{ANALYSIS AND PRESENTATION OF FINDINGS \\ BASIC QUANTITATIVE FINDINGS AND FACTOR ANALYSIS}

\section{Introduction}

This is the first of two chapters devoted to presenting the findings from this research. The first section of this chapter will focus on the basic quantitative findings from the mailed survey instrument. For those variables which required a response on a 5point bi-polar "Likert" scale (neutral or no opinion included) findings are presented with frequency tables of count and percentage. For those variables related to prior behavior, organizational and personal demographics, the frequency distribution of responses are presented in a form appropriate for the data. In concluding the first part of this chapter Chi-square tests are reported for the association of the organizational and demographic variables with the adoption of sox-like requirements.

The second section of this chapter uses exploratory factor analysis (EFA) methodology to facilitate understanding of how municipal finance officers structure their attitudes toward adoption of SOX-like requirements. The process begins with eliminating those measured variables with low communality from the factor structure. The process of selecting the appropriate number of factors to retain is then presented. The second part of this chapter concludes with presenting the factor loadings and interpretation of the factor model selected. To further test whether the factor model selected "makes sense," in the next chapter the SOX-like variables of interest will be regressed upon the factor scores (Fabrigar, Wegener, MacCallum, \& Strahan, 1999, p. 276). 


\section{Mailed Survey Instrument}

The author mailed surveys to all chief financial officers of municipalities in Florida and $\mathrm{Ohio}^{19}$ with populations of 10,000 or greater that did not contract out their finance/accounting function. Of the 313 mailed surveys, 132 or $42.2 \%$ returned usable surveys in a timely manner ${ }^{20}$. Cross-tabulation of received surveys against mailed surveys showed no response bias by state or city size.

Table 4-1

Responses by State

\begin{tabular}{|l|l|l|l|}
\hline State & $\begin{array}{l}\text { Number } \\
\text { Mailed }\end{array}$ & $\begin{array}{l}\text { Number } \\
\text { Received }\end{array}$ & $\begin{array}{l}\text { Percentage } \\
\text { Received }\end{array}$ \\
\hline Florida & 145 & 64 & $44.1 \%$ \\
\hline Ohio & 168 & 68 & $40.5 \%$ \\
\hline & & & \\
\hline Total & 313 & 132 & $42.2 \%$ \\
\hline
\end{tabular}

Table 4-2

Responses by City Size

In Percent ( $\mathrm{n}$ in parentheses)

\begin{tabular}{|l|l|l|}
\hline City Size (Population) & Mailed & Received \\
\hline $10,000-25,000$ & 58.1 & 56.8 \\
& $(182)$ & $(75)$ \\
\hline $25,001-99,999$ & 35.8 & 36.4 \\
& $(112)$ & $(48)$ \\
\hline 100,000 or greater & 6.1 & 6.8 \\
& $(19)$ & $(9)$ \\
\hline
\end{tabular}

The survey asked about the attitudes of municipal finance officers toward the required adoption of two major components of the Sarbanes-Oxley Act (SOX): Principal Officer(s) Certification (POC) and Independent Audit Committees (IAC). In addition, the respondents were asked to provide their opinions of specific consequences of POC

\footnotetext{
${ }^{19}$ Both Florida and Ohio require municipalities to publish their financial statements using the guidance provided by the Governmental Accounting Standards Board (GASB).

${ }^{20}$ In addition to the 132 usable surveys returned there was an additional four surveys received not included. Two were incomplete, one was sent by fax and lost, and one completed survey was received too late.
} 
and IAC adoption; their general attitude about the recent changes in governmental accounting; some indication of prior adoption rate of changes in accounting practices; as well as personal and organizational demographic variables.

\section{SECTION 1 - BASIC QUANTITATIVE FINDINGS}

Variable of Interest- Principal Officer(s) Certification (POC)

Principal Officer(s) Certification (POC) is one of the major components of the Sarbanes-Oxley Act (SOX). In a nutshell, it enhances accountability by assigning personal responsibility for the accuracy of the financial reporting and disclosures to an organization's chief executive officer (CEO) and chief financial officer (CFO). In effect the POC provision provides legal sanction to the view that management "owns" the financial statements ${ }^{21}$.

Table 4-3

Should POC be implemented as a required practice? In Percent ( $\mathrm{n}$ in parentheses)

\begin{tabular}{|l|c|c|c|c|c|}
\hline \multicolumn{1}{|c|}{ Question } & SA & A & N & D & SD \\
\hline $\begin{array}{l}\text { In general, I believe principal officer(s) certification } \\
\text { similar to SOX should be required of the principal } \\
\text { officer(s) of municipalities. }\end{array}$ & $\begin{array}{c}16 \\
(21)\end{array}$ & $\begin{array}{c}(53) \\
\text { (2) }\end{array}$ & $\begin{array}{c}17 \\
(22)\end{array}$ & $\begin{array}{c}(27) \\
(9)\end{array}$ \\
\hline
\end{tabular}

Results in Table 4-3 suggest strong support for the general proposition of principal officer certification ( $2 / 3$ of the non-neutral responses either strongly agreed or agreed). One interpretation of this finding is that our respondents view $\mathrm{POC}$ as a logical extension of the "management representation letter" that $96.0 \%$ of our respondents

\footnotetext{
${ }^{21}$ This is part of the "Expectations Gap" which has received a great deal of attention in the accounting literature. The "Expectations Gap" generally refers to the difference in perception by various users regarding who is responsible for the correctness of financial reporting and disclosures. For further details regarding the "Expectations Gap" see Hussain, 2003; MacEnroe \& Martin, 2001; Gibson, Pany, \& Smith, 1998.
} 
already provide. This would appear to be consistent with the Theory of Innovation Diffusion (TID) hypothesis that adoption of POC is more likely if it is similar to the previous practices of providing a management representation letter (Rogers, 1995, p. 15). Another is that in the post-Enron era, a sizable portion of our respondents understand how adoption of POC could better satisfy the increased public expectations for reliable financial reporting. This would dovetail with the hypothesis from TID that an innovation is more likely to be adopted if it is perceived as better than the idea it supersedes (Rogers, 1995, p. 15).

Table 4-4

If Your City was Required, or Voluntarily Adopted, Principal Officer(s) Certification, Who Should Sign and Attest to the Accuracy and Completeness?

Breakdown by Position

In Percent ( $\mathrm{n}$ in parentheses)

\begin{tabular}{|c|c|c|c|c|c|}
\hline POSITION & SA & A & N & D & SD \\
\hline Chief Financial Officer & 71 & 24 & 4 & -- & 1 \\
& $(94)$ & $(32)$ & $(5)$ & -- & $(1)$ \\
\hline City Manager & 40 & 26 & 28 & 3 & 3 \\
& $(53)$ & $(34)$ & $(37)$ & $(4)$ & $(4)$ \\
\hline The Mayor & 14 & 22 & 31 & 16 & 17 \\
& $(19)$ & $(29)$ & $(41)$ & $(21)$ & $(22)$ \\
\hline City Commissioners & 4 & 8 & 46 & 19 & 23 \\
& $(5)$ & $(10)$ & $(61)$ & $(25)$ & $(31)$ \\
\hline
\end{tabular}

The findings shown in Table 4-4 regarding "who" should sign and attest to the accuracy and completeness of the financial statements evidence an interesting bureaucratic-political split. On the one hand, there appears to be almost universal support ( $99 \%$ of those with an opinion) for the CFO's attestation, as well as very strong support 
for city managers. But support for mayoral attestation is mixed at best ${ }^{22}$, and for the commissioners, there is $42 \%$ opposition.

One interpretation of these findings is that our respondents see the CFO and city manager as directly responsible for financial operations and cognizant of daily operations. This is consistent with a Weberian-Wilsonian politics/administration dichotomy, i.e., the bureaucracy having the expertise needed for meaningful attestation with the elected "dilettante" commissioners, who are primarily part-time, having neither the time nor knowledge needed for this task (Bendor, Taylor, \& Van Gaalen, 1985, p. 1041).

This interpretation takes on, however, some thought-provoking normative connotations. In essence it suggests the non-elected principal officers see limited obligation for the elected officials - including those responsible for appropriations- - to attest to the completeness and accuracy of the CAFR. The embedded assumption, consistent with the Convergence $\mathrm{Model}^{23}(\mathrm{CM})$, is that appointed (or in the case of Ohio, possibly elected) finance officers and city managers can exercise sufficient stewardship despite their unelected status. This squares with the framers' view of SOX for the corporate sector, who believe that CEO's and CFO's are those ultimately responsible for the integrity of the financial disclosures.

\footnotetext{
${ }^{22}$ Support for mayorial attestation may be overstated and city manager understated. Approximately $2 / 3$ rds of those who strongly agreed or agreed with the having the mayor sign and attest to the financial statements were from municipalities in which the mayor is considered the chief administrative officer. In these "strong mayor" arrangements there may not be a city manager which would obviate the choice of the city manager.

${ }^{23}$ Convergence Model (CM) refers to the adoption of business-like measurement, reporting, and control techniques and procedures in the financial reporting process of governmental entities.
} 
If $P O C$ is required of municipalities the issue of who should sign and attest would need to be addressed. In the corporate sector the CEO and CFO have jointly been expected to have the knowledge of and responsibility for financial reporting. The POC requirement provided legal sanction to the expectation and provided for personal penalties. In the municipal sector the mayor and city council already have political accountability and at least implied legal responsibility for honest financial reporting. The question in the governmental sector is whether it is reasonable to expect the elected officials to have the requisite knowledge to meaningfully attest to the accuracy of the financial reports?

Perceptions of Benefits and Costs Associated with POC Adoption

TABLE 4-5

Potential Benefits Associated with a Municipality Either Being Required or Voluntarily Adopting Principal Officer(s) Certification In Percent ( $\mathrm{n}$ in parentheses)

\begin{tabular}{|c|c|c|c|c|c|}
\hline Question & SA & $\mathbf{A}$ & $\mathbf{N}$ & $\mathbf{D}$ & SD \\
\hline $\begin{array}{l}\text { Increase the importance of the CAFR as an instrument of } \\
\text { accountability (FR-ACCT) }\end{array}$ & $\begin{array}{c}11 \\
(15)\end{array}$ & $\begin{array}{l}30 \\
(40)\end{array}$ & $\begin{array}{c}23 \\
(31)\end{array}$ & $\begin{array}{c}31 \\
(41)\end{array}$ & $\begin{array}{c}4 \\
(5)\end{array}$ \\
\hline $\begin{array}{l}\text { Enhance the responsible financial reporting image of the } \\
\text { municipality. (FR-IMAGE) }\end{array}$ & $\begin{array}{l}13 \\
(17)\end{array}$ & $\begin{array}{l}40 \\
(53)\end{array}$ & $\begin{array}{l}25 \\
(33)\end{array}$ & $\begin{array}{l}18 \\
(24)\end{array}$ & $\begin{array}{c}4 \\
(5)\end{array}$ \\
\hline $\begin{array}{l}\text { Encourage the municipality's elected leadership to become } \\
\text { more involved in the financial reporting process.(EL- } \\
\text { INVOLV) }\end{array}$ & $\begin{array}{c}11 \\
\text { (14) }\end{array}$ & $\begin{array}{c}31 \\
(41)\end{array}$ & $\begin{array}{c}30 \\
(40)\end{array}$ & $\begin{array}{c}23 \\
(30)\end{array}$ & $\begin{array}{c}5 \\
5 \\
(7)\end{array}$ \\
\hline $\begin{array}{l}\text { Encourage muni.'s admin. leadership to become more } \\
\text { involved in financial reporting process. (ADM-INVOLV) }\end{array}$ & $\begin{array}{c}11 \\
(15)\end{array}$ & $\begin{array}{c}51 \\
(67)\end{array}$ & $\begin{array}{c}17 \\
(23)\end{array}$ & $\begin{array}{c}17 \\
(23)\end{array}$ & $\begin{array}{l}3 \\
(4)\end{array}$ \\
\hline Reduce the risk of lawsuits (LAWRISK) & $\begin{array}{c}2 \\
(3)\end{array}$ & $\begin{array}{c}8 \\
(10)\end{array}$ & $\begin{array}{c}34 \\
(45)\end{array}$ & $\begin{array}{c}44 \\
(58)\end{array}$ & $\begin{array}{c}12 \\
(16)\end{array}$ \\
\hline $\begin{array}{l}\text { Encourage a more positive attitude toward disclosure among } \\
\text { the municipality's admin. leadership and staff (DISCLOSE) }\end{array}$ & $\begin{array}{c}7 \\
(9)\end{array}$ & $\begin{array}{l}36 \\
(47)\end{array}$ & $\begin{array}{l}27 \\
(36)\end{array}$ & $\begin{array}{l}25 \\
(33)\end{array}$ & $\begin{array}{c}5 \\
(7)\end{array}$ \\
\hline Contribute to more favorable bond ratings (BONDRATE) & $\begin{array}{c}8 \\
(11)\end{array}$ & $\begin{array}{c}26 \\
(34)\end{array}$ & $\begin{array}{c}39 \\
(52)\end{array}$ & $\begin{array}{c}20 \\
(27)\end{array}$ & $\begin{array}{c}6 \\
(8)\end{array}$ \\
\hline
\end{tabular}

Table 4-5 results may shed further light on the conceptual support for requiring POC reflected in Table 4-3. A plurality of respondents either agree or strongly agree that 
POC will enhance the relative value of the CAFR as a tool for accountability (FR-ACCT), encourage elected leadership to become more involved in the reporting process (ELINVOLV), and encourage a more positive attitude toward disclosure among the administrative leadership and staff (DISCLOSURE). In addition, a majority of respondents (53\%) either agree or strongly agree with POC serving to enhance the community's reporting image (FR-IMAGE), and a sizable majority (62\%) believes that POC will encourage the city's administration to become more involved in the financial reporting process (ADM-INVOLV). On the other hand, there is ambivalence regarding the value of POC's value as a tool for enhancing bond ratings (BONDRATE), and a majority (66\%) does not believe POC would reduce the risk of lawsuits (LAWRISK). These findings suggest that while POC may induce greater intangible benefits such as participation in the financial reporting process and enhanced importance and reporting image, our respondents may not immediately recognize tangible rewards in reduced cost of operation (e.g., better bond ratings, less litigation) through its implementation.

TABLE 4-6

Potential Implementation Issues (Costs) Associated with a Municipality Adopting Principal Officer(s) Certification In percent ( $\mathrm{n}$ in parentheses)

\begin{tabular}{|c|c|c|c|c|c|}
\hline Question & SA & $\mathbf{A}$ & $\mathbf{N}$ & D & $\mathrm{SD}$ \\
\hline $\begin{array}{l}\text { The non-financial principal executive/administrative officers } \\
\text { would be unwilling to make the effort to become sufficiently } \\
\text { knowledgeable about financial reporting and disclosure } \\
\text { (FRKNOW) }\end{array}$ & $\begin{array}{c}19 \\
(25)\end{array}$ & $\begin{array}{c}45 \\
(60)\end{array}$ & $\begin{array}{c}14 \\
\text { (19) }\end{array}$ & $\begin{array}{c}19 \\
(25)\end{array}$ & $\begin{array}{c}2 \\
(3)\end{array}$ \\
\hline $\begin{array}{l}\text { The non-financial principal executive \& administrative officers } \\
\text { would be unwilling to make the effort to become sufficiently } \\
\text { knowledgeable about appropriate internal control procedures } \\
\text { (ICKNOW) }\end{array}$ & $\begin{array}{c}19 \\
(25)\end{array}$ & $\begin{array}{c}39 \\
(52)\end{array}$ & $\begin{array}{c}22 \\
(29)\end{array}$ & $\begin{array}{c}18 \\
(24)\end{array}$ & $\begin{array}{c}2 \\
(2)\end{array}$ \\
\hline $\begin{array}{l}\text { The signing principal officers would be personally concerned } \\
\text { with the potential for criminal penalties (CRIMINAL) }\end{array}$ & $\begin{array}{c}31 \\
(41)\end{array}$ & $\begin{array}{l}35 \\
(46)\end{array}$ & $\begin{array}{l}18 \\
(24)\end{array}$ & $\begin{array}{c}14 \\
(19)\end{array}$ & $\begin{array}{c}2 \\
(2)\end{array}$ \\
\hline $\begin{array}{l}\text { The cost of implementing the policy would be greater than the } \\
\text { benefits derived (COST>BENE) }\end{array}$ & $\begin{array}{c}23 \\
(31)\end{array}$ & $\begin{array}{c}32 \\
(42)\end{array}$ & $\begin{array}{c}35 \\
(46)\end{array}$ & $\begin{array}{c}8 \\
(11)\end{array}$ & $\begin{array}{c}2 \\
(2)\end{array}$ \\
\hline
\end{tabular}


Findings in Table 4-6 indicate some concern regarding the qualification of wouldbe attesters. On the face of it, the principal officers with financial management training and public sector experience would be qualified. This may not be the case for many elected officials or others with limited financial management training. This pool of prospective attesters is probably unaccustomed to an operating environment dominated by traditional fund accounting despite the possibility of having some business background. Others who have a broader social science or public management background may be seriously lacking in the rudiments of accounting or financial management in either sector (Jones, 1991; Kattelus, Cheng, \& Engstrom, 2005). This concern is shown in Table 4-6, where the majority of our respondents indicate that nonfinancial officers may be unwilling to take the time needed to become sufficiently knowledgeable about financial reporting and internal control (FRKNOW \& ICKNOW).

This human resource dimension is noteworthy and subject to two different interpretations. One is that of face value. Our respondents may have an objective read on the potential pool of non-financial principals and see few who could serve in this role. A less sanguine interpretation could be drawn from the Public Choice perspective, especially the Niskanen model (1971), and dovetails with our findings in Table 4-4. From this vantage, the bureaucracy may impute a limited human resources pool. In reality, they may be uncomfortable with non-financial principals (especially elected officials) acquiring financial expertise that would counterbalance that found in the bureaucracy, resulting in a loss of influence over financial management (Miller \& Moe, 1983, p. 297; Stiglitz, 1988, p. 207; Hirsch, 1970, p. 22). Regardless of interpretation, our respondents see a human resources deficit with regard to implementation of POC. 
Responses in Table 4-6 also raise some questions regarding the benefits and costs of implementing POC. A majority (55\%) of our respondents either agrees or strongly agrees that the cost of implementing POC would exceed the benefits (COST>BENE), while the modal response was neutral or no opinion. On the face of it, this finding would seem to be in contradiction to the support for POC reflected in Table 4-3. On the other hand, this contradiction is perhaps mitigated by the findings in Table 4-5 which showed the respondents perceived intangible benefits, e.g. greater administration involvement in financial reporting practices and enhancement of the financial reporting image of the entity. When viewed in this light, the results may be suggesting that required POC is supported not because the pecuniary benefits are greater than the cost, but rather as a result of the importance attached with non-pecuniary benefits.

The principal objection to POC adoption appears to be the personal exposure to criminal penalties. The well publicized image of Enron's Ken Ley and others being handcuffed could well have influenced the respondents concern with potential criminal and civil penalties. In Table 4-6, two-thirds of our respondents agree or strongly agree with the possibility that POC opens the door to potential criminal penalty (CRIMINAL). This squares with our findings in Table $4-5$, where $56 \%$ did not see POC as reducing the risk of lawsuits. The upshot is that univariate analysis of responses in Tables 4-5 and 4-6 suggests that respondents may view POC as "opening the door" for criminal and civil litigation. 
Variable of Interest - Independent Audit Committee (LAC)

Symbolically and legally, the attestation (POC) is critical. Substantially however the implementation of an independent audit committee (IAC) and related internal control requirements (section 404) may be SOX's greater contribution and its more onerous burden. Adoption of an IAC introduces a set of checks and balances into financial management with particular emphasis on bolstering internal controls and expectations of greater independence and financial knowledge being possessed by members of the audit committee. The framers of SOX apparently felt that independent and knowledgeable members of an audit committee were important to the assurance process. This view has been documented in prior research (Farber, 2005; Beasley, 1996, Dechow, Sloan, \& Sweeney, 1996) and emphasized by the Committee of Sponsoring Organizations of the Treadway Commission (COSO) (Auditing Standards Committee, 2007; COSO, 1994).

Table 4-7

Attitudes toward Implementing Mandatory Independent Audit Committee:

Need for Implementation by Size of Community In Percent ( $\mathrm{n}$ in parentheses)

\begin{tabular}{|l|c|c|c|c|c|}
\hline COMMUNITY SIZE & SA & A & N & D & SD \\
\hline 100,000 or greater & 23 & 36 & 20 & 16 & 6 \\
& $(30)$ & $(47)$ & $(26)$ & $(21)$ & $(8)$ \\
\hline $25,001-99,999$ & 5 & 24 & 33 & 27 & 11 \\
& $(7)$ & $(32)$ & $(44)$ & $(35)$ & $(14)$ \\
\hline Under 25,000 & 2 & 16 & 23 & 36 & 22 \\
& $(3)$ & $(21)$ & $(31)$ & $(48)$ & $(29)$ \\
\hline
\end{tabular}

Results in Table 4-7 reflect the attitudes of the all respondents from communities of different sizes on three different variables:

1. Should large communities be required to implement IAC?

2. Should medium sized communities be required to implement IAC?

3. Should small communities be required to implement IAC? 
In broad relief, our respondents see IAC as best suited for large communities ${ }^{24}$, with mixed support for medium sized communities, and significant opposition to implementation for smaller communities. This is directly analogous to the staged SOX implementation in the private sector. Apparently many of our respondents believe that implementing IAC would benefit larger cities with more complex operations, and the financial means and technical capacity to support roll-out.

While findings in Table 4-7 indicate support for larger communities adopting IAC; findings in Table 4-8 may reflect the "real" attitudes toward IAC adoption. Table 4-8 reflects the attitude of the respondents for required adoption of IAC in communities which are the same size as the respondent's community.

Table 4-8

Support for Independent Audit Committee Implementation

by Respondent's Community Size

In Percent ( $\mathrm{n}$ in parentheses)

\begin{tabular}{|l|c|c|c|c|c|}
\hline \multicolumn{1}{|c|}{ Question } & SA & A & N & D & SD \\
\hline $\begin{array}{l}\text { Should municipalities which are the same size as my } \\
\text { community be required to have an IAC with } \\
\text { responsibilities similar to the requirements of SOX? }\end{array}$ & 5 & 20 & 23 & 32 & 20 \\
$(7)$ & $(26)$ & $(30)$ & $(42)$ & $(27)$ \\
\hline
\end{tabular}

Results in Table 4-8 suggest strong opposition to requiring IAC adoption (2/3 of those who had an opinion either strongly disagreed or disagreed with required

\footnotetext{
${ }^{24}$ There is some evidence of support for large city implementation resulting from medium and small sized communities hoisting the requirement on large communities. However, cross-tabulation of the variable "Should large communities be required to implement IAC" with the community size of the respondents resulted in: $\chi 2$ of $8.93, d . f=8$, prob. $=0.3483$, two-tailed; suggesting the null hypothesis of no difference could not be rejected.
} 
adoption $^{25}$ ). Part of this opposition may reflect an accounting version of the NIMBY

(not-in-my-back-yard) phenomenon observed in zoning and environmental policy.

Another factor may be that only $29 \%$ of our respondents have audit committees in their respective communities, suggesting an element of inexperience with this concept and perhaps "fear of the unknown." Innovation diffusion theory suggests that lack of experience with audit committees is likely to increase the uncertainty of the perceived consequences of adopting an IAC; therefore increasing the likelihood of opposition to adoption (Rogers, 1983, p. 21).

Perceptions of Benefits and Costs Associated with IAC Adoption

TABLE 4-9

Benefits Associated with a Municipality Either Being Required or Voluntarily Adopting an Independent Audit Committee

In Percent ( $\mathrm{n}$ in parentheses)

\begin{tabular}{|l|c|c|c|c|c|}
\hline Question & SA & A & N & D & SD \\
\hline FR-ACCT & 9 & 26 & 30 & 30 & 6 \\
& $(12)$ & $(34)$ & $(39)$ & $(39)$ & $(8)$ \\
\hline FR-IMAGE & 9 & 36 & 30 & 22 & 4 \\
& $(12)$ & $(47)$ & $(39)$ & $(29)$ & $(5)$ \\
\hline EL-INVOLV & 8 & 36 & 23 & 29 & 5 \\
& $(11)$ & $(47)$ & $(30)$ & $(38)$ & $(6)$ \\
\hline ADM-INVOLV & 8 & 36 & 27 & 23 & 5 \\
& $(11)$ & $(47)$ & $(36)$ & $(31)$ & $(7)$ \\
\hline LAWRISK & 2 & 8 & 33 & 45 & 12 \\
& $(3)$ & $(11)$ & $(43)$ & $(59)$ & $(16)$ \\
\hline DISCLOSE & 5 & 30 & 34 & 25 & 7 \\
& $(6)$ & $(39)$ & $(45)$ & $(33)$ & $(9)$ \\
\hline BONDRATE & 5 & 27 & 37 & 25 & 7 \\
& $(6)$ & $(35)$ & $(49)$ & $(33)$ & $(9)$ \\
\hline
\end{tabular}

\footnotetext{
${ }^{25}$ While $2 / 3$ of those who had an opinion either strongly disagreed or disagreed with IAC adoption, there is evidence that smaller cities have greater opposition. One-half of the large cities, $56 \%$ of the medium sized cities, and $77 \%$ of the small cities who had an opinion strongly disagreed or disagreed with IAC implementation. This is not statistically significant $(\chi 2=8.6168, d f .=8, p=0.3756$, two-tailed) suggesting the null hypothesis of no difference could not be rejected.
} 
Findings in Table 4-9 give some idea as to why support for IAC is lacking. A plurality believes IAC will provide intangible benefits by enhancing the responsible financial reporting image for the municipality (FR-IMAGE) and encourage greater involvement by the elected and administrative leadership (EL-INVOLV \& ADM-INVOLV). However, relatively few of our respondents see intangible benefits such as increasing the importance of the CAFR as an instrument of accountability (FR-ACCT) or encouraging a more positive attitude toward disclosure reporting among the administrative leadership and staff (DISCLOSE). With regard to tangible benefits, only $1 / 3^{\text {rd }}$ of our respondents see IAC as resulting in improved bond ratings (BONDRATE) and only 10\% agree or strongly agree that it will reduce lawsuits (LAWRISK). On the whole, there is generally less agreement to the benefits of IAC when compared to POC (Table 4-5).

Findings in Table 4-10 provide further explanation for our respondents' lack of support for IAC adoption. Sizable proportions of our respondents seem to believe that establishment of this financial "shadow-bureaucracy" as it were, would be difficult (ELCONTROL \& ADMCONTROL). Our respondents are concerned that both elected officials and senior executive officials will lose their autonomy with regard to external auditors under an IAC regime. Many of our respondents seem to question if they will be able to secure a complement of knowledgeable members (PERSONNEL \& EXPERT). And lastly, $53 \%$ our respondents show agreement with the proposition that the costs of implementing IOC will outweigh the benefits (COST>BENE). 
TABLE 4-10

Implementation Issues (Costs) Associated with a Municipality Adopting an Independent

Audit Committee

In Percent ( $\mathrm{n}$ in parentheses)

\begin{tabular}{|c|c|c|c|c|c|}
\hline Question & SA & $\mathbf{A}$ & $\mathbf{N}$ & D & $\mathbf{S D}$ \\
\hline $\begin{array}{l}\text { The independent audit committee would be viewed by } \\
\text { elected officials as having too much control over the } \\
\text { selection, retention, and communication with the independent } \\
\text { auditors (ELCONTROL) }\end{array}$ & $\begin{array}{c}14 \\
(19)\end{array}$ & $\begin{array}{c}33 \\
(43)\end{array}$ & $\begin{array}{c}27 \\
(36)\end{array}$ & $\begin{array}{c}21 \\
(28)\end{array}$ & $\begin{array}{c}5 \\
(6)\end{array}$ \\
\hline $\begin{array}{l}\text { The independent audit committee would be viewed by the } \\
\text { Executive/Administrative leadership as having too much } \\
\text { control over the selection, retention, and communication with } \\
\text { the external auditors (ADMCONTROL) }\end{array}$ & $\begin{array}{c}14 \\
(18)\end{array}$ & $\begin{array}{c}41 \\
(54)\end{array}$ & $\begin{array}{c}26 \\
(34)\end{array}$ & $\begin{array}{c}17 \\
(22)\end{array}$ & $\begin{array}{c}3 \\
(4)\end{array}$ \\
\hline $\begin{array}{l}\text { It would be very difficult to find individuals from our } \\
\text { community who qualify and would be willing to serve on the } \\
\text { independent audit committee (PERSONNEL) }\end{array}$ & $\begin{array}{c}29 \\
(38)\end{array}$ & $\begin{array}{c}27 \\
(36) \\
\end{array}$ & $\begin{array}{c}17 \\
(22)\end{array}$ & $\begin{array}{c}23 \\
(31) \\
\end{array}$ & $\begin{array}{c}4 \\
(5)\end{array}$ \\
\hline $\begin{array}{l}\text { It would be very difficult to find an individual from our } \\
\text { community who is both an accounting "expert" and familiar } \\
\text { with the role and activities of a municipality } \\
\text { (EXPERT) }\end{array}$ & $\begin{array}{c}36 \\
(47)\end{array}$ & $\begin{array}{c}30 \\
(39)\end{array}$ & $\begin{array}{c}17 \\
(23)\end{array}$ & $\begin{array}{c}14 \\
(18)\end{array}$ & $\begin{array}{c}4 \\
(5)\end{array}$ \\
\hline COST $>$ BENE & $\begin{array}{c}24 \\
(32)\end{array}$ & $\begin{array}{c}29 \\
(38)\end{array}$ & $\begin{array}{c}36 \\
(47)\end{array}$ & $\begin{array}{c}10 \\
(13)\end{array}$ & $\begin{array}{c}2 \\
(2)\end{array}$ \\
\hline
\end{tabular}

Attitudes Regarding the Orientation of Government Accounting

The municipal reporting model required by GASB 34 incorporates many business-like measurements for reporting transactions and balances (GASB 34, 1999, para. 305). This $\mathrm{CM}$ has thus far centered on what is reported and how it is measured (relevance). If adopted, the POC and IAC provisions would broaden the CM in the governmental sector by addressing issues of defined accountability and enhanced independence of those involved in the assurance process (reliability).

The $\mathrm{CM}$ can be seen as blurring distinctions between the public and private sector. The recent New Public Management (NPM) movement, as well as the municipal reform movement which occurred during the early decades of the twentieth century, have supported governments adopting business-like processes and procedures (Boyne, 2002). 
On the other hand, many public administration scholars (Sayre, 1958; Allison, 1979) have argued that governments and business are so fundamentally unalike that adoption of business-like practices by the governmental sector "would be at best fruitless and at worst counterproductive" (Boyne, 2002, p. 98).

The well documented public/private dichotomy literature has not provided a robust resolution of which private sector processes and techniques should, or can, be adopted in the public sector (Berman \& West, 1998; Boyne, 2002). As a result, it is anticipated that individuals will have varying perspectives regarding public-private differences and similarities. For example, when the initial draft of GASB 34 was released for comment, there was both expressed support for, and opposition to, the proposed measurement focus and basis of accounting (MFBA) to be used in the government-wide statements (GASB 34, 1999, para. 305).

The question is whether the attitudes and beliefs of the respondents regarding required $\mathrm{POC}$ and IAC adoption reflect how municipal finance officers' view the CM? The responses in Table 4-11 provide evidence of their view of the CM as related to the municipal reporting requirements of GASB 34. 
Table 4-11

Attitudes toward Orientation of Government Accounting

In Percent ( $\mathrm{n}$ in parentheses)

\begin{tabular}{|c|c|c|c|c|c|}
\hline Question & SA & $\mathbf{A}$ & $\mathbf{N}$ & D & SD \\
\hline $\begin{array}{l}\text { Municipalities owe a greater responsibility to the average } \\
\text { citizen to be publicly accountable than private enterprises } \\
\text { owe to their investors (RESPONSIBILITY) }\end{array}$ & $\begin{array}{c}24 \\
(32)\end{array}$ & $\begin{array}{c}33 \\
(43)\end{array}$ & $\begin{array}{c}11 \\
(14)\end{array}$ & $\begin{array}{c}28 \\
(37)\end{array}$ & $\begin{array}{c}5 \\
(6)\end{array}$ \\
\hline $\begin{array}{l}\text { Statement } 34 \text { and subsequent statements are moving } \\
\text { municipal financial reporting and disclosure to the } \\
\text { orientation of financial reporting and disclosure of private } \\
\text { enterprises (CONVERGENCE) }\end{array}$ & $\begin{array}{c}13 \\
(17)\end{array}$ & $\begin{array}{c}58 \\
(77)\end{array}$ & $\begin{array}{c}11 \\
(14)\end{array}$ & $\begin{array}{c}14 \\
(18)\end{array}$ & $\begin{array}{c}5 \\
(6)\end{array}$ \\
\hline $\begin{array}{l}\text { The financial reporting and disclosures of municipalities } \\
\text { should more closely resemble the financial reporting and } \\
\text { disclosures of private enterprises. (CONVERGENCE } \\
\text { ACCEPTANCE) }\end{array}$ & $\begin{array}{c}4 \\
(5)\end{array}$ & $\begin{array}{c}26 \\
(34)\end{array}$ & $\begin{array}{c}21 \\
(28)\end{array}$ & $\begin{array}{c}40 \\
(53)\end{array}$ & $\begin{array}{c}9 \\
(12)\end{array}$ \\
\hline $\begin{array}{l}\text { The financial reporting and disclosures of municipalities } \\
\text { should provide information which helps the average citizen } \\
\text { to better understand the role and activities of the municipality } \\
\text { (INFORMATION) }\end{array}$ & $\begin{array}{c}39 \\
(51)\end{array}$ & $\begin{array}{c}55 \\
(73)\end{array}$ & $\begin{array}{c}3 \\
(4)\end{array}$ & $\begin{array}{c}2 \\
(2)\end{array}$ & $\begin{array}{c}2 \\
(2)\end{array}$ \\
\hline $\begin{array}{l}\text { Changes in municipal reporting as a result of Statement } 34 \\
\text { and subsequent statements provides information which is } \\
\text { more useful to the average citizen in understanding the role } \\
\text { and activities of the municipality (USEFUNESS) }\end{array}$ & $\begin{array}{c}5 \\
(6)\end{array}$ & $\begin{array}{c}28 \\
(37)\end{array}$ & $\begin{array}{c}25 \\
(33)\end{array}$ & $\begin{array}{c}24 \\
(32)\end{array}$ & $\begin{array}{c}18 \\
(24)\end{array}$ \\
\hline
\end{tabular}

Analysts at Touche Ross observed over three decades ago that successful implementation of financial reporting must be "what makes sense and best serves users" (Touche Ross, 1977, p. 5). The responses in Table 4-11 suggest that there may be a significant difference between the goals and objectives of GASB via Statement 34 and successors, and what the financial officers see as making sense to the "average citizen." While $94 \%$ of the respondents strongly agree or agree that financial reporting should help average citizens better understand municipal functions and roles (INFORMATION), only $1 / 3$ of the respondents view adoption of the GASB 34 reporting model as benefiting the average citizen's knowledge of municipal operations (USEFULNESS). The lack of usefulness analogues with the observation that the current reporting model is complex and difficult to read and interpret (Gauthier, 2007b, p. 9; Chase \& Phillips, 2004, p. 27) and consistent with the recommendation by the Government Finance Officers 
Association (GFOA) of a Popular Annual Financial Report (PAFR) for use by the average citizen (Montondon \& Lilley, 2005, p. 53).

A clear majority of the respondents view the GASB 34 reporting model as reflecting a business-like orientation (CONVERGENCE); on the other hand, less than 1/3 strongly agree or agree that the GASB 34 reporting model should more closely resemble the private sector model (CONVERGENCE ACCEPTANCE). While the findings indicate the respondents' view that the GASB 34 reporting model does incorporate a business-like orientation, the municipal finance officers have some hesitation with this business-like orientation.

A majority (57\%) of the respondents strongly agreed or agreed that municipalities owe a greater responsibility to the average citizen to be publicly accountable than private enterprises owe to their investors (RESPONSIBILITY). On the face of it, this indicates an endorsement by municipal chief financial officers' of the importance of accounting to the fulfillment of public accountability. This conforms with Paul Posner's (2006) observation that accountability in the public sector has "grown to an iconic status" and those in the "accountability professions are its most vigilant advocates" (p. 72). Stephen Page (2006) has suggested the greater emphasis on accountability has resulted from the new public management (NPM) reforms, which includes the CM, by "granting public managers and line staff increased flexibility in exchange for increased accountability" (p. 167). 
Innovation Adoption Rate

TID recognizes differences between "early adopters" and "late adopters" suggesting there are individuals or organizations which will tend to accept innovations earlier than others (Rogers, 1995, p. 263-280). Conceptually related is TPB research which has suggested that measuring prior behavior may improve the prediction of later behavior (Ajzen, 2002). For these reasons survey questions were included which measured prior instances of early adoption of GASB Statements 34 and 44.

Table 4-12

Adoption Rate of GASB 34

\begin{tabular}{|l|c|c|}
\hline & Frequency & Percent \\
\hline Early implementer & 39 & 29.6 \\
\hline Implemented as prescribed & 87 & 65.9 \\
\hline Late implementer & 4 & 3.0 \\
\hline Not implemented & 2 & 1.5 \\
\hline & 132 & 100 \\
\hline
\end{tabular}

Table 4-13

Adoption Rate of GASB 44

\begin{tabular}{|c|c|c|}
\hline & Frequency & Percent \\
\hline Implemented early & 22 & 16.7 \\
\hline Will implement as prescribed & 67 & 50.7 \\
\hline No decision on implementation & 43 & 32.6 \\
\hline Total & 132 & 100 \\
\hline
\end{tabular}

Cross tabulation of ADOPTION RATE 34 with ADOPTION RATE 44 showed significant association (prob. $\leq 0.05$ ) indicating those municipalities which did adopt GASB 34 either early or as prescribed also had either adopted GASB 44 early or were planning to adopt GASB 44 when prescribed. However, cross tabulation of required POC (Table 4-3) and required IAC (Table 4-8) with either ADOPTIN RATE 34 or ADOPTION RATE 44 indicated no significant measure of association between the adoption 
rates and attitudes toward required POC and IAC. This finding suggests a limited relationship between the adoption rate of accounting rules and implementation of new auditing regulations.

Organizational and Personal Characteristics

Cross-tabulation between the variables of interest - required POC (Table 4-3) and required IAC (Table 4-8) - against the organizational and personal characteristics measured had no significant measure of association between the demographic variables and attitudes toward required POC or establishment of an IAC. This finding is consistent with TPB, suggesting that formation of an attitude toward a specific act is determined from the individual evaluations of the consequences of such an act (Azjen, 1988, p. 150); rather than organizational and personal demographics.

Personal Demographics of Respondents

Table 4-14

Gender

\begin{tabular}{|c|c|c|}
\hline Gender & Frequency & Percentage \\
\hline Female & 45 & 34.1 \\
\hline Male & 87 & 65.9 \\
\hline Total & 132 & 100 \\
\hline
\end{tabular}

Table 4-15

Age

\begin{tabular}{|c|c|c|}
\hline Age & Frequency & Percentage \\
\hline Under 26 & 0 & 0.0 \\
\hline 26 to 35 & 8 & 6.1 \\
\hline 36 to 45 & 32 & 24.2 \\
\hline 46 to 55 & 61 & 46.2 \\
\hline 56 to 65 & 26 & 19.7 \\
\hline Over 65 & 5 & 3.8 \\
\hline Total & 132 & 100 \\
\hline
\end{tabular}


Table 4-16

Education

\begin{tabular}{|l|l|l|}
\hline Education & Frequency & Percent \\
\hline High School Diploma & 10 & 7.6 \\
\hline Associates Degree & 5 & 3.8 \\
\hline Bachelors Degree & 71 & 53.8 \\
\hline Masters Degree & 41 & 31.0 \\
\hline Doctorate Degree & 3 & 2.3 \\
\hline Law Degree & 2 & 1.5 \\
\hline \multicolumn{1}{|c|}{ Total } & 132 & 100 \\
\hline
\end{tabular}

Table 4-17

Certified Public Accountants

\begin{tabular}{|c|c|c|}
\hline Certified Public Accountant & Frequency & Percent \\
\hline $\mathrm{CPA}$ & 66 & 50.0 \\
\hline Non-CPA & 66 & 50.0 \\
\hline Total & 132 & 100 \\
\hline
\end{tabular}

Organizational Demographics of Respondents' Communities

Table 4-18

State Location

\begin{tabular}{|l|c|c|}
\hline State & Frequency & Percent \\
\hline Florida & 64 & 48.5 \\
\hline Ohio & 68 & 51.5 \\
\hline \multicolumn{1}{|r|}{ Total } & 132 & 100 \\
\hline
\end{tabular}

Table 4-19

City Size

\begin{tabular}{|l|c|c|}
\hline Size by Population & Frequency & Percent \\
\hline Small $(10,000-25,000)$ & 75 & 56.8 \\
\hline Medium $(25,001-99,999)$ & 48 & 36.4 \\
\hline Large $(100,000$ or more) & 9 & 6.8 \\
\hline Total & 132 & 100 \\
\hline
\end{tabular}


Table 4-20

Chief Administrative Officer of Municipality

\begin{tabular}{|c|c|c|}
\hline Chief Administrative Officer & Frequency & Percent \\
\hline City Manager & 81 & 61.4 \\
\hline Mayor & 41 & 31.0 \\
\hline Other & 10 & 7.6 \\
\hline Total & 132 & 100 \\
\hline
\end{tabular}

Table 4-21

Selection of Chief Financial Officer

\begin{tabular}{|l|c|c|}
\hline Appointment/Election of CFO & Frequency & Percent \\
\hline Appointed by City Manager & 63 & 47.7 \\
\hline Appointed by City Council/Mayor & 45 & 34.1 \\
\hline Elected & 24 & 18.2 \\
\hline Total & 132 & 100 \\
\hline
\end{tabular}

Table 4-22

Chief Financial Officer Directly Reports to Whom

\begin{tabular}{|l|c|c|}
\hline CFO reports to: & Frequency & Percent \\
\hline Citizens (when elected) & 24 & 18.2 \\
\hline City Council/Mayor & 35 & 26.5 \\
\hline City Manager & 64 & 48.5 \\
\hline Assistant City Manager & 4 & 3.0 \\
\hline Other & 5 & 3.8 \\
\hline \multicolumn{1}{r|}{ Total } & 132 & 100 \\
\hline
\end{tabular}

Does your city provide a management representation letter? $(96.2 \%)$

Does your city currently have an audit committee? $(29.5 \%)$

\section{SECTION 2 - HOW MUNICIPAL FINANCE OFFICERS STRUCTURE ATTITUDES TOWARD ADOPTION OF SOX-LIKE REQUIREMENTS}

Summaries of the responses to the individual variables of the survey have been provided in section one as a way of describing what the data shows. In this section of the chapter the focus shifts from analysis of individual variables to groups of variables. 
Exploratory factor analysis is utilized to gain insight into how and in what way the measured or observed variables "cluster or hang together" (Stevens, 1996, p. 362) and to "facilitate the understanding of the relations that exist between the observed variables" (Guadagnoli \& Velicer, 1998, p. 265).

\section{Organization of Research Instrument}

The research survey instrument contained twenty-three items to measure specific consequences (favorable and unfavorable) associated with the specific acts of POC and IAC adoption. These twenty-three independent variables were categorized in the survey instrument as follows:

1. Potential favorable outcomes associated with the adoption of POC (Table 4-5).

2. Potential favorable outcomes associated with the adoption of IAC (Table 4-9).

3. Reservations or concerns associated with the adoption of POC (Table 4-6).

4. Reservations or concerns associated with the adoption of IAC (Table 4-10). An additional category included in the EFA analysis was those five independent variables from:

5. General beliefs about the appropriateness of the GASB 34 prescribed reporting model (Table 4-11)

The beginning domain of independent variables considered in the EFA analysis includes the above five groups which represent twenty-eight measured variables in total. The organizational and personal demographics as well as the adoption rate variables (Tables 4-12 and 4-13) are nominal variables and not included. 
Factor Analysis

This is an initial study of the acceptability of required POC and IAC. As such, the strong prior knowledge necessary to utilize confirmatory factor analysis is not present (Stevens, 1996, p. 389; Henson \& Roberts, 2006, 2006, p. 395). Without prior knowledge of the number of observed variables to include in the factor analysis, which measured variables will "load" on a particular factor, or how many factors are present in the dataset; exploratory factor analysis (EFA) is the "more sensible approach" for this study (Fabriger, Wegener, MacCullum, \& Strahan, 1999, p. 277).

In addressing the issue of what observed variables to retain in the analysis, MacCullum, Widaman, Zhang, \& Hong (1999) have emphasized the importance of removing variables with low communalities to increase the quality of the results (p. 96). Fabrigar et al. (1999) support the removal of low communality variables because "variables with low reliability will have low communalities....[and] A second reason why a variable might have a low communality is that the variable is unrelated to the domain of interest and thus shares little in common with other measured variables in that domain" (p. 273). 
Table 4-23

Communalities

Principal Axis Method - No Rotation

(Convergence in 6 Factors)

\begin{tabular}{|l|c|}
\hline Observed Variable & Communality \\
\hline Specific benefits (POC) & \\
\hline FR-ACCT (POC) & 0.687 \\
\hline FR-IMAGE (POC) & 0.760 \\
\hline EL-INVOLV (POC) & 0.510 \\
\hline ADM-INVOLV (POC) & 0.585 \\
\hline LAWRISK (POC) & 0.670 \\
\hline DISCLOSE (POC) & 0.664 \\
\hline BONDRATE (POC) & 0.541 \\
\hline Specific benefits (IAC) & \\
\hline FR-ACCT (IAC) & 0.649 \\
\hline FR-IMAGE (IAC) & 0.665 \\
\hline EL-INVOLV (IAC) & 0.596 \\
\hline ADM-INVOLV (IAC) & 0.683 \\
\hline LAWRISK (IAC) & 0.641 \\
\hline DISCLOSE (IAC) & 0.683 \\
\hline BONDRATE (IAC) & 0.697 \\
\hline Specific unfavorable consequences (POC) & \\
\hline FRKNOW & 0.881 \\
\hline ICKNOW & 0.813 \\
\hline CRIMINAL & 0.266 \\
\hline COST>BENE (POC) & 0.519 \\
\hline Specific unfavorable consequences (IAC) & \\
\hline ELCONTROL & 0.587 \\
\hline ADMCONTROL & 0.658 \\
\hline PERSONNEL & 0.675 \\
\hline EXPERT & 0.709 \\
\hline COST>BENE (IAC) & 0.634 \\
\hline General Beliefs about GASB 34 & 0.107 \\
\hline RESPONSIBILITY & 0.339 \\
\hline CONVERGE & 0.219 \\
\hline CONVERGE ACCEPTANCE & 0.072 \\
\hline INFORMATION & 0.312 \\
\hline USEFULNESS & \\
\hline & \\
\hline
\end{tabular}

In Table 4-23, except for the observed variable "CRIMINAL," all of the low communalities (shown in bold) are with the observed variables from the category of "general beliefs about GASB 34." The low communalities of the observed variables included in the "general beliefs about GASB 34" is sufficient reason to eliminate this category from further consideration in the factor analysis (MacCullum, Wildaman, Zhang, \& Hong, 1999; Fabrigar et al., 1999). 
Having identified the twenty-three observed variables to retain for analysis the next analytical step was to determine the number of factors to retain. The determination of the number of factors to retain has been described as "likely to be the most important decision a researcher will make" (Zwick \& Velicer, 1986, p. 432). The "indeterminacy" of factor analysis (Maraun, 1996; Stevens, 1996) has led to the development of several heuristics and guidelines for selecting the factor model using statistical rationale as well as subjective judgment (Conway \& Hoffcutt, 2003, p. 152; Fabrigar et al., 1999, p. 283; Henson \& /Roberts, 2006, p. 396).

The un-rotated data converged ${ }^{26}$ at the six factor model, indicating an upper limit of extracting no more than six factors. The factor loadings shown in Table 4-24 represent the correlation between the observed variable and the factor or group of observed variables selected. The first two factors contained at least six highest valued factor loadings (shown in bold), factor 3 contained just two variables and factors four through six only extracted one variable. It is also noted the variables extracted in factors four through six are complex variables which have higher loadings on factors one and two. Considering only the number of variables defining a factor and the magnitude of their factor loadings, suggests the two or maybe three factor model would be reliable (Guadagnoli and Velicer, 1988, p. 274).

\footnotetext{
${ }^{26}$ Convergence occurs when there is very little or no variance remaining to be accounted for.
} 
Table 4-24

Factor Loadings equal to or greater than 10.401 value Principal Axis Method - No Rotation

23 Observed Variables

(Bold indicates the highest factor loading for individual variables)

\begin{tabular}{|l|l|l|l|l|l|l|}
\hline Observed Variables & \multicolumn{5}{|c|}{ Factors } \\
\hline & 1 & 2 & 3 & 4 & 5 & 6 \\
\hline FR-ACCT (POC) & 0.733 & & & & & \\
\hline FR-IMAGE (POC) & 0.774 & & & & & \\
\hline EL-INVOLV (POC) & 0.651 & & & & & \\
\hline ADM-INVOLV (POC) & 0.611 & & & & & \\
\hline LAWRISK (POC) & 0.590 & & & & & -0.427 \\
\hline DISCLOSE (POC) & 0.740 & & & & & \\
\hline BONDRATE (POC) & 0.656 & & & & & \\
\hline FR-ACCT (IAC) & 0.779 & & & & & \\
\hline FR-IMAGE (IAC) & 0.728 & & & & & \\
\hline EL-INVOLV (IAC) & 0.712 & & & & & \\
\hline ADM-INVOLV (IAC) & 0.735 & & & & & \\
\hline LAWRISK (IAC) & 0.665 & & & & & \\
\hline DISCLOSE (IAC) & 0.723 & & & & & \\
\hline BONDRATE (IAC) & 0.721 & & & 0.465 & & \\
\hline FRKNOW & & 0.510 & -0.725 & & & \\
\hline ICKNOW & & 0.546 & -0.667 & & & \\
\hline CRIMINAL & & & & & & \\
\hline COST >BENE (POC) & -0.432 & $\mathbf{0 . 4 5 9}$ & & & & \\
\hline ELCONTROL & & 0.471 & & & 0.404 & \\
\hline ADMCONTROL & & 0.574 & & & & \\
\hline PERSONNEL & & 0.659 & & & & \\
\hline EXPERT & & 0.668 & & & & \\
\hline COST>BENE (IAC) & & 0.626 & & & & \\
\hline
\end{tabular}

In addition to an analysis of the factor loadings, two popular rules for determining the number of factors to retain have been Kaiser's "eigenvalue greater than one" rule and Cattell's "scree test" (Henson \& Roberts, 2006; Conway \& Hoffcutt, 2003).

Computation of the factor eigenvalues of the unrotated data suggests four factors should be retained. The scree test suggested three factors should be retained. Consideration of the analysis of factor loadings, Kaiser's rule and Cattrell's scree test suggests the number of factors to retain should be either the 2-factor model, 3-factor model, or the 4-factor model. 
Prior to making a final decision on the number of factors to retain, the factors will be rotated "to find a more interpretable solution" (Conway \& Hoffcutt, 2003, p. 152). As Fabrigar et al. (1999) observed: "A model that fails to produce a rotated solution that is interpretable and theoretically sensible has little value" (p. 281). Results shown in Table 4-25 were obtained using the principal axis method with varimax orthogonal rotation.

Table 4-25

Alternative Factor Extraction Models

Principal Axis Method - Varimax Rotation

\begin{tabular}{|c|c|c|c|c|c|c|}
\hline \multirow[b]{2}{*}{ Model } & & \multicolumn{4}{|c|}{ Factors Extracted } & \multirow[b]{2}{*}{ Cum. $\%$} \\
\hline & & 1 & 2 & 3 & 4 & \\
\hline 2 Factor & $\begin{array}{l}n \\
\mathrm{e} \\
\mathrm{a}\end{array}$ & $\begin{array}{c}14 \\
7.14 \\
0.93\end{array}$ & $\begin{array}{c}8 \\
3.04 \\
.80\end{array}$ & & & 95.8 \\
\hline 3 Factor & $\begin{array}{l}\text { n } \\
\text { e } \\
\mathrm{a}\end{array}$ & $\begin{array}{c}14 \\
7.17 \\
0.93\end{array}$ & $\begin{array}{c}6 \\
2.66 \\
0.80\end{array}$ & $\begin{array}{c}3 \\
1.96 \\
0.79\end{array}$ & & 97.0 \\
\hline 4 Factor & $\begin{array}{l}\mathrm{n} \\
\mathrm{e} \\
\mathrm{a}\end{array}$ & $\begin{array}{c}10 \\
4.63 \\
0.91\end{array}$ & $\begin{array}{c}6 \\
2.64 \\
0.80\end{array}$ & $\begin{array}{c}3 \\
1.96 \\
0.79\end{array}$ & $\begin{array}{c}8 \\
3.81 \\
0.90\end{array}$ & 97.5 \\
\hline
\end{tabular}

$\mathrm{n}=$ number of observed variables in factor

$\mathrm{e}=$ eigenvalue of factor

$\mathrm{a}=$ cronbach's alpha of factor

Most of the metrics reported in Table 4-25 for the 2-factor, 3-factor, and 4-factor models suggest any of the models would work equally well. The cumulative percentages after rotation are all greater than $90 \%$. The reliability (cronbach's alpha) for each factor is acceptable $(0.79$ to 0.93$)$. The number of observed variables in each of the factors is equal to or greater than three (Fabrigar et al., 1999, p. 274).

The 4-factor model, which was included because of selection by Kaiser's rule, is eliminated for several reasons. The factor structure includes four complex variables (variables with high loadings on more than one factor) which is undesirable following the 
guidance of Thurstone's "simple structure" concept (Fabrigar et al., 1999, p. 281). The eigenvalue and number of extracted observed variables is greater in the fourth factor than in the first. Finally, several researchers have found the Kaiser rule to be less accurate than the scree test in selection of the appropriate number of factors to retain (Henson \& Roberts, 2006, p. 399; Stevens, 1996, p. 367; Fabrigar et al., 1999, p. 279).

Table 4-26

Comparison of Factor Structure of

2-Factor Model vs. 3-Factor Model

23 Observed Variables - Varimax Rotation

\begin{tabular}{|c|c|c|c|c|c|}
\hline \multirow[b]{2}{*}{ Observed Variable } & \multicolumn{2}{|c|}{$\begin{array}{c}\text { Factors of } \\
\text { 2-Factor Model }\end{array}$} & \multicolumn{3}{|c|}{$\begin{array}{c}\text { Factors of } \\
\text { 3-Factor Model }\end{array}$} \\
\hline & 1 & 2 & 1 & 2 & 3 \\
\hline \multicolumn{6}{|l|}{ Specifie benefits (POC) } \\
\hline FR-ACCT (POC) & $\mathrm{X}$ & & $\bar{X}$ & & \\
\hline FR-IMAGE (POC) & $\mathrm{X}$ & & $\mathrm{X}$ & & \\
\hline EL-INVOLV (POC) & $\mathbf{X}$ & & $\mathrm{X}$ & & \\
\hline ADM-INVOLV (POC) & $\mathrm{X}$ & & $\mathrm{X}$ & & \\
\hline LAWRISK (POC) & $\mathrm{X}$ & & $\mathrm{X}$ & & \\
\hline DISCLOSE (POC) & $\mathrm{X}$ & & $\mathrm{X}$ & & \\
\hline BONDRATE (POC) & $\mathrm{X}$ & & $\mathrm{X}$ & & \\
\hline \multicolumn{6}{|l|}{ Specific benefits (IAC) } \\
\hline FR-ACCT (IAC) & $\mathrm{X}$ & & $\bar{X}$ & & \\
\hline FR-IMAGE (IAC) & $\mathrm{X}$ & & $\mathrm{X}$ & & \\
\hline EL-INVOLV (IAC) & $\mathrm{X}$ & & $\bar{X}$ & & \\
\hline ADM-INVOLV (IAC) & $\mathrm{X}$ & & $\mathrm{X}$ & & \\
\hline LAWRISK (IAC) & $\mathrm{X}$ & & $\bar{X}$ & & \\
\hline DISCLOSE (IAC) & $\mathrm{X}$ & & $\mathrm{X}$ & & \\
\hline BONDRATE (IAC) & $\mathrm{X}$ & & $\mathrm{X}$ & & \\
\hline \multicolumn{6}{|l|}{ Specific unfavorable consequences (POC) } \\
\hline FRKNOW & & $\mathrm{X}$ & & & $\mathbf{X}$ \\
\hline ICKNOW & & $\mathrm{X}$ & & & $\mathbf{X}$ \\
\hline CRIMINAL & & - & & & $\mathbf{X}$ \\
\hline COST $>$ BENE (POC) & & $\mathrm{X}$ & & $\mathrm{X}$ & \\
\hline \multicolumn{6}{|l|}{ Specific unfavorable consequences (IAC) } \\
\hline ELCONTROL & & $\mathrm{X}$ & & $\mathrm{X}$ & \\
\hline ADMCONTROL & & $\mathrm{X}$ & & $\mathrm{X}$ & \\
\hline PERSONNEL & & $\mathbf{X}$ & & $\mathrm{X}$ & \\
\hline EXPERT & & $\mathrm{X}$ & & $\mathrm{X}$ & \\
\hline COST $>$ BENE (IAC) & & $\mathrm{X}$ & & $\mathrm{X}$ & \\
\hline Number of Observed Variables Selected & 14 & 8 & 14 & 6 & 3 \\
\hline
\end{tabular}


Combining statistical rationale with substantive judgment, argument for selecting either the 2-factor model or 3-factor model could be made (Conway \& Hoffcutt, 2003, p. 152; Fabrigar et al., 1999, p. 283; Henson \& Roberts, 2006, p. 396). They both have Thurstone's simple structure and factor 1 in both models contains all of the favorable consequences. On the other hand, neither model derived from EPA is "ideal" in the selection and distribution of negative consequences. Factor 2 of the 2-factor model did not select the negative consequence (CRIMINAL). The "problem" with the 3-factor model was the inclusion of COST $>\mathrm{BENE}$ (POC) in the second factor (which selected all of the IAC negative consequences) and excluded COST $>$ BENE (POC) from the third factor (which selected the remaining POC negative consequences). Although both models have "interpretable" factors (Zwick \& Velicer, 1986, p. 440), "Occam's Razor" or "principle of parsimony" suggests the choice of the 2-factor model.

\section{Interpretability of 2 Factor Model}

The 2-factor model which emerged from the EFA analytic protocol provided a solution which is "interpretable and theoretically sensible" (Fabrigar et al., 1999, p. 281). The 2-factor model is consistent with TPB guidance in that beliefs about specific consequences of an act are expected to be most influential in the formation of an attitude toward that act (Ajzen, 1988, p. 120). The distribution of variables is neatly categorized into favorable consequences in factor 1 and the negative consequences (except for CRIMINAL) in factor 2. 
Table 4-27

2-Factor Model

Factor Loadings $\geq|0.40|$

Principal Axis Method - Varimax Rotation

\begin{tabular}{|l|r|c|}
\hline Observed Variable & Factor 1 & Factor 2 \\
\hline FR-ACCT (POC) & 0.755925 & \\
\hline FR-IMAGE (POC) & 0.771399 & \\
\hline EL-INVOLV (POC) & 0.657639 & \\
\hline ADM-INVOLV (POC) & 0.634577 & \\
\hline LAWRISK (POC) & 0.617361 & \\
\hline DISCLOSE (POC) & 0.775998 & \\
\hline BONDRATE (POC) & 0.672494 & \\
\hline FR-ACCT (IAC) & 0.772903 & \\
\hline FR-IMAGE (IAC) & 0.681487 & \\
\hline EL-INVOLV (IAC) & 0.704417 & \\
\hline ADM-INVOLV (IAC) & 0.717967 & \\
\hline LAWRISK (IAC) & 0.662093 & \\
\hline DISCLOSE (IAC) & 0.683493 & \\
\hline BONDRATE (IAC) & 0.695447 & \\
\hline FRKNOW & & 0.473681 \\
\hline ICKNOW & & 0.517979 \\
\hline CRIMINAL & & - \\
\hline COST>BENE (POC) & & 0.553974 \\
\hline ELCONTROL & & 0.411414 \\
\hline ADMCONTROL & & 0.545841 \\
\hline PERSONNEL & & 0.704615 \\
\hline EXPERT & & 0.695591 \\
\hline COST BBENE (IAC) & & 0.705008 \\
\hline
\end{tabular}

The two factors of the 2-factor model were interpreted as:

- Factor 1 -Favorable consequences (FAVCONS) - This factor selected all fourteen of the variables from the two categories: "favorable outcomes specifically associated with the adoption of principal officer(s) certification (POC)" and "favorable outcomes specifically associated with the adoption of an independent audit committee."

- Factor 2 - Unfavorable consequences (UNFAVCONS) - This factor contains all five of the measured variables from the category "reservations or concerns 
associated with the adoption of IAC" and three of the four variables from the category "reservations or concerns associated with the adoption of POC."

The factor loadings (correlation between measured variable and factor) are larger with the first factor (FAVCONS) than with the second factor (UNFAVCONS). With FAVCONS all fourteen of the loadings are greater than $|0.60|$ and the four highest loadings are equally split between POC and IAC regressors. Comparatively, only the three highest loading regressors in UNFAVCONS have loadings greater than $|0.60|$ and they are all regressors related to IAC adoption. To examine this further, in the next chapter required POC and required IAC are regressed upon the factor scores (Fabrigar et al., 1999, p. 276).

\section{Concluding Comments for this Chapter}

In the first section of this chapter the responses to the individual, measured variables were summarized in frequency tables of count and percentage as a way of describing the results from the mailed survey. The responses to the dependent variables of interest, required $\mathrm{POC}$ and required IAC, suggested the municipal finance officers have strong support for required POC and strong opposition to required IAC.

The responses to "who" should be the principal officers attesting to the accuracy of the financial statements revealed an interesting normative issue of whether and to what extent financial accountability should be separated from political accountability. The responses of the municipal finance officers seems to indicate an agreement with the Weberian-Wilsonian politics/administration dichotomy, i.e., the municipal finance 
officers do not see the elected officials as having the requisite time or knowledge to meaningfully attest to the accuracy of the financial statements.

Favorable and unfavorable consequences specifically related to both required POC and required IAC were measured. On the surface, the respondents appeared to consider intangible, non-pecuniary consequences as much or more than tangible, pecuniary consequences. A common theme which seemed to emerge was a human resource dimension deficit in the form of an insufficient supply of individuals financially literate about governmental financial reporting and internal controls. This problem was partially mitigated with the adoption of POC if the principal officers attesting to the financial statements were the city manager and municipal finance officer. However, with adoption of IAC the respondents expressed concern with being able to secure the necessary complement of knowledgeable, apolitical members for the committee.

The personal and organizational demographics were interesting in their variety; however cross-tabulation between the dependent variables and the demographic variables showed no significant association. These empirical results were consistent with the TPB and were eliminated from further evaluation.

In the second section of the chapter EFA was employed to gain a further understanding of how municipal finance officers structure their attitudes toward POC and IAC. The variables included in the category of "general beliefs about GASB 34 " had low communalities and were eliminated from further consideration.

The 2-factor model which emerged was consistent with the guidance provided by TPB in that perceived favorable and unfavorable consequences specifically associated with either POC or IAC are believed to be the most influential in the formation of 
attitudes toward adoption of POC and IAC (Ajzen, 1991; Ajzen, 1988). The 2-factor model separated the positive and negative consequences as two separate constructs in a "simple structure." The 2-factor model is interpretable and made theoretical sense, however it is readily acknowledged that within an exploratory study of a single dataset external validity verification through replication is not possible (Henson \& Roberts, $2006, p .400)$. That disclaimer notwithstanding, in the next chapter the variables of interest, required POC and IAC, will be regressed upon the factor scores (Fabrigar et al., 1999, p. 276). 


\section{CHAPTER V \\ PRELIMINARY CAUSAL FINDINGS \\ ELITE INTERVIEWS}

\section{Introduction}

This is the second of two chapters devoted to presenting the findings from this research. In the previous chapter the respondents indicated strong support for adopting POC (Table 4-3) and equally strong opposition to adopting IAC (Table 4-8). Chi-square analysis of POC and IAC against the personal and organizational characteristics found no significant measure of association between the organizational and personal demographics measured and the support for POC and opposition to IAC. Factor analysis suggested elimination of the measured variables included in the domain of "general beliefs about GASB 34" and highlighted the importance of the perceived positive and negative consequences.

The first section of this chapter is an initial effort at gaining at least some understanding of the relationships between the independent variables (positive and negative consequences) and the dependent variables (POC and IAC). The analysis begins by extending the findings from the EFA analysis from the previous chapter (Table 4-16). Instead of considering both favorable and unfavorable consequences related to POC and IAC, the favorable and unfavorable consequences specifically associated with POC and specifically with IAC are examined separately. After determining the factor structure for POC and IAC separately, POC and IAC are regressed upon their respective factor scores.

Next, consideration is given to exploring causal relationship between POC and IAC and their specific favorable and unfavorable consequences. Using Ordinary Least 
Square (OLS) models POC and IAC are regressed upon their associated favorable and unfavorable consequences. Significant regressors are then deployed in logistic regression models.

In the second section of this chapter the responses obtained from interviews with "elite experts" from the government accounting-auditing field are summarized. The interviewees included recognized academics and practitioners as well as a representative from GASB. The interviews were conducted to gain a richer understanding of the findings from the quantitative analysis and to address some issues surrounding the research. Complete responses are provided in Appendix B.

\section{Multiple Regression Analysis of Factors}

In the previous chapter all of the non-demographic independent variables associated with POC and IAC were analyzed utilizing EFA. The outcome of the factor analysis was a 2-factor model. The first factor (FAVCONS) included all favorable consequences associated with POC and IAC. The second factor (UNFAVCONS) included all but one of the negative consequences associated with POC and IAC [CRIMINAL (POC)]. The next procedural step is to examine if a similar factor structure would be found if the consequences of POC and IAC are separately analyzed. 
Table 5-1

Consequences Specifically Related to POC

Factor Loadings $\geq|0.40|$

Principal Axis Method - Varimax Rotation

\begin{tabular}{|l|r|r|}
\hline Observed Variables & $\begin{array}{c}\text { Factor 1 } \\
\text { POC FAVCONS }\end{array}$ & $\begin{array}{c}\text { Factor 2 } \\
\text { POC UNFAVCONS }\end{array}$ \\
\hline FR-ACCT (POC) & 0.840449 & \\
\hline FR-IMAGE (POC) & 0.874393 & \\
\hline EL-INVOLV (POC) & 0.682240 & \\
\hline ADM-INVOLV (POC) & 0.711447 & \\
\hline LAWRISK (POC) & 0.595038 & \\
\hline DISCLOSE (POC) & 0.799497 & \\
\hline BONDRATE (POC) & 0.651824 & 0.910070 \\
\hline FRKNOW (POC) & & 0.915748 \\
\hline ICKNOW (POC) & & 0.474786 \\
\hline CRIMINAL (POC) & & -- \\
\hline COST>BENE (POC) & & \\
\hline
\end{tabular}

Table 5-2

Consequences Specifically Related to IAC

Factor Loadings $\geq|0.40|$

Principal Axis Method - Varimax Rotation

\begin{tabular}{|l|c|c|}
\hline Observed Variables & $\begin{array}{c}\text { Factor 1 } \\
\text { IAC FAVCONS }\end{array}$ & $\begin{array}{c}\text { Factor 2 } \\
\text { IAC UNFAVCONS }\end{array}$ \\
\hline FR-ACCT (IAC) & 0.788554 & \\
\hline FR-IMAGE (IAC) & 0.793804 & \\
\hline EL-INVOLV (IAC) & 0.737205 & \\
\hline ADM-INVOLV (IAC) & 0.776539 & \\
\hline LAWRISK (IAC) & 0.652934 & \\
\hline DISCLOSE (IAC) & 0.787718 & \\
\hline BONDRATE (IAC) & 0.792048 & 0.475452 \\
\hline ELCONTROL (IAC) & & 0.578897 \\
\hline ADMCONTROL (IAC) & & 0.776022 \\
\hline PERSONNEL (IAC) & & 0.786715 \\
\hline EXPERT (IAC) & & 0.661184 \\
\hline COST>BENE (IAC) & & \\
\hline
\end{tabular}

Table 5-1 and Table 5-2 are the results of two separate factor analyses. The factors extracted from the consequences associated with POC are shown in Table 5-1 and 
the factors extracted from the consequences associated with IAC are shown in Table 5-2.

In both cases the factor structure replicates the previous findings by separating the favorable consequences into the first factor and unfavorable consequences in the second factor. These findings, although not as compelling as replication with a separate sample, do provide some evidence of the reliability of the factor structure (Harlow, 2005, p. 208). To test the relationship of the factors to POC and IAC, Ordinary Least Squares (OLS) regressions of POC and IAC on their respective factors is utilized.

Table 5-3

POC Regressed upon Factor Scores Multiple Regression

\begin{tabular}{|l|c|c|c|}
\hline & Coef. & s.e. & Prob. \\
\hline Intercept & 2.6212 & 0.0857 & 0.0000 \\
\hline POC FAVCONS & 0.6076 & 0.0818 & 0.0000 \\
\hline POC UNFAVCONS & -0.1429 & 0.0809 & 0.0797 \\
\hline \multicolumn{2}{|c|}{ Model R ${ }^{2}=0.31 ;$ F-ratio $=28.95$}
\end{tabular}

Table 5-4

IAC Regressed upon Factor Scores Multiple Regression

\begin{tabular}{|l|c|c|c|}
\hline & Coef. & s.e. & Prob. \\
\hline Intercept & 3.4242 & 0.0823 & 0.0000 \\
\hline IAC FAVCONS & 0.5512 & 0.0788 & 0.0000 \\
\hline IAC UNFAVCONS & -0.3798 & 0.0748 & 0.0000 \\
\hline \multicolumn{2}{|c|}{ Model R $R^{2}=0.36$; F-ratio $=36.25$}
\end{tabular}

The findings from regressing $\mathrm{POC}$ and $\mathrm{IAC}$ on their respective factor scores are generally in accord with the support for POC and opposition to IAC ${ }^{27}$. The factors are highly significant (prob. $<0.01$ ) except for the unfavorable consequences associated with POC, which is marginally significant (prob. $<0.08$ ). The coefficient signage of the

\footnotetext{
${ }^{27}$ By multiplying the respective regression equations by the average values of the factor scores of the respective factors calculates values which indicate support for POC and opposition to IAC.
} 
factors indicates the positive influence of the favorable consequences and the negative influence of the unfavorable consequences. The larger ratio of the coefficients (unfavorable consequences/favorable consequences) for IAC compared to POC; plus the increase in significance of the unfavorable consequences for IAC, suggests the unfavorable consequences are becoming more important in the decision to oppose IAC.

The macro level of the findings of factor analysis is generally considered to provide "greater external validity and, as such, are more likely to replicate (Henson \& Roberts, 2006, p. 394). The findings of the regression of POC and IAC on their respective factors is consistent with TPB, which suggests municipal finance officers would form favorable or unfavorable intentions to adopt POC and IAC based upon their assessment of the specific perceived consequences (Ajzen, 1991). Next the analysis drills down to a more micro level to explore the relationship of required POC and required IAC to their specific individual favorable and unfavorable consequences.

\section{Some Preliminary Causal Findings}

The analysis for assessing support for POC and opposition to IAC is in two steps. First, Ordinary Least Squares (OLS) regression was utilized with the five-point Likert scales as dependent variable (Table 4-3 and Table 4-8). The initial domain of regressors are the favorable and unfavorable consequences specifically associated with POC and IAC. Given the exploratory nature of this work, variables achieving a 0.10 level of significance on the initial regression (Full Model) were retained to define a smaller set of independent variables (Reduced Model) in which the traditional 0.05 level of significance threshold was adopted. Significant regressors from the reduced model were then 
deployed in a logistic regression (Agresti, 1990) with a dichotomous dependent variable in which "agree" and "strongly agree" were combined to form one category, and the "disagree" and "strongly disagree" responses were combined to form the second, with neutral responses removed from consideration. The regressors continued to use the fivepoint Likert scale. It was believed this two-stage approach made sense in that the initial regression would lead to a parsimonious final model in which the dichotomous form of the dependent variables more closely resembles a "real world" situation favoring or opposing adoption.

\section{Table 5-5}

Ordinary Least Squares Regression of POC on

Associated Consequences

Full Model and Reduced Model

\begin{tabular}{|l|c|c|c|c|c|c|c|}
\cline { 2 - 8 } \multicolumn{1}{c|}{} & \multicolumn{3}{c|}{ Full Model } & & \multicolumn{2}{c|}{ Reduced Model } \\
\hline Favorable Consequences & Coef & s.e. & Prob. & & Coef & s.e. & Prob. \\
\hline FR-ACCT (POC) & 0.01 & 0.14 & & & & & \\
\hline FR-IMAGE (POC) & 0.12 & 0.16 & & & & & \\
\hline EL-INVOLV (POC) & 0.24 & 0.11 & $<0.05$ & & 0.32 & 0.11 & $<0.01$ \\
\hline ADM-INVOLV (POC) & -0.21 & 0.12 & $<0.10$ & & -0.06 & 0.11 & \\
\hline LAWRISK (POC) & 0.26 & 0.13 & $<0.05$ & & 0.37 & 0.11 & $<0.01$ \\
\hline DISCLOSE (POC) & 0.19 & 0.13 & & & & & \\
\hline BONDRATE (POC) & 0.09 & 0.12 & & & & & \\
\hline Unfavorable Consequences & & & & & & & \\
\hline FRKNOW & 0.18 & 0.17 & & & & & \\
\hline ICKNOW & -0.22 & 0.17 & & & & & \\
\hline CRIMINAL & 0.11 & 0.09 & & & & & \\
\hline COST $>$ BENE (POC) & -0.26 & 0.10 & $<0.05$ & & -0.30 & 0.09 & $<0.01$ \\
\hline
\end{tabular}

$$
\text { Model } R^{2}=0.38 ; F \text {-ratio }=6.55 \quad \text { Model } R^{2}=0.32, F \text {-ratio }=14.83
$$


Table 5-6

Ordinary Least Squares Regression of IAC on

Associated Consequences

Full Model and Reduced Model

\begin{tabular}{|c|c|c|c|c|c|c|}
\hline \multirow[b]{2}{*}{ Favorable Consequences } & \multicolumn{3}{|c|}{ Full Model } & \multicolumn{3}{|c|}{ Reduced Model } \\
\hline & Coef. & s.e. & Prob. & Coef. & s.e. & Prob. \\
\hline FR-ACCT (IAC) & 0.10 & 0.12 & & & & \\
\hline FR-IMAGE (IAC) & -0.02 & 0.14 & & & & \\
\hline EL-INVOLV (IAC) & 0.10 & 0.13 & & & & \\
\hline ADM-INVOLV (IÁC) & 0.10 & 0.14 & & & & \\
\hline LAWRISK (IAC) & 0.13 & 0.12 & & & & \\
\hline DISCLOSE (IAC) & 0.26 & 0.13 & $<0.10$ & 0.48 & 0.08 & $<0.01$ \\
\hline BONDRATE (IAC) & -0.01 & 0.13 & & & & \\
\hline \multicolumn{7}{|l|}{ Unfavorable Consequences } \\
\hline ELCONTROL & -0.16 & 0.10 & $<0.10$ & -0.11 & 0.08 & \\
\hline ADMCONTROL & 0.06 & 0.11 & & & & \\
\hline PERSONNEL & 0.21 & 0.11 & $<0.10$ & 0.25 & 0.11 & $<0.05$ \\
\hline EXPERT & -0.27 & 0.12 & $<0.05$ & -0.28 & 0.12 & $<0.05$ \\
\hline COST>BENE(IAC) & -0.35 & 0.11 & $<0.01$ & -0.40 & 0.10 & $<0.01$ \\
\hline
\end{tabular}

The significant (prob. $<0.05$ ) independent variables in the reduced model (Table

5-5) for POC were EL-INVOLV(POC), LAWRISK (POC), and COST>BENE (POC). EL-INVOLV (POC) and LAWRISK (POC) are favorable consequences and the one significant unfavorable consequence was COST $>B E N E$ (POC). The significant independent variables in the reduced model (Table 5-6) for IAC were DISCLOSE (IAC), PERSONNEL (IAC), EXPERT (IAC), and COST>BENE (IAC). The single significant favorable consequence was DISCLSOSE (IAC) and the three significant unfavorable consequences were EL-CONTROL (IAC), PERSONNEL (IAC), and COST>BENE (IAC). The significant regressors were then deployed in binomial logistic regression models (Agresti, 1990). The dichotomous dependent variables for POC and IAC were derived by combining "agree" and "strongly agree" to form one category and "disagree" and "strongly disagree" were combined to form the second category. Those respondents which had a neutral response to POC 
adoption were removed from consideration, which reduced the cases considered from 132 to 110 . Likewise, the reduction in cases for IAC was from 132 to 102 .

Table 5-7

Logistic Regression: Strongly Agree/Agree vs. Disagree/Strongly Disagree "In general, I believe principal officer(s) certification similar to SOX should be required of the principal officer(s) of municipalities."

\begin{tabular}{|l|c|c|c|}
\hline Variable & Coef. & s.e. & Prob. \\
\hline EL-INVOLV (POC) & 0.58 & 0.26 & 0.03 \\
\hline LAWRISK (POC) & 1.19 & 0.40 & 0.00 \\
\hline COST>BENE (POC) & -0.64 & 0.27 & 0.02 \\
\hline
\end{tabular}

$$
\begin{gathered}
N=110, \text { Pseudo Model } R^{2}=0.61 \\
\text { Percent correctly classified }=80.9 \%
\end{gathered}
$$

Table 5-8

Logistic Regression: Strongly Agree/Agree vs. Disagree/Strongly Disagree "Should municipalities be required to have an independent audit committee with responsibilities similar to the requirement of Sarbanes-Oxley?"

\begin{tabular}{|l|c|c|c|}
\hline Variable & Coef. & s.e. & Prob. \\
\hline DISCLOSE (IAC) & 1.18 & 0.32 & 0.00 \\
\hline PERSONNEL (IAC) & 0.85 & 0.46 & 0.06 \\
\hline EXPERT (IAC) & -0.92 & 0.43 & 0.03 \\
\hline COST $>$ BENE (IAC) & -1.46 & 0.45 & 0.00 \\
\hline
\end{tabular}

$\mathrm{N}=102$, Pseudo Model $\mathrm{R}^{2}=0.49$

Percent correctly classified $=87.3 \%$

Findings in Tables 5-7 and 5-8 are essentially identical to those found in our multiple regression models, despite a reduction in cases and different functional form. The only difference in findings is in the IAC model, in which one of the human resources variables-finding willing IAC members (PERSONNEL)--becomes marginally significant $(\mathrm{p} .<.06)$. The fact that our predictors held up well despite shrinkage of cases and change 
of dependent variable functional form speaks positively to the robustness of these findings (Stevens, 1996).

The POC model (Table 5-7) identified EL-INVOLV (POC), LAWRISK (POC), and COST $>$ BENE (POC) as significant regressors which correctly classify $80.9 \%$ of the responses to the dichotomous dependent POC variable. Likewise, the IAC model identified DISCLOSE (IAC), PERSONNEL (IAC), EXPERT (IAC), and COST>BENE (IAC) as significant regressors which correctly classified $87.3 \%$ of the responses to the dichotomous IAC variable. In both models correct identification of the responses to the dependent variables were substantially above what would be expected from mere chance.

The significant regressors in both models are those variables where significant differences exist between those who support and those who oppose the dependent variables. Compared to the macro understanding of the relationship between the perceived consequences and attitudes toward POC and IAC adoption (regression of POC and IAC on factors, Tables 5-3 and 5-4), the significant regressors identified in Tables 57 and 5-8 represent a more variable specific or micro level understanding of the variables which had value in discriminating between those who supported and those who opposed POC and IAC in this study.

The POC model (Table 5-7) identified encouraging the municipality's elected leadership to become more involved with the financial reporting process, which is in agreement with the stated objectives of SOX. Both those who supported and opposed POC did not see POC as reducing the risk of lawsuits, but those who supported POC did believe POC adoption would provide some protection from lawsuits. Although both 
those who supported and opposed POC perceived the cost of implementation would be greater than the benefits, those who supported POC saw this as less of a problem.

Findings from the IAC model (Table 5-8) indicate municipal finance officers who are opposed to IAC do not perceive IAC as encouraging a more positive attitude toward disclosure among the administrative leadership and staff. They also indicated they felt it would be difficult for municipality's to find individuals from their community who would qualify and serve on the IAC as well as a problem in finding an "expert" to serve on the IAC. This finding could reflect the government accountants' assessment of differences between the private and public sector. In addition to the "sunshine laws" applicable to public sector entities, comments received from the respondents ${ }^{28}$ indicated there might be some concern with finding audit committee members who did not have personal or political agendas. They also commented about finding individuals from the community who would have sufficient knowledge of municipal accounting and auditing. Several comments were received about how it would be difficult, especially for smaller towns, to have a sufficient pool of volunteers to draw from. More than $95 \%$ of those who opposed IAC were either neutral or agreed that the cost of implementing IAC would be greater than the benefits received. Coupled with the human resource deficit problem the findings provide some initial insight into why municipal finance officers view implementation of IAC as onerous ${ }^{29}$.

\footnotetext{
28 "Comments received from respondents" refers to comments received on the surveys (Appendix C).

${ }^{29}$ It is worth noting that in the year after this study was conducted the GFOA released new guidance on municipal audit committees which may provide some relief to the cost of implementing and staffing of an audit committee (Gauthier, 2007a).
} 


\section{Elite Post-Survey Interviews}

To further assist in interpreting the findings from the quantitative analysis and to address some issues not directly included in the survey, the author arranged interviews with "elite experts" from the government accounting-auditing field. The respondents included practitioners from Florida (2) and Ohio (3), as well as academics (2), and a representative from the GASB. The interviews consisted of eleven specified open-ended questions plus an opportunity for the respondents to provide any additional comments (see Appendix B).

The first question dealt with the finding that survey respondents believed the "technocracy" (i.e., the city manager and finance director) should be the attesters to the accuracy of the financial statements rather than the elected officials. As noted earlier, this is consistent with the Weberian-Wilsonian politics/administration dichotomy, i.e. the bureaucracy having the expertise needed for meaningful attestation with the elected "dilettante" commissioners having neither the time nor knowledge needed for the task (Bendor, Taylor, \& Van Gaalen, 1985, p. 1041). This view was basically supported by more than half of the interviewees, who often viewed elected officials as similar to a corporate board of directors. As one interviewee stated, "most council members....are largely unaware of their responsibility for faithful representation....they think the statements are the audit firm's." On the other hand, those who viewed mayors as the chief executive officer felt they should also attest to the financial statements.

While there was almost universal support for CFO attestation, some might argue that municipal CEOs, be they city managers or mayors, are not likely to have the requisite accounting-auditing knowledge for meaningful attestation as in the private 
sector. The interviewees were asked if this deficiency provides a rationale for not adopting SOX-like provisions or whether the municipal CEO should be required to have some financial training. The majority of the interviewees endorsed the idea of financial training. Some concern regarding the cost and time to train elected officials was voiced. There was also a suggestion that current state and auditor oversight might be sufficient. Only one interviewee specifically stated that SOX-like requirements should not apply to the public sector.

During the research period there was an interesting issue which occurred at a South Florida city that inspired the following question. If a CFO is suspicious of some financial irregularity involving a superior and the CFO is not protected under "whistle blower" laws or does not have an inspector general to report to; could the IAC be a forum for CFO to discuss the suspicion? The interviewees unanimously supported the idea that the IAC could serve this purpose. However, they did suggest that in lieu of having an IAC there were other alternatives.

There were two major obstacles which were related to the lack of support for adopting an IAC: many believed there would be few individuals from the community who would have the requisite accounting background and knowledge of municipal operations. Others felt the IAC could be politicized as a sort of de facto shadow government. The interviewees were asked if they believed these concerns were legitimate.

The interviewees seemed to be from two separate camps. There were certainly those who believed finding "technically qualified" volunteers might be difficult, especially for smaller cities. Others believed that finding competent volunteers would be 
easier. While some believed the "shadow government" might be extreme, there were also those who believed that an IAC could become a politicized committee. Suggested solutions included having an audit committee composed of elected officials only or stating very clearly the responsibilities of the audit committee. A few of the interviewees reflected a public choice perspective by suggesting the concern with staffing the IAC was simply a smokescreen for those who wanted to avoid accountability and transparency.

In a related question the interviewees were asked whether the low percentage $(29.5 \%)$ of respondents reporting their municipalities had an audit committee indicated an anti-audit bias in municipal government. The interviewees almost unanimously indicated "anti-audit bias" was not the correct characterization. Reasons given for the low percentage included: fear of additional oversight, lack of knowledge about the advantages of an audit committee, and lack of the requirement. One interviewee was encouraged by the fact that almost $30 \%$ of the respondents did have an audit committee.

In the sixth question of the interview the interviewees were asked to help interpret a finding from the survey. The survey revealed that over $90 \%$ of the respondents indicated that financial reporting and disclosures should provide information which helps the average citizen to better understand the role and activities of the government. In addition, $57 \%$ agreed that municipalities owe a greater responsibility to the average citizen to be "publicly accountable" than private enterprises owe to their investors. On the face of it these attitudes are laudable and would seem to be coincident with the intent of the GASB.

The puzzlement is with the interpretation of these findings. It has been recognized that government financial statements are difficult to read and interpret (Chase 
\& Phillips, 2004, p. 27) which suggests the accounting profession has not achieved its goal of providing information which is understandable and useful (FASB Concept Statement 2,1980 ). This problem may in part be the responsibility of the accounting profession, but it has also been recognized that Americans are lacking in financial literacy. Recent statements from the Federal Reserve Chairman, Ben Bernanke (Bernanke, 2006), as well as research from the AICPA (AICPA, 2006), suggest that most Americans are so financially illiterate that they could not understand even the most rudimentary of financial statements - indeed, they have difficulty figuring out if they owe more than they own, or vice versa. Furthermore, research from the GASB itself suggests few individual citizens pay attention to governmental financial statements in the first place (Jones, Scott, Kimbro, \& Ingram, 1985, p. 25).

The interviewees were asked to select from three alternative interpretations:

1. The survey respondents told us "what we wanted to hear" but felt otherwise.

2. The survey respondents believe the average citizen does deserve a clearer financial statement, but overcoming financial literacy is not their responsibility.

3. The survey respondents understand that their primary audience is not the general public, but informing other constituencies such as bond raters in a more transparent, accurate manner will ultimately benefit the average citizen.

In general the interviewees rejected the idea that survey respondents were simply telling us what we wanted to hear or a socially desirable response. The municipal finance officers sincerely believe the average citizen does need to be involved and informed about the financial affairs of their government. It was also recognized the current 
financial reporting model was difficult for the average citizen to understand. As one respondent stated, "the vast majority of citizens and legislators never open a CAFR and wouldn't know what to make of one if they did." Several alternatives to the financial statement as the form of communicating to the average citizen were suggested: the budget document, the Popular Annual Financial Report ${ }^{30}$ (PAFR), and intermediaries such as bond raters, watchdog groups, and the media.

In question seven the interviewees were asked to address a dichotomy found in the survey findings. A sizable majority of the survey respondents agreed that since the implementation of GASB 34, public-sector financial reporting had become more business-like. Yet a similar majority felt this would not benefit the average citizen and that it was a step in the wrong direction. The interviewees were asked how they would interpret these findings and whether they believed this was residue from the conflict with depreciation recognition.

As might be expected, the representative from the GASB was the most defensive of the new reporting model required under GASB $34^{31}$. He felt the criticism of the new reporting model as adopting a business-like model was unfounded and that depreciation recognition was being found as not as difficult as originally assumed by the preparers. Another interviewee thought GASB 34 "was a step in the right direction" and recognition of depreciation was appropriate. Others agreed the new reporting model had at least a similar appearance to the private-sector model. Their main concern was that the new

\footnotetext{
${ }^{30}$ The PAFR is a supplemental report recommended by GFOA, but is not a substitute for the CAFR. The purpose of the PAFR is too provide a more user friendly format for presenting the government's financial activities (see GFOA, 2006).

${ }^{31}$ See also GASB (2006) Why governmental accounting and financial reporting is - and should be different. This white paper defends the GASB reporting model as being different from the private sector model and discusses the recognition of infrastructure assets.
} 
reporting model, with its allowed differences between the basis of accounting on the entity-wide statements versus the fund statements, was very difficult for even those trained in accounting to understand. A finding consistent with the view that the GASB reporting model complicates financial reporting to both the public and elected officials (Frank \& Gianakis, 2008).

In question eight the interviewees were asked if they believed that if financial statements did become more transparent and understandable, would this weaken or strengthen the power of the financial bureaucracy relative to elected officials or other stakeholders such as the media or public. In general the respondents felt that whether the financial bureaucracy was strengthened or weakened was the wrong question. Their basic position was that if financial statements could be more transparent and understandable this would be of benefit to both the municipality and the citizens, e.g., it would provide "a more healthy climate and interaction between the elected and the electors."

In questions nine and ten interviewees were asked their opinions on issues which were not discussed in the survey instrument but nevertheless were related to this research. In question nine, the interviewees were asked their opinion on "who" should impose SOX-like regulations. The interviewees overwhelming thought it should be the responsibility of each state, however there was some recognition the federal government might get involved through the SEC, OMB, or/and GAO.

In question ten, the desire was to get some sense of the interviewees' attitude toward using the internet as a way of disseminating financial and related information to the public. The question to Ohio interviewees, which are required to post their CAFRs 
on a state sponsored website, was directed more to their experiences; for other interviewees the question was one of their perception of possible value.

The Ohio interviewees thought having the CAFRs available on the web was a good idea. But, they also mentioned how easy access to the CAFR did not overcome users' lack of understanding of the financial reports nor did it "kindle the interest of the average citizen in the community's financials". The Florida practitioners felt that posting of the budget document and CAFR could be done at relatively low cost. The nonpractitioners thought the PAFR or something like it would be appropriate. They also suggested that cities could take greater advantage of web technology by linking to budgets, CAFRs, bond documents, and performance measurements.

In question eleven the interviewees were asked what a would-be promulgator of SOX-like standards such as POC and IAC would need to consider prior to implementation. The responses included cost-benefit analysis, specific instructions on how to implement, which municipalities and timing, and an explanation of why the regulations are necessary. One interviewee thought "there would need to be a huge default or scandal - such as with Enron - that would roll these out".

In the final interview question the interviewees were asked to provide any additional comments. Most of the interviewees provided no comment. One interviewee discussed why encouraging municipalities to institute an internal audit program would be beneficial and less costly than starting with an IAC without an internal audit function. The addition of internal audit professionals could create the necessary critical mass for evolving to an IAC without a "top down approach to legislative improvements". Two of the interviewees were specifically asked if providing a PAFR would be useful in 
communicating with their citizens. Both the Florida and Ohio interviewee thought providing a PAFR would be beneficial. As the Ohio interviewee stated, "the PAFR is key to the citizen involvement in municipal finance".

Summarizing the Elite Post-Survey Interviews

The post-survey interviews were administered to knowledgeable individuals from academia, practice, and the GASB. The interviews consisted of open-ended questions regarding POC and IAC implementation issues, views of GASB 34, and other related issues. While the interviewees provided a variety of responses to the interview questions, the individuals interviewed seemed to share a belief in the importance of financial accounting to municipal accountability. Some additional insights gained from the interviews include:

1. Whether the signing CEO is a mayor or city manager, the interviewees endorsed the idea of the CEO obtaining some training to understand accounting and auditing.

2. While there was general recognition of the potential value of an IAC, there was also the recognition of potential problems of obtaining apolitical, qualified members

3. There was general recognition that the CAFR does not serve the informational needs of the average citizen and that communication to the public through instrumentalities like the PAFR may be better. 
4. Although having the CAFR available on the internet was considered a good idea, other reports such as the budget and a PAFR may be more appropriate in reaching the public.

One underlying theme which seemed to drive the interviewees' comments was the suggestion that reliable financial information communication to the public is a subject which merits study not only from accounting professionals, but also from those with a generalist public administration perspective. The inclusion of government accounting and auditing in public administration curricula has been a long-standing contention (Jones, 1991). 


\section{CHAPTER VI \\ DISCUSSION OF THE STUDY \\ AND \\ SUMMARY OF FINDINGS}

At the beginning of the twenty-first century, scandals in the financial reporting practices in the private sector brought about widespread concern about the reliability of financial reporting. The U.S. Congress responded to the crisis in the capital markets by adopting the Sarbanes-Oxley Act of 2002 (SOX). Although SOX was implemented to improve the reliability of financial reporting in the private sector, major components of SOX have filtered through to the public sector. Federal agencies, as well as some nonprofit entities, have come under regulations which reflect "the spirit of SOX" (Hawkins \& Hardwick, 2005). States and local governments have not been subject to SOX-like regulations, nevertheless there is some evidence that SOX-like practices and requirements may be on the horizon which provided impetus to this study. The GFOA's 2006 recommendations regarding the structure and functioning of municipal audit committees reflects the influence of SOX (Gauthier, 2007a) and recent comments by SEC Chairman Cox reflects an interest in having the authority to oversee municipal accounting and auditing (Cox, 2007). Implicit in Chairman Cox's comments is the suggestion that SOX-like regulations might be appropriate for the municipal sector.

The author acknowledges there are many issues which would need resolution prior to municipalities becoming subject to SOX-like regulations, e.g., state sunshine laws and freedom of information acts, who would author and enforce the regulations, etc. Notwithstanding the importance of resolving these important issues this research is designed as an exploratory effort aimed at investigating the willingness of municipal 
finance officers to accept two of the major components of SOX. The two major components of SOX which are the subject of this study are POC and IAC. POC would require the leadership of a municipality to have personal accountability for the "truthfulness" of the published financial statements. The IAC requirement would significantly change the structure and heighten the responsibilities of audit committees. Simply stated these provisions are aimed at clarifying who is accountable for the financial disclosures and adds an additional layer of "independent" oversight of the municipality's accounting processes and procedures.

Both POC and IAC can be characterized as administrative innovations that have the goal of increasing trust in the financial statements. Typically innovation research is concerned with innovations which increase efficiency or effectiveness. A distinguishing feature of this research is neither POC nor IAC are innovations focused on increasing effectiveness or efficiency. Another distinguishing feature of this research is that it focuses on innovation acceptance prior to it being a requirement rather than on innovation adoption post-requirement. This affords the opportunity to provide an "early read" of the perceived benefits, obstacles, and availability of resources for overcoming the obstacles prior to required adoption. This information may assist would-be promulgators of the regulations by providing some guidelines in forming these innovations to fit the municipal sector.

Another distinguishing feature of this research is the focus on the acceptability of two innovations rather than the typical focus upon the acceptability of a single innovation. Comparing the willingness of municipal finance officers to accept two different innovations permitted the examination of whether innovation acceptance is 
innovation specific. The findings of support for POC and opposition to IAC suggest that municipal finance officers assess the acceptability of an innovation based upon the specific attributes of the innovation, which is consistent with innovation adoption theory (Rogers, 2003).

The finding of support for POC and the self-reporting of early implementation of GASB 34 and GASB 44 suggests that specific acts of accepting innovation and external regulations requiring oversight can be found in the bureaucratic municipal environment. These findings are consistent with the substantial literature which reports local governments' adoption of accounting innovations, e.g., balanced scorecard, accrual and entity wide reporting, and performance measurement. At the very least it brings into question the often held view that innovation and bureaucracy are mutually exclusive (Vigoda_Gadot, Shoham, Schwabsky, \& Ruvio, 2005, p. 57; Bingham, 1976, p. 1).

With both the support of POC and opposition to IAC the respondents appeared to consider intangible, non-pecuniary consequences as much or more than tangible benefits. A common theme which seemed to emerge was a human resource dimension deficit in the form of an insufficient supply of individuals financially literate about governmental financial reporting and internal controls. This problem was partially mitigated with the adoption of POC if the principal officers attesting to the reliability of the financial statements were the city manager and municipal finance officer. However, this raises some interesting legal and normative issues about "who" should be held accountable for the relevance and reliability of the municipal financial statements. Municipalities are political entities and the elected officials have political accountability as well as legal responsibility for honest financial reporting. The question in the government sector is 
whether it is reasonable to expect the elected officials to have the requisite knowledge to meaningfully attest to the accuracy of the financial reports?

When the "elite interviewees" were questioned about this issue they tended to believe it was the responsibility of the appointed officials to account for and attest to the expenditures and receipts of the municipality to the elected officials. Their view was that the budget was a policy document which was the responsibility of the elected officials with the financial statements reflecting the execution of the budget and the responsibility of the appointed officials. This view is consistent with the well documented politicsadministration dichotomy, but fails to address the generally held view that financial statements are the political and legal responsibility of the elected officials. Confounding the issue of "who is responsible for what," as one interviewee stated most of the elected officials tend to incorrectly believe the accuracy of the financial statements is the responsibility of the auditor (GASB Representative, Question 1).

To partially mitigate the lack of financial knowledge the interviewees were asked whether the municipal CEO (elected or appointed) should be required to have additional financial training. While the majority of the interviewees endorsed this idea, as noted by the survey respondents, the municipal CEO may be unwilling to become sufficiently knowledgeable about financial reporting and disclosure or appropriate internal control procedures. It appears the municipal financial officers' are acknowledging that they are the ones most knowledgeable about the correctness of the financial statements and should be signatory, but they would like to have additional non-financial personnel take some responsibility for the financial statements. The implication for the financial management component of public administration education is in broadening the studies to include 
coverage of governmental accounting and auditing (see Kattelus, Cheng, \& Engstrom, 2005).

With the opposition to IAC adoption the human resource deficit was expressed by the significant concern with finding apolitical members and "experts" with the required knowledge to meaningfully review the internal controls and act as the liaison with the external auditors. This could be a very realistic view of the difficulty municipalities may face in securing a complement of knowledgeable, apolitical members for an IAC and was echoed by about half of the elite interviewees. The scarcity of individuals with the requisite knowledge of governmental financial reporting, the comparative low or noncompensation for serving, coupled with the potential legal liabilities, and the amount of time required to properly fulfill their responsibilities ${ }^{32}$ could very well be reasons why it may very well be difficult to find IAC members for municipalities. However, it should be noted that a few of the interviewees suggested the concern with staffing the IAC was simply a smokescreen for those who wanted to avoid accountability and transparency. Another concern with the IAC which emerged was the concern that an IAC might be viewed by both elected and appointed officials as having too much control over the selection, retention, and communication with the external auditors. This could be interpreted as a fear of having someone from "outside the government looking inside the government" (interviewee) and/or as simply the loss of some autonomy. As the interviewees commented the finding that only $29.5 \%$ of the respondents reported currently having an audit committee could suggest "municipal governance hasn't really

\footnotetext{
${ }^{32}$ In the private sector independent audit committee members have received higher compensation than regular board members as well as indemnity agreements and liability insurance provided by the corporation (Williams, 2005). In exchange, the audit committee members are putting in a deal more time (Burrowes \& Hendricks, 2005, p. 58).
} 
thought of the value" (interviewee) of an audit committee. This finding suggests that prior to moving to a full blown IAC requirement that municipalities continue to be encouraged to adopt a non-independent audit committee.

On the positive side finance officers did see an enhanced financial reporting image of the community as a benefit with both the adoption of POC and IAC. Support was also found for encouraging both elected and administrative leadership to become more involved in the financial reporting process. These findings are consistent with the objectives of SOX to enhance the reliability of financial disclosures through greater involvement of non-financial personnel. However if pressed to show support for SOXlike mechanisms for "improving the accuracy and reliability of corporate disclosures" (Sarbanes-Oxley, 2003, Preamble), they have some reservations with regard to their cost of implementation.

Survey respondents' indication that the cost of implementation would be greater than the benefits derived was found to be significant with both POC and IAC. While this finding would seem to be consistent with the opposition to IAC, the finding of cost greater than benefit with the support for POC would, on the surface, appear to be inconsistent. One possible explanation for this discrepancy may be that when considering cost versus benefit the respondents were thinking in terms of tangible, pecuniary benefits, rather than total "benefits" and "costs." Another possible explanation is that there is an "automatic" negative response to any unfunded mandate.

That POC or IAC could reduce the risk of lawsuits did not receive support, although with POC supporters it appeared to be less of a problem and was identified as one of the significant regressors in the POC logistic model. A related finding was that a 
majority of the respondents indicated that they believed the signing principal officers would be personally concerned with the potential for criminal penalties. The upshot is that respondents may not view POC or IAC as serving as a prophylactic measure protecting them from criminal penalties or lawsuits. That respondents' supported POC adoption despite their concerns with potential lawsuits or criminal penalties suggests these concerns were not critical to their support for POC. The municipal finance officers may believe they have sufficient protection through sovereign immunity or they may believe that although lawsuits are always possible their probability of being found guilty of a civil or a criminal offense was a manageable risk.

One consequence which received mild support for both POC and IAC was the encouragement of a more positive attitude toward disclosure among the administrative leadership and staff. This was the one favorable consequence which was found significant in the IAC logistic model. Other consequences which received mild support with POC and basically a neutral support when related to IAC were: increasing the importance of the CAFR as an instrument of accountability and contribution to more favorable bond ratings. Neither of these consequences were found significant when POC and IAC were independently regressed upon them. One explanation may be that while these consequences may be important to the municipal finance officers they are not perceived as favorable consequences resulting from POC or IAC adoption.

However, events which occurred subsequent to the administration of the survey document may stimulate interest in using POC and IAC to enhance municipal bond ratings. The bursting of the housing bubble and resulting credit-crunch which began in 2007 and continues into 2008 have negatively affected the U.S. economy, stock market, 
and bond market. Among the multiple consequences has been an impact upon municipal bond financing. Municipal bonds rely upon bond insurance to increase their bond ratings which serves to decrease the interest rate municipalities are required to pay.

In short, if the rating of the insurer is higher than the issuing municipality, the bonds receive the higher rating. Unfortunately, this also works in reverse. The recent rating downgrade of bond insurers (AMBAC and MBIA) because they also insured subprime debt had the consequence of insured municipal bonds having ratings lower than the issuing municipality. In the short-run this has resulted in either re-issuing the bonds with a different insurer or re-issuing the bonds without insurance (Fox, 2008). In the longer run, it is possible that municipalities with less than prime ratings may seek to improve their ratings by adopting SOX-like practices to increase confidence in their financial reporting.

Although the respondents' views toward the GASB 34 reporting model were not found to influence their support for POC or their opposition to IAC, the notion of increasing the importance and usefulness of financial reporting were found with the investigation of the GASB 34 reporting model. Over $90 \%$ of the respondents thought that financial reporting should provide information which helps the average citizen to better understand the role and activities of the municipality. And, $57 \%$ of the respondents felt that they owed a greater responsibility for being accountable to the average citizen than private enterprises owe to their investors. These are laudable views and are consistent with the stated objectives of the GASB to have financial reporting play "a major role in fulfilling government's duty to be publicly accountable in a democratic society" (GASB Concepts Statement 1, 1987, para. 56). 
The respondents also indicated the GASB 34 reporting model was moving municipal financial reporting in the direction of the private sector model; which would be consistent with the goals of the NPM movement. But, they did not believe the municipal financial reporting model should be more like the private sector model, nor did they believe the new model provided information that was more useful to the average citizen for understanding the role and activities of municipalities. In short, while the finance officers agreed with the goals of the GASB 34 reporting model, they did not believe the new reporting model was the solution for reaching the average citizen.

That the GASB 34 reporting model is complex and difficult to read and interpret (Chase \& Phillips, 2004, p.27) was confirmed by several of the interviewees. As one interviewee stated she had "personal experience of a CPA misinterpreting the GASB 34 statements." If CPAs are having difficulty interpreting the new reporting model it would seem to follow that municipal finance officers' would not believe the GASB 34 reporting model is better serving the information needs of the average citizen. Part of this could be related to the general financial illiteracy discussed by Federal Reserve Chairman, Ben Bernanke, as well as the AICPA (Bernanke, 2006; AICPA, 2006). Another reason could be that although municipal financial statements could be of value to average citizen, their primary audience is not the general public. As one interviewee stated, "If they [average citizens] do not understand, they will put trust in those they think does understand. That information could come from bond holders, the media, elected officials, or government auditors."

A less sanguine interpretation would be that if the general public is provided with financial statements that are more transparent and understandable this enhanced 
"information symmetry" may threaten the existing information advantage of the financial bureaucracy. When the interviewees were asked to weigh in on this, their comments indicate that providing transparent and understandable financial information to the general public was of greater value than any loss to the information advantage of the bureaucracy or elected officials. This suggests that municipal finance officers possess a "publicness" mindset which recognizes the value of having an informed citizenry.

\section{Concluding Remarks}

The findings of this research are consistent with the previously stated hypotheses. First, that intentions to favor or oppose adoption of POC and IAC result from the municipal finance officer's evaluation of the associated perceived attributes. Second, general beliefs about the GASB 34 reporting model would not be influential to the formation of the municipal finance officer's intention to accept or oppose POC and IAC. In addition there was no significant measure of association found between the support for POC and opposition to IAC with prior behavior, personal demographics of the respondents, or the organizational demographics of the municipalities. In short, the findings suggest the acceptance of POC or IAC are more associated with behavioral beliefs than with the traditional sociological variables so often used in public administration studies (see Frank, Christian, \& Scutelnicu, forthcoming).

This study is believed to be the first study to examine the willingness of municipalities to accept or oppose POC and IAC. The findings of this study are offered as an "early read" of the willingness of municipal finance officers to accept POC and oppose IAC. It provides some preliminary indication of some perceived benefits and 
obstacles associated with both POC and IAC. The coefficient of correlation $\left(\mathrm{R}^{2}\right)$ found between POC and its associated consequences (.38) and between IAC and its associated consequences (.44) compare favorably to other studies utilizing TPB (Sutton, 1998). Nonetheless there are limitations to the findings of this study.

The primary research instrument of this study was a mailed survey instrument sent to all municipalities in Florida ${ }^{33}$ and Ohio with a population of 10,000 or greater. The responses showed no response bias by state or city size. On the other hand, although the surveys were sent to a great lake state and a southern state which may reflect the views of municipalities in these regions, the findings are limited to municipalities located in Florida and Ohio. Another limitation is that while the response rate of $42.2 \%$ compares favorable to similar research, their remains a concern with non-response bias.

This study only touched the surface of what could be known about the willingness of municipalities to accept administrative innovations. The combination of innovation acceptance with the theory of planned behavior was found to be a useful framework for studying the relationship between willingness to accept an innovation and determinants of that willingness. Use of this framework could be of value in studying innovation acceptance in multiple domains including public administration, public policy, and government accounting policy. Recommendations for future research would include replication of the study in states other than Ohio and Florida. Another approach for future research would be focus on cities of a certain size. For example, in this research although there was no response bias, there were only nine respondents which were from

\footnotetext{
${ }^{33}$ Two municipalities in Florida which would otherwise qualify were eliminated from the targeted population because they contracted out the operation of their finance departments.
} 
cities with populations of 100,000 or greater. Nevertheless, the findings suggested the perceived need for "SOX-like" regulations might be greatest with larger communities. 


\section{REFERENCES}

A price worth paying: America's response to Enron and other scandals was the Sarbanes-Oxley law. It is costing plenty-but is it working? (2005, May 21) The Economist, 375, 71-73.

Ackerman, A. (2007). Outgoing GFOA head slams GASB; Group's "time has come and gone." Bond Buyer, June 12, 2007, 360(32650).

Agresti, A. (1990). Categorical data analysis. New York: Wiley and Sons.

Ajzen, I. (1985). From intentions to actions: A theory of planned behavior. In J. Kuhl and J. Beckman (Eds.), Action-control: From cognition to behavior (pp. 11-39), Berlin: Springer-Verlag.

Ajzen, I. (1988). Attitudes, personality, and behavior. Chicago: Dorsey Press.

Ajzen, I. (1991). The theory of planned behavior. Organizational Behavior and Human Decision Processes, 50, 179-211.

Ajzen, I. (2002). Residual effects of past on later behavior: Habituation and reasoned action perspectives. Personality and Social Psychology Review, 6 (2), 107-122.

Ajzen, I. and Fishbein, M. (1977). Attitude-behavior relations: A theoretical analysis and review of empirical research. Psychological Bulletin, 84 (5), 888-918.

Ajzen, I. and Fishbein, M. (1980). Understanding attitudes and predicting social behavior. Englewood Cliffs, NJ: Prentice Hall.

Allen, T. (1999). News release 6/30/99: GASB releases new standard that will significantly change financial reporting by state and local governments. Norwalk,CT: Governmental Accounting Standards Board.

Allison, G. (1979). Public and private management: Are they fundamentally alike in all unimportant respects? In Shafritz, J. \& Hyde, A. (Eds), Classics of Public Administration: ( $4^{\text {th }}$ ed., pp. 383-400). Fort Worth, TX: Harcourt Brace College Publishers.

American Accounting Association (1972). Report of the committee on concepts of accounting applicable to the public sector, 1970-1971. The Accounting Review, 47 Supplement, 77-108.

American Institute of Certified Public Accountants (2006). What is 360 degrees of financial literacy? Retrieved August 1, 2006, from http://www.aicpa.org/ financialliteracy/what_is_360.asp. 
Anderson, R. (1997). Accountability requirements of development projects. Public Fund Digest, 7(2).

Auditing Standards Committee of the American Accounting Association (2007). Comment on PCOAB rulemaking docket matter no. 21. Sarasota, FL: American Accounting Association. Retrieved March 9, 2007 from http://aaahq.org/audit/ASC/LetterToPCAOB_02_23_07.pdf

Barlas, S. (2007). SEC proposes changes to section 404. Strategic Finance, 88(8), 24.

Beasley, M.S. (1996). An empirical analysis of the relation between the board of director composition and financial statement fraud. The Accounting Review, $71(4), 443-465$.

Beasley, M., Carcello, J., and Hermanson, D. (1999). Fraudulent Financial Reporting: 1987-1997, An analysi of U.S. public companies. Research commissioned by the Committee of Sponsoring Organizations of the Treadway Commission.

Bedard, J., Graham, L., Hoitash, R. and Hoitash, U. (2007). Sarbanes-Oxley section 404 and internal controls. The CPA Journal, 77(10), 34-37.

Bendor, J., Taylor, S. and Van Gaalen, R. (1985). Bureaucratic expertise versus legislative authority: A model of deception and monitoring in budgeting. The American Political Science Review, 79 (4), 1041-1060.

Berman, E.M., \& West, J.P. (1998). Productivity enhancement efforts in public and nonprofit organizations. Productivity in Review, 22(2), 207-219.

Bernanke, B. (2006). Testimony of Chairman Ben S. Bernanke before the committee on banking, housing, and urban affairs of the United States senate, May 23, 2006.

Retrieved from http://www.federalreserve.gov/newsevents/testimony/ bernanke20060523a.htm on November 2, 2006.

Bernier,L. and Hafsi, T. (2007). The changing nature of public entrepreneurship. Public Administration Review, 67 (3), 488-503.

Bingham, R. (1976). The Adoption of Innovation by Local Government. Lexington, MA: D.C. Heath and Company.

Bingham, R. (1978). Innovation, bureaucracy, and public policy: A study of innovation adoption by local government. The Western Political Quarterly, 31(2), 178-205.

Blair, E. and Zinkhan, G. (2006). Nonresponse and generalizability in academic research. Academy of Marketing Science Journal, 34(1), 4-7. 
Brignall, S. and Modell, S. (2000). An institutional perspective on performance measurement and management in the 'new public sector.' Management Accounting Research, 11, 281-306

Boster, R.S. (2007). The public company accounting oversight board: Déjà vu Seidman's quasi government. Public Budgeting \& Finance, 27(3), 130-137.

Boyne, G.A. (2002). Public and private management: What's the difference? Journal of Management Studies, 39(1), 97-122.

Brown, R. (2005). Enron/Anderson: Crisis if U.S. accounting and lessons for government. Public Budgeting \& Finance, 25(3), 20-32.

Burton, J. (1980). Public reporting by governmental units: A revised financial reporting model for municipalities. In D. Solomans (Ed.), Improving the financial discipline of states and cities: Proceedings of the Arthur Young Professors' roundtable 1979. Reston:VA: The Council of Arthur Young Professors, 9-19.

Carnegie, G. and West, B. (2005). Making accounting accountable in the public sector. Critical Perspectives on Accounting, 16, 905-928.

Cavalluzzo, K. and Ittner, C. (2004). Implementing performance measurement innovations: Evidence from government. Accounting, Organizations and Society, $29,243-267$.

Chase, B. and Phillips, R. (2004). GASB 34 and government financial condition: An analytical toolbox. Government Finance Review, 20(2), 26-31.

Chia, Y. and Koh, H. (2007). Organizational culture and the adoption of management accounting practices in the public sector: A Singapore study. Financial Accountability \& Management, 23(2), 189-213.

Christiaens, J. and Rommel, J. (2008). Accrual accounting reforms: Only for businesslike (parts of) governments. Financial Accountability \& Management, 24(1), 59-75.

Committee of Sponsoring Organizations of the Treadway Commission (1994). Internal control - integrated framework. Jersey City, NJ: American Institute of Certified Public Accountants.

Conner, M. and Armitage, C. (1998). Extending the theory of planned behavior: A review and avenues for further research. Journal of Applied Social Psychology, $28(15), 1429-1464$. 
Conway, J.M., \& Huffcutt, A.I. (2003). A review and evaluation of exploratory factor analysis practices in organizational research. Organizational Research Methods, 6(2), 147-168.

Cox, C. (2007). Speech by SEC Chairman: Integrity in the municipal market. Retrieved February 24, 2008, from http://www.sec.gov/news/speech/2007/ spch071807cc.htm.

Creswell, J. (2002). Educational research: Planning, conducting, and evaluating quantitative and qualitative research. Upper Saddle River, NJ: Merrill Prentice Hall.

Cycyota, C. and Harrison, D. (2006). What (not) to expect when surveying executives: A meta-analysis of top manager response rates and techniques over time. Organizational Research Methods, 9(2), 133-160.

Daft, R. (1978). A dual-core model of organizational innovation. Academy of Management Journal, 21 (2), 193-210.

Damanpour, F. (1991). Organizational innovation: A meta-analysis of effects of determinants and moderators. The Academy of Management Journal, 34(3), 555590.

Damanpour, F. and Wischnevsky, D. (2006). Research on innovation in organizations; Distinguishing innovation-generating from innovation-adopting organizations. Journal of Engineering and Technology Management, 23, 269-291.

Davis, F. (1989). Perceived usefulness, perceived ease of use, and user acceptance of information technology. MIS Quarterly, 13(3), 319-340.

Davis, F., Bagozzi, R., and Warshaw, P. (1989). User acceptance of computer technology: A comparison of two theoretical models. Management Science, 35 (8), 982-1003.

Dechow, P.M., Sloan, R.G., \& Sweeney, A.P. (1996). Causes and consequences of earnings manipulation: An analysis of firms subject to enforcement actions by the SEC. Contemporary Accounting Research, 13(1), 1-36.

Del Vecchio, S., Johnson, G., and Magner, N. (2007). GASB 34 implementation: Perspectives of government accounting and finance officials. Academy of Accounting and Financial Studies Journal, 11(Special Issue), 1-11.

Dillman, D. (2007). Mail and internet surveys: The tailored design method. Hoboken, NJ: Wiley. 
Downs, G. and Mohr, L. (1976). Conceptual issues in the study of innovation. Administrative Science Quarterly, 21(4), 700-714.

Durst, S. and Newell, C. (1999). Better, faster, stronger: Government reinvention in the 1990s. The American Review of Public Administration, 29(1), 61-76.

Duquette, D. (2005). Putting SOX on Federal agencies. The Journal of Government Financial Management, 54(1), 58-61.

Elliot, M., Armitage, C., and Baughan, C. (2003). Drivers' compliance with speed limits: An application of the theory of planned behavior. Journal of Applied Psychology, $88(5), 964-972$.

Fabrigar, L.R., Wegener, D.T., MacCallum, R.C., \& Strahan, E.J. (1999). Evaluating the use of exploratory factor analysis in psychological research. Psychological Methods, 4(3), 272-299.

Farber, D.B. (2005). Restoring trust after fraud: Does corporate governance matter? The Accounting Review, 80(2), 539-561.

Fard, H.D. and Anvary Rostamy, A.A. (2007). Promoting public trust in public organizations: Explaining the role of public accountability. Public Organization Review, 7(4), 331-344.

Feldman, A. (2005). Surviving Sarbanes-Oxley. Inc.com. retrieved September, 2005, from http://www.inc.com/magazine/20050901/surviving-so.html.

Financial Accounting Standards Board (1980). Statement of financial accounting concepts no. 2: Qualitative characteristics of accounting information. Norwalk, CT: Financial Accounting Standards Board.

Fishbein, M. and Ajzen, I. (1975). Belief, attitude, intention, and behavior: An introduction to theory and research. Reading, MA: Addison-Wesley Publication Company.

Foltin, C. (2008). Unrest in government accounting. The CPA Journal, 78(3), 26-31.

Fowler, F. (1998). Survey research methods ( $2^{\text {nd }}$ ed.) Newbury Park, CA: Sage Publications, Inc.

Fowler, F. (1992). How unclear terms affect survey data. Public Opinion Quarterly, $56(2), 218-231$. 
Fox, Z. (2008). Shake-up brewing in municipal bonds. North County Times, April 15, 2008, Escondido,CA. Retrieved July 12, 2008 from http://infotrac.galegroup. com.ezproxy.fiu.edu/itw/infomark/97/469/35329170w16/purl=rc1_GBFM_0_CJ1 $77890360 \&$ dyn $=23$ !xrn_204_0_CJ177890360?sw_aep=flstuniv

Frank, H., Christian, P. and Scutelnicu, G. (forthcoming). Generating the public financial management knowledge base: Analyzing method and directions as a subdiscipline of public administration. Journal of Public Budgeting, Accounting \& Financial Management, forthcoming.

Frank, H. and Gianakis, G. (2008). What hath GASB wrought? The new reporting model's perceived utility to finance Officers - A national perspective from the trenches. A paper presented at the Southeastern Conference of Public Administration, September 24-27, Orlando, Florida.

Frank, H., Gianakis, G. and McCue, C. (2005). Will GASB 34 induce changes in local government forecasting practice? A preliminary investigation. Journal of Public Budgeting, Accounting \& Financial Management, 17(4), 557-573.

Gaffney, S. (2007). GFOA rebuffs SEC bid to oversee accounting standards and mandate disclosures for issuers of municipal debt. Government Finance Review, 23(5), 7577.

Gauthier, S. (2007a). A new vision for public sector audit committees. Government Finance Review, 23(2),10-16.

Gauthier, S. (2007b). Interpreting local government financial statements. Government Finance Review, 23 (3), 8-14.

Geiger, D. and Ittner, C. (1996). The influence of funding source and legislative requirements on government cost accounting systems. Accounting, Organizations and Society, 21 (6), 549-567.

George, N. (2005). The role of audit committees in the public sector. The CPA Journal, $75(8), 42-43$.

Gianakis, G. and McCue, C. (1997). Administrative innovation among Ohio local government finance officers. American Review of Public Administration, 27(3), 270-286.

Gibson, K.M., Pany, K., \& Smith, S.H. (1998). Do we understand each other? Journal of Accountancy, 185(1), 53. 
Government Accountability Office (2006). Government auditing standards, 2006 revisions, exposure draft. Washington, DC: U.S. Government Printing Office (document GAO-06-729G). Retrieved January 4, 2008 from http://www.gao.gov/new.items/so6729.pdf.

Government Finance Officers Association (2006). Recommended Practice for Audit Committees. Retrieved July 6, 2008, from http://www.gfoa.org/ downloads/caafrAudit_Committee_revised.pdf.

Government Finance Officers Association (2007). The GFOA wants to reassess the GASB's role. Retrieved December 18, 2007, from http://www.gfoa.org/ omdex.php?option $=\mathrm{cpm} \_$content\&task $=$view\&id $=559$.

Governmental Accounting Standards Board (1987). Governmental Accounting Standards Board concepts statement no. 1: Objectives of financial reporting. Norwalk,CT: Governmental Accounting Standards Board.

Governmental Accounting Standards Board (1999). Statement No. 34 of the Governmental Accounting Standards Board: Basic financial statements-and management's discussion and analysis-for state and local governments. Norwalk, CT: Governmental Accounting Standards Board.

Governmental Accounting Standards Board (2006a). Why governmental accounting and financial reporting is - and should be-different. Retrieved April 17, 2006, from http://www.gasb.org/white_paper_full.pdf.

Governmental Accounting Standards Board (2006b). Why governmental accounting and financial reporting is - and should be - different. Retrieved April 17, 2006, from http://www.gasb.org/white paper_full.pdf.

Greer, T., Chuchinprakarn, N., and Seshadri, S. (2000). Likelihood of participating in mail survey research: Buisiness respondents' perspectives. Industrial Marketing Management, 29, 97-109.

Grumet, L. (2007). Rethinking Sarbanes-Oxley: Taking stock of its pluses and Minuses. The CPA Journal, 77(11), 7.

Guadagnoli, E., \& Velicer, W.F. (1988). Relation of sample size to the stability of component patterns. Psychological Bulletin, 103(2), 265-275.

Harlow, L. (2005). The essence of multivariate thinking: Basic themes and methods. London: Lawrence Erlbaum Associates.

Hawkins, K. and Hardwick, K. (2005), Revised OMB circular A-123: Sox for federal agencies. The Journal of Government Financial Management, 54(3), 54-63. 
Henson, R.K., \& Roberts, J.K. (2006). Use of exploratory factor analysis in published research: Common errors and some comment on improved practice. Educational and Psychological Measurement, 66(3), 393-416.

Higganbotham, S. (2001). New Jersey office pushes for municipalities to adopt GAAP. Bond Buyer, January 31, 2001, 335(31067).

Hintze, J. (1997). User's guide - II: NCSS 97 statistical system for windows. Kaysville, UT: Number Cruncher Statistical Systems.

Hirsch, W. (1970). The economics of state and local government. New York: McGraw-Hill Book Company.

Holt, G. (2006). SOX: "best practices" or too much accountability. The Bottom Line: Managing Library Finances, 19(3), 139-145.

Hussain, I. (2003). Auditing expectations gap: A possible solution. Journal of American Academy of Business, 3(1/2), 67.

Icerman, R. and Sinason, D. (1996). Government accountability to the public: The dynamics of accountability in the U.S. Public Fund Digest, 7(1), 65-81.

Ijiri, Y. (2005). US accounting standards and their environment: A dualistic study of their 75-years of transition. Journal of Accounting and Public Policy, 24, 255279.

Jackson, A. and Lapsley, I. (2003). The diffusion of accounting practices in the new "managerial" public sector. The International Journal of Public Sector Management, 16 (5), 359-372.

Johnson, G. and Langsam, S. (1991). Historical sources and current status of GAAP for state and local governments. The Governments Accountants Journal, 40(2), 5464.

Jones, D.B., R.B. Scott, L. Kimbro, and R.Ingram (1985). Research Report: The needs of users of governmental financial reports. Stamford, CT: Governmental Accounting Standards Board.

Jones, L.R. (1991). Public financial management curriculum and course design: A response to the National Task Force Report. Public Budgeting and Financial Management, 3(1), 171-190.

Kamal, M. (2006). IT innovation adoption in the government sector: Identifying the critical success factors. Journal of Enterprise Information Management, 19 (2), 192-222. 
Karan, R. (2003). Selective commercialization of public-sector accounting and its consequences for public accountability. Australian Accounting Review, 13(3), 1525.

Kaske, M. (2007). N.J.'s OPEB liability totals $\$ 68.7 \mathrm{~B}$ including $\$ 10.7 \mathrm{~B}$ at the local level. Bond Buyer, July 27, 2007, 361(40).

Kattelus, S.C., Cheng, R.H., \& Engstrom, J.H. (2005). The challenges of crossdisciplinary work: Accounting and financial reporting for governments and nonprofits. Journal of Public Budgeting, Accounting \& Financial Management $17(2), 152-165$.

Keating, E. and Berman, E. (2007). Unfunded public employee heath care benefits and GASB No. 45. Accounting Horizons, 21(3), 245-263.

Kim, S. (2005). The role of trust in the modern administrative state: An integrative model. Administration \& Society, 37(5), 611-635.

Kimberly, J. and Evanisko, M. (1981). Organizational innovation: The influence of individual, organizational, and contextual factors on hospital adoption of technological and administrative innovations. Academy of Management Journal, 24(4), 689-713.

Kloot, L. and Martin, J. (2007). Public sector change, organizational culture and financial information: A study of local government. The Australian Journal of Public Administration, 66(4), 485-497.

Kravchuk, R. and Voorhees, W. (2001). The new governmental financial reporting model under GASB statement no. 34: An emphasis on accountability. Public Budgeting \& Finance, Fall 2001, 1-30.

Lapsley, I. and Pallot, J. (2000). Accounting, management and organizational change: A comparative study of local government. Management Accounting Research, 11, 213-229.

Larkin, D. (2007). The acronyms go at it in the great Texas OPEB debate. Bond Buyer, April 9, 2007, 360(32605).

Larson, P. (2005). A note on mail surveys and response rates in logistics research. Journal of Business Logistics, 26(2), 211-222.

Levinsohn, A. (2005). First-year verdict of SOX 404: Burdensome, costly, and confusing. Strategic Finance, 86, 67-68.

MacCallum, R.C., Widaman, K.F., Zhang, S., \& Hong, S. (1999). Sample size in factor analysis. Psychological Bulletin, 4(1), 84-99. 
Malmi, T. (1999). Activity-based costing diffusion across organizations: An exploratory empirical analysis of Finnish firms. Accounting, Organizations and Society, 24, 649-672.

Mansfield, E. (1961). Technical change and the rate of imitation. Econometrica, 29(4), 741-766.

Maraun, M. (1996). Metaphor taken as myth: Indeterminacy in the factor analysis model. Multivariate Behavioral Research, 31(4), 517-538.

McCue, C., Gianakis, J. and Frank, H. (2007). GASB statement 34 and the managerial accounting nexus. Journal of Public Budgeting, Accounting \& Financial Management, 19(2), 153-177.

McEnroe, J.E., \& Martens, S.C. (2001). Auditors' and investors' perceptions of the "expectation gap". Accounting Horizons, 15(4), 345-358.

Miller, G. and Moe, T. (1983). Bureaucrats, legislators, and the size of government. The American Political Science Review, 77 (2), 297-322.

Mohr, L. (1969). Determinants of innovation in organizations. The American Political Science Review, 63(1), 111-126.

Montondon, L. and Lilley, T. (2005). How readable are those financial reports? The Journal of Government Financial Management, 54(1), 52-56.

Moon, M. (1999). The pursuit of managerial entrepreneurship: Does organization matter? Public Administration Review, 59(1), 31-43.

Mulligan, L. (2007). What's good for the goose is not good for the gander: SarbanesOxley-style nonprofit reforms. Michigan Law Review, 105(8), 1981-2009.

Mulgan, R. (2000). 'Accountability': An ever-expanding concept? Public Administration, 78(3), 555-573.

Neuman, W. L. (1997). Social research methods: Qualitative and quantitative approaches $\left(3^{\text {rd }}\right.$ Ed.). Boston: Allyn and Bacon

Neuman, W.L. (2006). Social research methods: Qualitative and quantitative approaches $\left(6^{\text {th }}\right.$ ed.) Boston: Pearson - Allyn and Bacon

Niskanen, W. (1971). Bureaucracy and representative government. Chicago: Aldine-Atherton.

OMB Circular A-123 (2004). Management's Responsibility for Internal Control. 
Ouellette, J. and Wood, W. (1998). Habit and intention in everyday life: The multiple processes by which past behavior predicts future behavior. Psychological Bulletin, 124 (1), 54-74.

Page, S. (2006). The web of managerial accountability: The impact of reinventing government. Administration \& Society, 38(2), 166-197.

Pallot, J. (1999). Beyond NPM: Developing strategic capacity. Financial Accountability \& Management. 15(3), 419-426.

Parles, L., O'Sullivan, S., and Shannon, J. (2007). Sarbanes-Oxley: An overview of current issues and concerns. Review of Business, 27(3), 38-46,

PCAOB Auditing Standard 2 (2004). Auditing standard no. 2: An audit of internal control over financial reporting performed in conjunction with an audit of financial statements. Washington, DC: Public Company Accounting Oversight Board.

Posner, P. (2006). Accountability institutions and the policy process: The United States experiences. OECD Journal on Budgeting, 5(3), 71-96.

Raghunandan, K. and Rama, D. (2006). SOX section 404 material weakness disclosures and audit fees. Auditing: A Journal of Practice \& Theory, 25(1), 99-114.

Rezaee, Z. and Crumbly, L. (2007). The role of forensic auditing techniques in restoring public trust and investor confidence in financial information. Forensic Examiner, $16(1), 44-49$.

Rogers, E. M. (1983). Diffusion of innovations ( $3^{\text {rd }}$ ed.). New York: The Free Press.

Rogers, E. M. (1995). Diffusion of innovations ( $4^{\text {th }} e d$. .). New York: The Free Press.

Rogers, E. M. (2003). Diffusion of innovations $\left(5^{\text {th }}\right.$ ed.). New York: The Free Press.

Rubin, I. (2000). The politics of public budgeting: Getting and spending, borrowing and balancing ( $4^{\text {th }}$ edition). New York: Chatham House Publishers.

Ruscio, K. (1996). Trust, democracy, and public management: A theoretical argument. Journal of Public Administration Research and Theory, 6(3), 461-477.

Sarbanes-Oxley Act (2002). Pub. L. No. 107-204, 116 Stat. 745.

Sayre, W. (1958). Premises of public administration: Past and emerging. Public Administration Review, 18 (2), 102-105. 
Securities and Exchange Commission (2007). Disclosure and accounting practices in the municipal securities market. Retrieved February 27, 2008, from http://www.sec.gov/news/press/2007/2007-148wp.pdf

Smith, P. and Richmond, K. (2007). Call for greater accountability within the U.S nonprofit sector. Academy of Accounting and Financial Studies Journal, 11(2), 75-87.

Smith, P. (1996). Measuring outcome in the public sector. London: Taylor \& Francis

Staats, E. (1996). New dimensions of accountability in government. Public Fund Digest, $7(1), 1-7$.

Stevens, J. (1996). Applied multivariate statistics for the social sciences $\left(3^{\text {rd }}\right.$ ed.). Mahwah, NJ: Lawrence Erlbaum Associates.

Stiglitz, J. (1988). Economics of the public sector (2 ${ }^{\text {nd }}$ ed.). New York: W.W. Norton \& Company.

Sutton, S. (1998). Predicting and explaining intentions and behavior: How well are we doing? Journal of Applied Social Psychology, 28 (15), 1317-1338.

The Laws That Govern the Securities Industry. Retrieved November 3, 2005, from http://www.sec.gov/about/laws.shtml.

To, M. and Ngai, E. (2007). The role of managerial attitudes in the adoption of technological innovations: An application to B2C E-commerce. International Journal of Enterprise Information Systems, 3(2), 23-33.

Touche Ross (1977). Issues and viewpoints: Public financial reporting by local governments. New York: Touche Ross \& Co.

Vinnari, E. and Nasi, S. (2008). Creative accrual accounting in the public sector: 'Milking' water utilities to balance municipal budgets and accounts. Financial Accountability \& Management, 24(2), 97-116.

Venkatesh, V., Morris, M, Davis, G. and Davis, F. (2007). User acceptance of information technology: Toward a unified view. MIS Quarterly, 27(3), 425-478.

Vermeer, T., Raghunandan K., and Forgione, D. (2006). The composition of nonprofit audit committees. Accounting Horizons, 20(1), 75-90. 
Vigoda-Gadot, E., Shoham, A., Schwabsky, N., and Ruvio, A. (2005). Public sector innovation for the managerial and the post-managerial era: Promises and realities in a globalizing public administration. International Public Management Journal, $8(1), 57-81$.

Walker, D. (2004). GAO answers the question: What's in a name? Roll Call, July 19, 2004. Retrieved June 27, 2008 from http://www.gao.gov/about/namechange.html

Walker, D. (2005). Reclaiming public trust in the wake of recent corporate accountability failures. International Journal of Disclosure and Governance, 2(3), 264-271.

Walker, R. (2006). Innovation type and diffusion: An empirical analysis of local government. Public Administration, 84(2), 311-335.

Wang, X. and Wan Wart, M. (2007). When public perception leads to trust: An empirical assessment of managers' perceptions. Public Administration Review, 67(2), 265278.

Watson, D. (1997). Innovative governments: Creative approaches to local problems. Westport, CT: Praeger Publishers.

Weidman, S. (2002). A behavioral model of decision to accrue and disclose environmental liabilities. Dissertations Abstracts International, 63 (03), p. 1031. (UMI No. 3046038).

Williams, S. (2005). Meet the experts. Accounting Horizons, 19(4), 255-265.

Zwick, W.R., Velicer, W.F. (1986). Comparison of five rules for determining the number of components to retain. Psychological Bulletin, 99(3), 432-442. 
Appendix A - Cover Letters and Survey Instrument 


\section{Cover Letter - First Mailing}

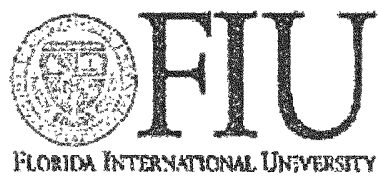

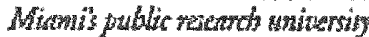

Arange

Thle

June 27,2005

Deprement

chy of

Shool Addres:

City State Zip Code

Dear Mr M. Last Name,

As I am sure you are aware, the Sartanes-Oxley Act of 2002 (SOX) was a Congressional response to the reporing and disclosure abuses which hed to the collapse of Eoron, WordCom, Arthur Anderson, and other conporations. Although the target of this legislation was publely traded commercial coutcrorses, some have argued that it is only ander of tine wnil requircmonts which are the swae as or sinilar to SOX should be applied to mulicipal findncial reporing and diselosure. This survey is intended to gamer your opinion on implementation of such requirements in the local sector.

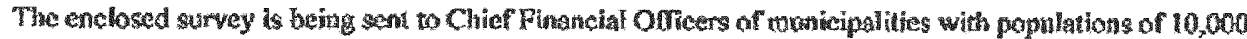
or greater in Florida and Ohio. Completion of the survey should take no more that in mimutes. There are wo comcel or incomed answers and, of courge, your respenses lo this survey will be strictly conidential, with only aggregated rindings crer being rejorted.

The results of this survey will be used in both scholarly and applied settugs. If you wish to be opprised ditectly of the survey results, or have any questions regarding the instrument, please contact me at 954 5920487 or druk0100ru.cdu.

Please respond to this survey by 3 uly 15,2005 . Simply return the survey in the enclosed, self-gadressed,

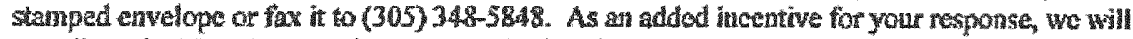
contribute \$1.00 to the American Cancer Sociely Lor avery response.

Thank you in advance for your lime and assistance in this study. Your participation is greatly appreciated.

Sincerely,

Douglas R. Finge

MD. Candidate

Worida Intertatonal University

<KF now Cods?

सrachars
Howard rank, Ph. D.

Associate Professor of Public Administration

Florida luemational Unimersily

Enail: Howandfofu,edu 


\section{Cover Letter - Second Mailing}

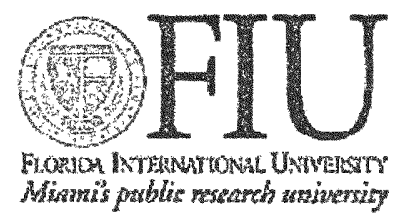

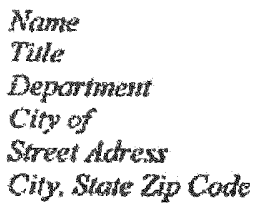

July 25,2005

SECOND REOUEST

Dear Mr MMs Last Nowne.

Several weeks ago we sent you n survey regrading the possible imptementation of disclosure requirements in local governments that prould be comparablo to the Sarbancs Oxley Act of 2002(SOX). Profosior Trank and I realize that you are a busy professional and may hawe forgoten to complete the fnotrument. We have received mearly 100 rasponscs to date and hope to add yout opmion to the tally.

As I an sure you are aware, the Sarbanss-Oxley Act of 2002 (SOX) was a Congressional response to the teporting and disclosum abuses which led lo the collanse of Enron, WorldCon, Arthur Andersun, and

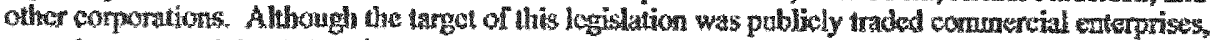
some have argued that is inly a mattor of time until requitements which ane the same or gimilar to SOX should be applied to municipal foxancial reporting and dischosurc.

The enclosed strwey is being sent to Chief Financial Officers of municipalities with populations of 10,000 or grater in Florida and Ohio. Completion of the servey should tak no more thon 10 minutes. There are no comecl on incorreat atswers and, of course, your respouses to this survey will be strictly confidential, with only aggregated findings ever being reported.

"The resuls of this survey will be used in both scholarly and applied settings. If you wish do be appriscd

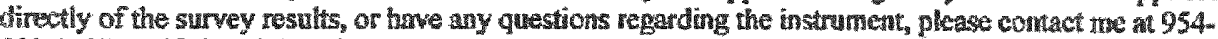
592-9487 or difnkolatededa.

Please respond to this survey by Augcst 15,2005 . Simply rehurn the survey the the enclosed, self addressed stamped envelope or fax it ta (305) 348-5848. As an added incentive for your response, we will contribute 1.00 to the American Cancer Socicty Por every rosponck.

Thank you in advance for your time and assistance in this study. Your participation is greatly aptrexesed

Sincerely,

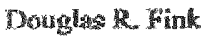

MD. Cundidate

Florida Internationol University

STP Plase codes
Foward Frouk, Dh.D.

Asscciate Professor of Public Administration

clorida Internationat Uniwersity

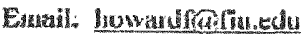

Exalomes

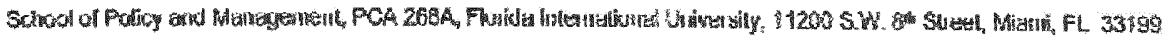




\section{Survey - Page 1}

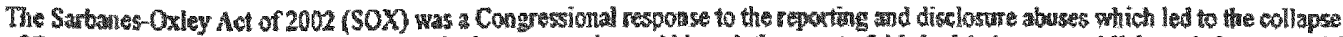

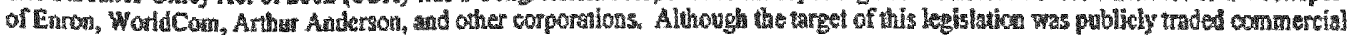

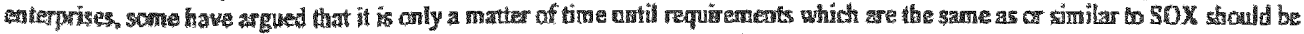
applied to municipal financial raporting and disclosure. Below is one of the majw reguirenents of SOX.

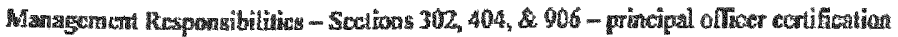

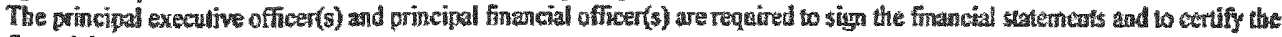

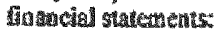

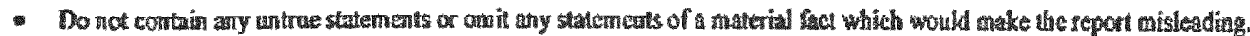

- Do fairy present in all material respects the financial condition and revults of conerations of the isset.

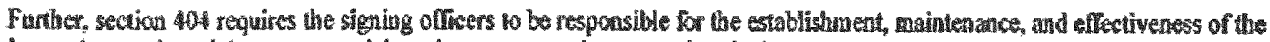

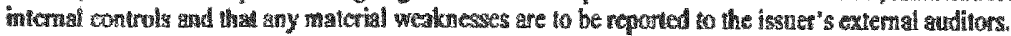

Finally, fallure to couply with these requirenente can sabject the signimg of

QUESTIONS - Sextion:

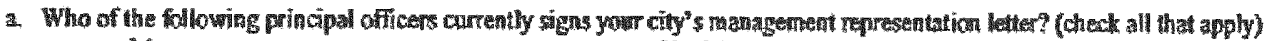

- Mays

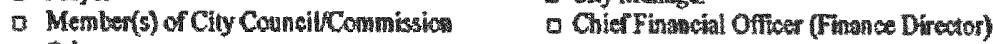

o Oher:

b. If your city was regeired to, or whantwity adopted, primipal officer(s) certifications simnar $6 \mathrm{SOX}$, who of the following do you believe should sign the CArR asd

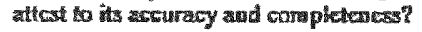

1. Mayor.

2. Mernews of City Council/Commisston

3. City Marager.

4. Chich Funcial Ofreor (F thance Dirceter)

c. In gexeral, I be iveve primcipal officur(s) certifications similar to SOX should be required of the princignt officen(s) of municipadtices.

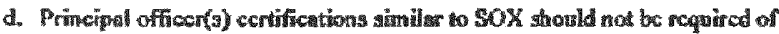
municipalitues, but should be considered as est practices" of good gowtrunce.

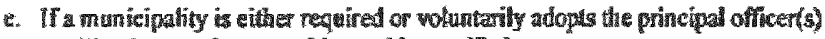

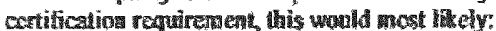

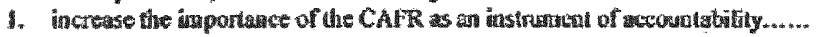

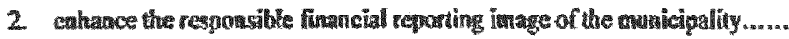

3. wrour the finarial reporting rocess.

4. cucourage the municipality"s adthinituative leadership to bexne mote inYolved in the francial reporting process.

5. refuce the risk af lawshits.

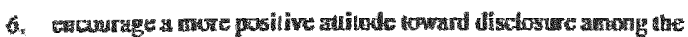
municinally's"s adminisaraive leadership ard saff.

\begin{tabular}{|c|c|c|c|c|}
\hline $\begin{array}{l}\text { Sornengly } \\
\text { Avo: }\end{array}$ & Arres & Nesatcal & Disuever & $\begin{array}{l}\text { Sitrangly } \\
\text { Dissorion }\end{array}$ \\
\hline SA & $\mathbb{A}$ & $W$ & D & SD \\
\hline SA & A & 鉸 & D & SD \\
\hline $\mathrm{A}$ & A & 噒 & $n$ & Swit \\
\hline $\mathrm{SA}$ & A & 霑 & D & SD \\
\hline SA & A & $N$ & D & 50 \\
\hline$S A$ & A & W & b & 50 \\
\hline $\mathbf{S A}$ & A & $\frac{1}{4}$ & $D$ & $\$ 10$ \\
\hline SA & A. & $v$ & D & 30 \\
\hline $\mathrm{SA}$ & A & T & $D$ & $\$$ \\
\hline 5 & A & X & $D$ & SD \\
\hline $\mathbf{S A}$ & A & N & D & 51) \\
\hline$S A$ & A & $n$ & $D$ & $\mathrm{SD}$ \\
\hline$S$ & A & $\mathbb{N}$ & D & $\mathrm{SD}$ \\
\hline
\end{tabular}

7. contribute to onore fawrable bond ratinge. 


\section{Survey - Page 2}

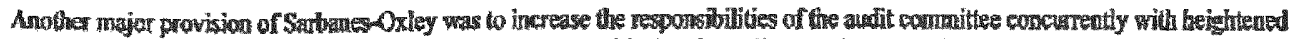

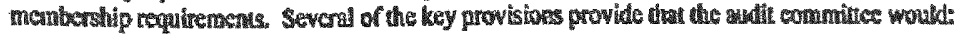

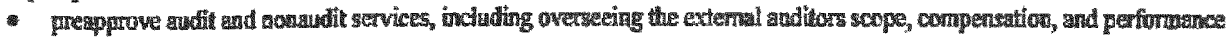
of the extertal sulditurs

be wolely responsible for the hiring and fing of the extamal anditors

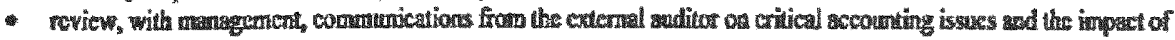
alternative GAAP trewnent

- resolve any diffenences betweet mangenent and the extemal autitors

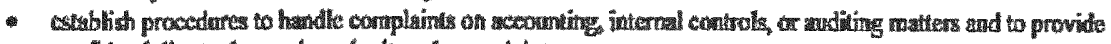

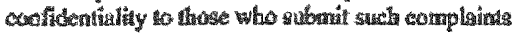

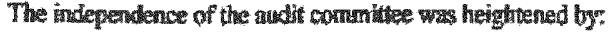

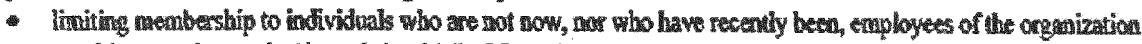

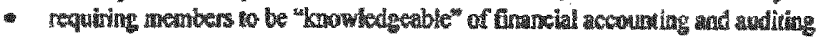

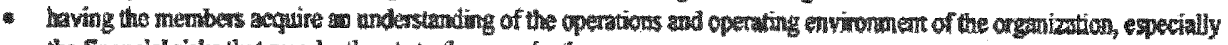
the financial risks that may be threats to the wranization

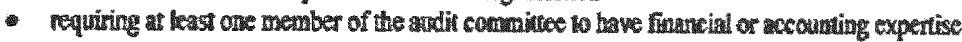

QUESTONS

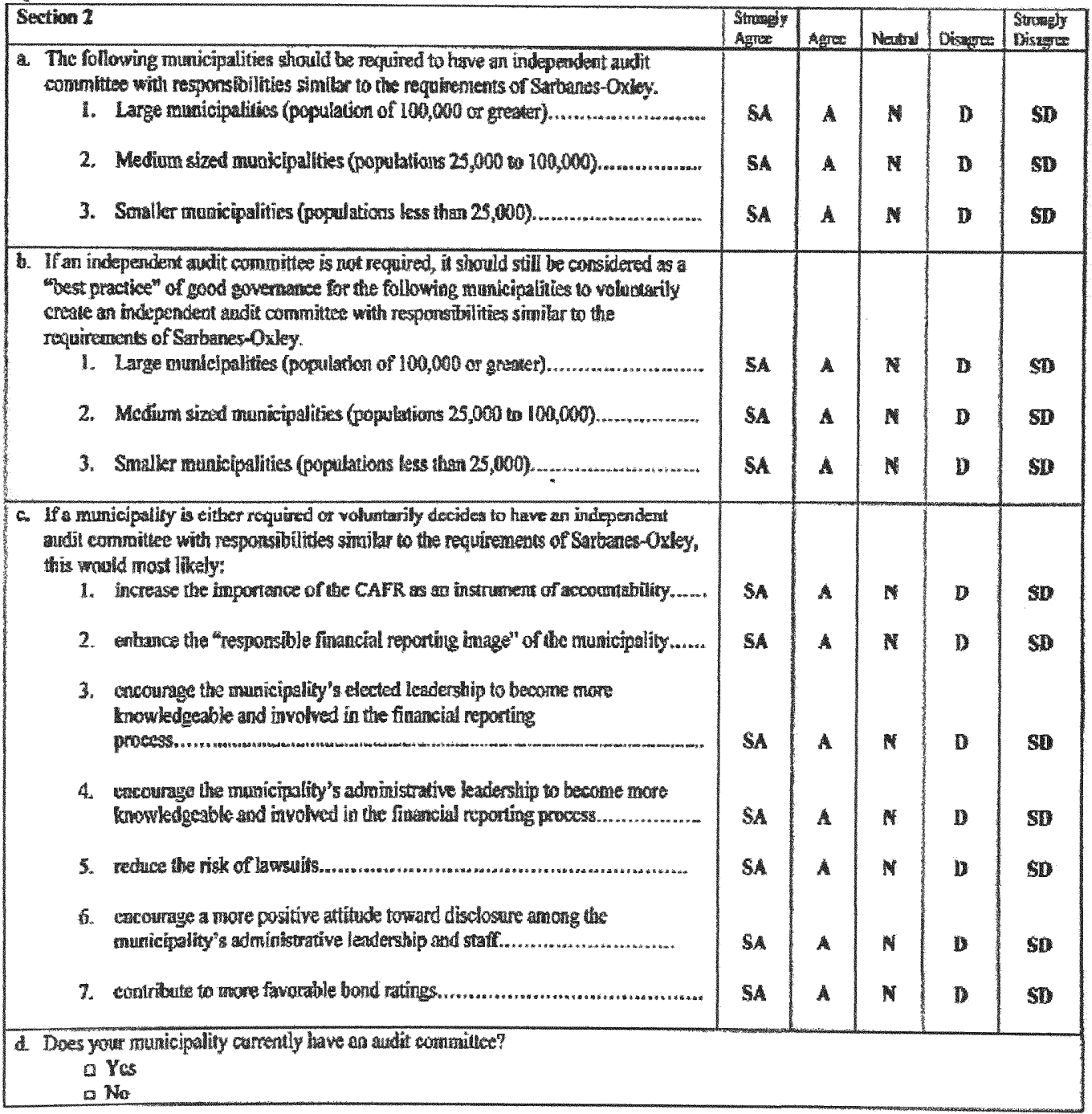




$$
\text { Survey - Page } 3
$$

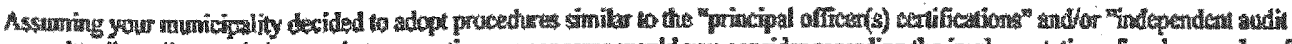

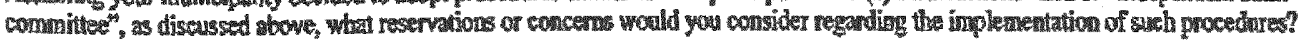

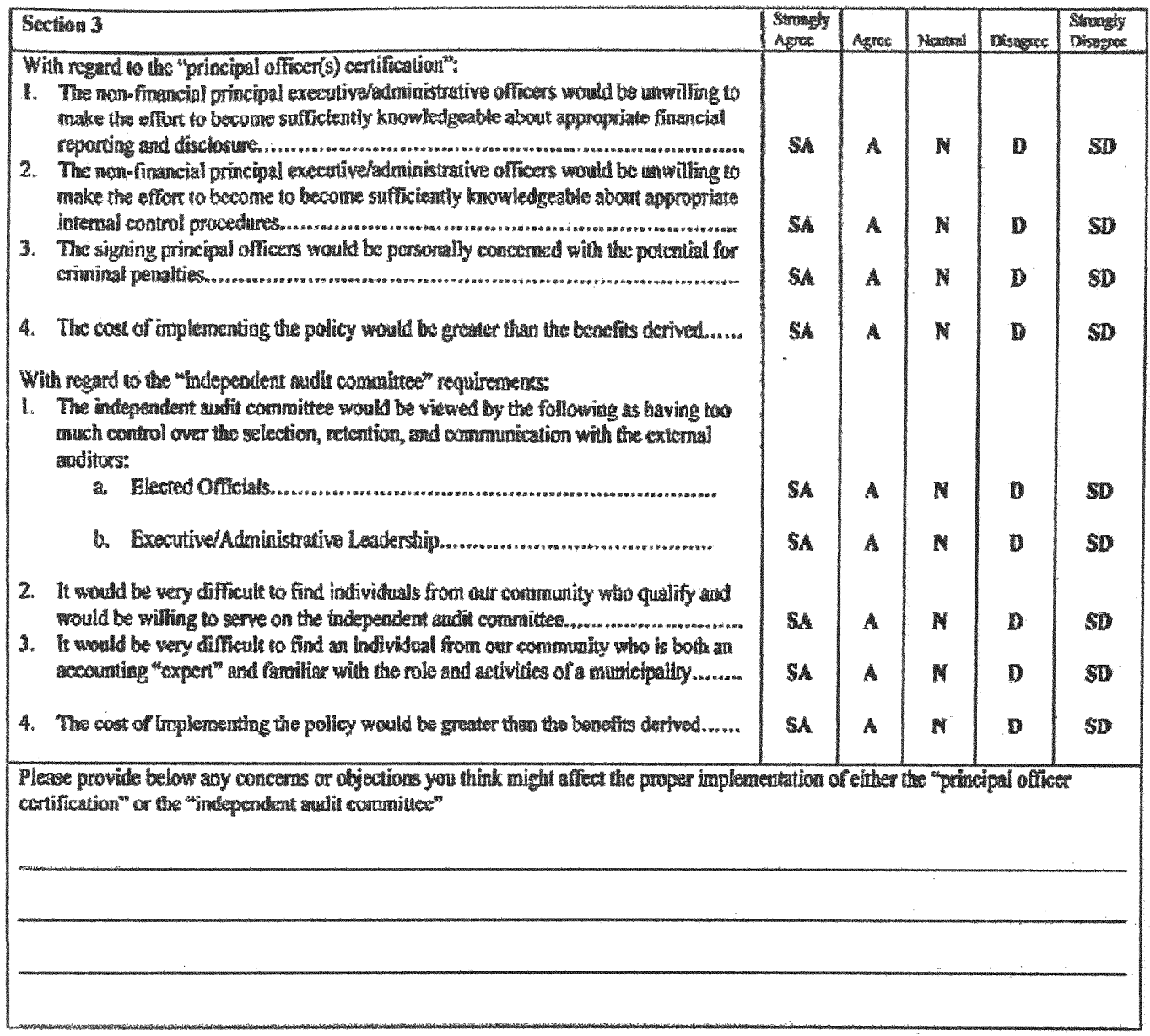

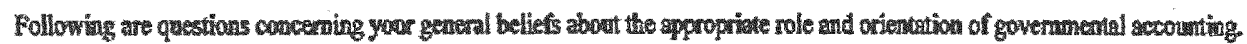

\begin{tabular}{|c|c|c|c|c|c|}
\hline serion 6 & 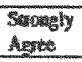 & A A 말릉 & Ncombsil & Dissyger & $\begin{array}{l}\text { Strongly } \\
\text { Disuryos }\end{array}$ \\
\hline 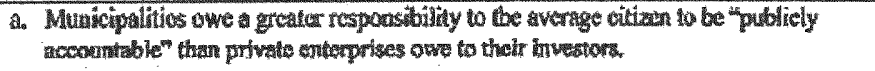 & $\$$ & A & $N$ & 0 & SD \\
\hline 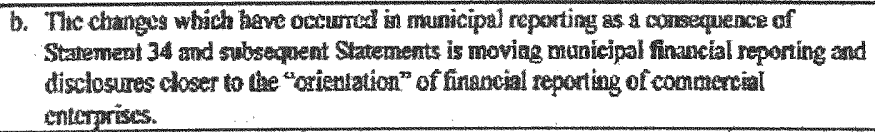 & SA & $A$ & $\mathbb{N}$ & D & S0 \\
\hline 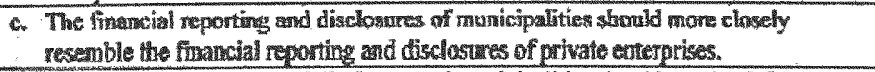 & $\$$ & $A$ & $N$ & 1) & SD \\
\hline 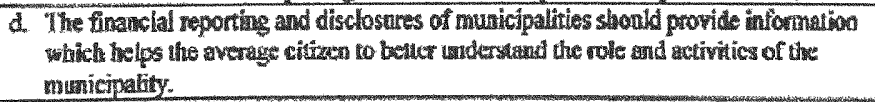 & 8 & A. & $\mathrm{N}$ & $p$ & $\$ 0$ \\
\hline 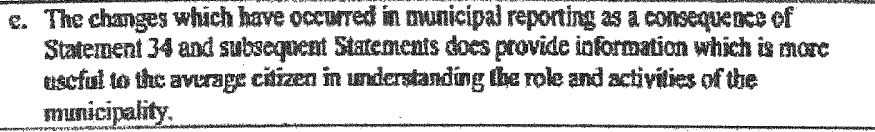 & $S A$ & $A$ & N & $D$ & SO \\
\hline
\end{tabular}




$$
\text { Survey - Page } 4
$$

Section 5. The followng section a forre, and your Inamcetoudget dapartment.

1. In your cily, who would he considered the chlet

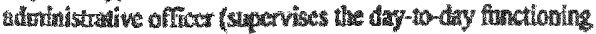
of the ciny adnothistationy?

$$
\begin{aligned}
& \text { - Ciry Mands } \\
& - \text { Mayos }
\end{aligned}
$$$$
\text { Other: }
$$

2. Is the Chis rinancial Ofices of your cly:

$$
\begin{aligned}
& \text { - Appointed by the City Manager } \\
& \text { - Atpoontred by the city ConcilMayor } \\
& \text { c Elected by the Cirizens }
\end{aligned}
$$

3. In any cify, the Chef Finandial orficer dircety rowats w:

$$
\begin{aligned}
& \text { a The Citizens (when elseted) } \\
& \text { - The city CouncinMayor } \\
& \checkmark \text { The City Manxager } \\
& \text { - An Assistant City Manger } \\
& \text { - Other: }
\end{aligned}
$$

4. Number of years yon baven ton enployed an accounting budgeting cajecity by:

your carrent cint? years

other munichal govemnets? Yyars

Federal or State agencies? years

public sccoumting firn(s) yours

grivate industry and aher? yests:

5. Your gonda:

$$
\text { o Female }
$$$$
\text { a Male }
$$

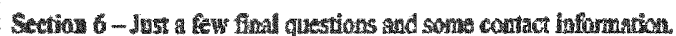

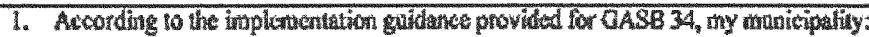

a wa an early mplementes of CASB 34

- inplenented GASB 34 in the year precribed

a was a late inothenter of GASB 34

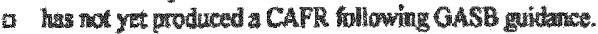

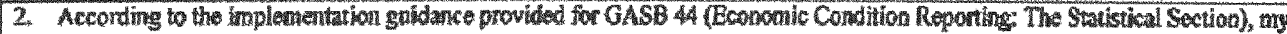

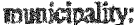

v has arraty uxylemented $\mathrm{CASB} 44$

a will be inchlersenting CASS 4 as guided

o has not made 1 decision os the date of implententing GASB 44

3. 1 I have any questions about your respones to his swrvey, I cas contact you follows:

Name* Tilkt

Street, City, State:

Comall Addrese:
6. Vour ouge in years

$\begin{array}{ll}\text { c Les than } 25 & 04655 \\ \text { - } 26-35 & 956-65 \\ \text { D } 3645 & \text { 0 ONe } 65\end{array}$

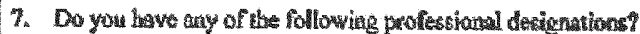
(check will which apply)

- CPA a CMA DOher:

8. Are you a anternber of any of the Thinwing? (check all whith apply)
d State Sority OFCPAS
Arenican fisstibute of $\mathrm{CPAs}$

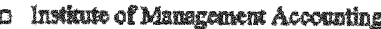
a Coventatu Finane OAficers Associalion
- American Sociely of Puble Aduinistation
a Other

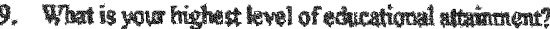
a Huth Shool
- Maste Degre
- Associatus Dogres
S Dochorate Degres
c) Bactolon Degren
a Law Degres

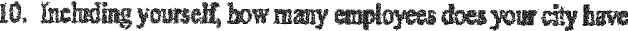
perfomming general Intancial accounting/badgeting fanctions?

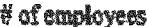

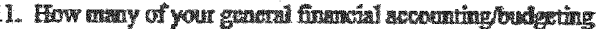
persounel se either CPAs or CMAAs?

If of coployed

Fins 
Appendix B - Elite Interviews 


\section{Example of Interview Request}

Dear Dr. <Last Name >,

Last year I mailed a survey to municipal finance officers in Ohio and Florida (populations greater than 10,000) regarding their attitude about whether two of the major provisions of Sarbanes-Oxley should be adopted by municipalities. I am happy to report the survey had a $42.2 \%$ response rate and I have been able to obtain some valuable insight. (Attached is a very brief summary which includes some demographic information you may find interesting.)

I am in the process of writing up the results from the survey and, as I am sure you can imagine, many times there are alternative interpretations. I have been able to interview practitioners, but I would like to have the prospective from leading researchers like you. Interviewing you is especially important to me because I am personally aware of your distinguished contribution to the municipal accounting profession. In addition, my Major Professor, Dr. Howard Frank, suggested I contact you.

If you agree to be interviewed, I have developed a process that hopefully will make it very convenient for you. All you need to do is go to the following link: http://chua2.fiu.edu/SocialWork/doug6/login.asp

When you arrive at the login you will be asked for:

Login: <interviewer's email address>

Password: Please enter a password of your choosing.

Only you and I will have access to your responses. Your responses will be held in the strictest confidence and will never be disclosed as your responses.

You can access the web survey multiple times (using your login and password) which allows you to complete the survey as your time permits. When you have completed the survey, please send me an email so I know. After I know you have completed the survey I will then email you to confirm and if necessary arrange a time to call to discuss your responses.

Please advise whether you would agree to be interviewed. I hope you will.

Thanks,

Douglas R. Fink

954-592-0487

cc: Dr. Howard Frank, Major Professor 


\section{Executive Summary}

\section{General Statement about the Survey}

The survey was administered during the summer of 2005 . It was sent to the chief financial officer of those municipalities in Florida and Ohio with a population of 10,000 or greater. The survey had a response rate of $42.2 \%$ and there was no evidence of response bias by state or community size.

The survey was principally concerned with the receptivity of Sarbanes-Oxley like requirements in the municipal sector. The inquiry focused on two areas of SarbanesOxley: Principal Officer(s) Certification and Independent Audit Committee. Because municipal accounting has been so dramatically changed by GASB 34 , the survey also inquired about the Orientation of Municipal Accounting.

\section{General Conclusions Regarding Principal Officer(s) Certification (POC)}

The respondents indicated support for required POC adoption. The principal officers designated were either both the chief financial officer and the city manager or with the "strong mayor" form of government it was the chief financial officer and mayor. In taking a broad view of the responses, it appears that with POC the intangible benefits outweighed the lack of tangible benefits and recognized implementation obstacles.

\section{General Conclusions Regarding Independent Audit Committee (IAC)}

The respondents indicated opposition to required IAC adoption. This was confirmed by the respondents expecting less intangible benefits than POC, lack of tangible benefits, and the recognition of some very real implementation issues.

\section{General Conclusions Regarding the Orientation of Municipal Accounting}

A clear majority of the respondents perceive an obligation on their part to maximize disclosure to their residents and to help the average citizen understand municipal functions and roles. Similarly, most respondents view GASB as the onset of a more private-sector like reporting model in government. But over $2 / 3^{\text {rds }}$ of our respondents are neutral or opposed to the adoption of the private-entity reporting model, and only $1 / 3^{\text {rd }}$ view adoption of the GASB 34 reporting model as benefiting the average citizen's knowledge of municipal operations.

\section{Demographics of Respondents You may find Interesting}

Percentage of respondents who indicated they have a signed "management representation letter?" $-96.2 \%$

Percentage of respondents who indicated they have an audit committee. $-29.5 \%$ 
Who is considered as the chief administrative officer of the city?

- City Manager - $61 \%$

- Mayor $-31 \%$

- Other $-8 \%$

Who appoints or elects your city's chief financial officer?

- Appointed by city manager $-48 \%$

- Appointed by City Council/Mayor - 34\%

- Elected-18\%

Who does the chief financial officer directly report to?

- The citizens (when elected) - $18 \%$

- The city council/mayor $-27 \%$

- City manager $-48 \%$

- Assistant city manager $-3 \%$

- Other $-4 \%$

Percentage of chief financial officers who are CPAs? - 50\% (Only 1 respondent was both a CPA and CMA. This was the only CMA.)

Percentage of respondents with a masters degree or higher. $-35 \%$

The survey results were obtained in the summer of 2005. At that time, with regard to implementing GASB 34, the respondents indicated the following:

\begin{tabular}{|l|l|}
\hline My municipality was an early implementer of GASB 34 & $29.6 \%$ \\
\hline My municipality implemented GASB 34 in the year prescribed & $65.9 \%$ \\
\hline My municipality was a late implementer of GASB 34 & $3.0 \%$ \\
\hline My municipality has not yet produced a CAFR following GASB guidance & $1.5 \%$ \\
\hline
\end{tabular}

Again, during the summer of 2005, the respondents indicated their implementation of GASB 44 (Economic Condition Reporting: The Statistical Section) as follows:

\begin{tabular}{|l|l|}
\hline My municipality has already implemented GASB 44 & $17 \%$ \\
\hline My municipality will be implementing GASB as guided & $51 \%$ \\
\hline My municipality has not made a decision on the date of implementing GASB 44 & $33 \%$ \\
\hline
\end{tabular}




\section{Questions for Interviews}

Number 1

Most of our respondents believed the "technocracy," (i.e., the city manager and finance director/CFO) should be attesters to financial statements. At the same time, most felt the mayor and/or council should not. From the perspective of familiarity with accounting technology and internal control, this is understandable. However, from a normative standpoint, does it seem fitting that those who appropriate funds should not also be the same as those who attest to the truthfulness of the municipal financial statements?

Number 2

The average mayor or city manager may not have the accounting-auditing expertise of their private sector counterparts such as CEO or COO. Some might argue that this differential provides rationale for not adopting SOX-like provisions. Other might say that the public sector could emulate the private and remediate these deficiencies through training. Which alternative do you prefer and why?

Number 3

A municipal CFO may perceive him or herself as independent. But the reality of municipal hierarchy means they are subordinate to any of several actors in the system. If the $\mathrm{CFO}$ were to be suspicious that some irregularity involving a superior might need to be addressed, to whom might they turn? In answering this question, you should probably assume that only a handful of large municipalities would have an inspector general or similar office, and many CFO's may not be covered by laws that protect "whistle blowers." Could an independent audit committee serve this function?

\section{Number 4}

Many of our respondent expressed deep reservations about implementation of IAC. Their opposition was twofold: many believed that there would be few available to serve who had the requisite accounting background and knowledge of municipal operations. Others felt it could become politicized as a sort of de facto shadow government. Do you believe these concerns are legitimate? If so, why?

\section{Number 5}

Only $29.5 \%$ of our respondents indicated their respective cities had audit committees? Do you feel this indicates an anti-audit bias in municipal governance? 


\section{Number 6}

Over $90 \%$ of our respondents felt it was critically important for financial statements to help citizens better understand their governments. And, $57 \%$ agreed that municipalities owe a greater responsibility to the average citizen to be "publicly accountable" than private enterprises owe to their investors.

On the face of it, these attitudes are laudable. But recent statements from our Federal Reserve Chairman, Ben Bernanke, as well as research from the AICPA, suggest that most Americans are so financially illiterate that they could not understand even the most rudimentary of financial statements-indeed, they have difficulty figuring out if they owe more than they own, or vice versa. Furthermore, research from the GASB itself suggests few citizens pay attention to government financial statements in the first place.

With that said, one could explain our findings in any of three ways:

a) Our respondents told us "what they think we wanted to hear" but felt otherwise;

b) Our respondents believe that the average citizen does deserve a clearer financial statement, but overcoming citizen financial illiteracy is not their responsibility.

c) Our respondents understand that their primary audience is not the general public, but informing other constituencies such as bond raters in a more transparent, accurate manner will ultimately benefit the average citizen.

Which of these interpretations makes the most sense to you and why?

\section{Number 7}

One of the great contradictions of our finding is as follows. A sizable majority of our respondents agreed that since the implementation GASB 34, public sector financial reporting is becoming more private sector-like. Yet a similar majority felt this would not benefit the average citizen and that it was a step in the wrong direction?

How do you interpret this dichotomy? Do you feel this is in part residue over the conflict regarding asset depreciation and its recording?

\section{Number 8}

If the financial statements become more transparent and understandable to the public, do you think this would weaken or strengthen the power of the financial bureaucracy relative to elected officials or other stakeholders such as the media or public?

\section{Number 9}

Assuming SOX-like provisions were adopted in local governments, "who" should impose them? It would seem the choice is either the individual states or a federal agency such as the Government Accountability Office (GAO). Please comment. 


\section{Number 10 FLORIDA}

The advent of the internet makes the widespread dissemination of a government annual financial report to all citizens who request it quite simple and inexpensive. If local governments were required to undertake this, what would be the "shape and form" of this document? Would it be comprised primarily of financials, per a CAFR? Would it combine financials with SEA's (the direction taken by federal agencies)? Would it be required to show comparisons relative to peers or national standards?

\section{Number 10 OHIO}

The advent of the internet makes the widespread dissemination of a government annual financial report to all citizens who request it quite simple and inexpensive. In this regard, Ohio is one of the leading states in requiring that CAFRs be available at one central location. Do you think this has been of value? For example, does it seem that your citizens are using this website to obtain a copy of your CAFR? Has it lowered your cost of printing CAFRs for public dissemination? On the other hand, has having the CAFR so readily available created some unintended consequences?

\section{Number 11}

Based on your knowledge and experience in the field, what do you think a would-be promulgator of SOX-like standards such as POC and IAC would need to consider prior to implementation, and why?

Number 12

Please provide any additional comments. 


\section{Question 1}

Most of our respondents believed the "technocracy," (i.e., the city manager and finance director/CFO) should be attesters to financial statements. At the same time, most felt the mayor and/or council should not. From the perspective of familiarity with accounting technology and internal control, this is understandable. However, from a normative standpoint, does it seem fitting that those who appropriate funds should not also be the same as those who attest to the truthfulness of the municipal financial statements?

\section{Practitioner - Large City, Florida}

It is my view that the City Manager and CFO should attest to the truthfulness of the financial statements. It is the Council's (legislative of governing body) responsibility to set policy and approve the budget and the executive to implement, carry out, and report back. Just as Florida has a Chief Financial Officer that prepares the State Financial Statements, I would not expect the Legislature or Speaker or President to attest to the accuracy of the financial statements. There are not in a position to know or have direct knowledge about the expenditure of public funds at the time expenditure occurs.

In this case, it is the Council that appropriates and provides the authority to spend and it is the executive that is to spend and account. It is a principal (council) agent (CFO and Manager) relationship. The only thing the legislative body can or should attest to is the approved spending plan - that is their responsibility.

\section{Practitioner - Medium City, Ohio}

Yes. Mayors should also attest financial statements. In our city, the mayor is the chief executive officer and has extensive knowledge in municipal finance (and is a CPA). He would not like it if he were excluded because academics and city managers, etc. see mayors as unfit for this duty.

\section{Practitioner - Medium City, Ohio}

The Council should be held in the same light as a Board of Directors in the private sector. Since they are not management, the financial statements should be presented to them not attested by them.

\section{Practitioner - Very Small City, Ohio}

In the current post-Enron era it may seem appropriate to have the persons ultimately responsible for the safeguarding of tax dollars to have a stake in the responsibility associated with presenting the financial statements truthfully. However, it is overkill to a certain extent and impractical for the most part. Unless the Mayor/City Manager are actively involved in the operations of the finance department (we know that the Council is not) it would be unfair to ask them to attest to the correctness of the statements. 


\section{Academic}

Following the model from the corporate environment, the management must attest to the financial statements. This includes several board of director positions.

\section{Practitioner - Large City, Florida}

I believe the chief executive should be responsible for attesting to the financial statements accuracy. In the case of a strong Mayor form of government - this is the Mayor. (This is case with the City of XXXXX) In reality - the elected official is going to sign the attest statement with a firm reliance on the finance officials advise and consent.

\section{GASB Representative}

In my opinion, when one says that the financial report is the representation of management, that means the elected officials who are ultimately responsible for the government and accountable to the citizens. The CFO or city manager work for the elected officials, be they council members or a mayor. Of course, most council members do not realize this. They do not realize that they financial statements are theirs; instead, they think the statements are the audit firm's. They are largely unaware of their responsibility for faithful representation.

\section{Academic}

I believe that the city's CEO (e.g., mayor) should also certify the financial statements. 


\section{Question 2}

The average mayor or city manager may not have the accounting-auditing expertise of their private sector counterparts such as $\mathrm{CEO}$ or COO. Some might argue that this differential provides rationale for not adopting SOX-like provisions. Other might say that the public sector could emulate the private and remediate these deficiencies through training. Which alternative do you prefer and why?

\section{Practitioner - Large City, Florida}

I prefer the latter. The Manager is responsible for organization internal controls and for establishing the correct and proper control environment. It is the Manager's responsibility to hire the right person to be the CFO. In most governments, the Council has no authority to direct employees or evaluate employees reporting to the City Manager. Therefore, it follows that the only person the Council can evaluate is the City Manager. The buck stops with the City Manager. If the Manager does not know about the financial affairs of the government, he/she has a responsibility to obtain training, make sure the external auditors are extremely qualified and familiar with government accounting and auditing, and/or hire a qualified internal auditor.

The Manager should not be able to defer any financial reporting deficiency to the CFO. It is the Manager's job to manage and to assemble a team that understands financial accounting and internal control. Internal control is management's responsibility, not only the CFO.

\section{Practitioner - Medium City, Ohio}

I prefer to see much more training for mayors in the financial arena. Perhaps they can get a certification that would including fiscal and other training.

\section{Practitioner - Medium City, Ohio}

There are more differences in the private/public comparison greater than the mayor or city manager not having accounting-auditing experience (which is also true). There is no reason to enhance financial statements to appear more profitable or any profit motive. In Ohio, the State has oversight responsibilities for audits supplemented by county duties to oversee appropriations.

Where there are portions of SOX such as audit committees that may enhance the public sector process, in general the public sector should not adopt SOX.

\section{Practitioner - Very Small City, Ohio}

How about the part-time Mayor of a small city that has a full-time Finance Department which is run by a CPA and the Mayor is say, a butcher by trade and all he wants to do is selfless public service for his residents? Would his signature, if required, have any 
meaning and would it make sense to hold him accountable for something beyond his field of expertise? The same would apply to Township Trustees who are newly elected and have no real background in Government Finance except the knowledge that taxes make the township go round.

Again, it is understandable to have some accountability by imposing and enforcing policies such as establishment of Audit Committees and possibly even expanding the scope of the annual audit contract to concentrate on various areas of the government which may be prone to fraud.

\section{Academic}

I support the strategy of remedying the deficiencies through training. It is important that the mayor or city manager and elected board members be accountable for the financial status of the community they represent. If they are not as knowledgeable as they should be, we will not be able to advance increased accounting-auditing assurances.

\section{Practitioner - Large City, Florida}

I think a hybrid approach is necessary. The chief executive of the government should be better informed regarding control issues and risks, but not necessarily to the point of advanced understanding and knowledge. If the chief executive is elected, the time needed to fully train them in these areas will be very limited. The finance professional should be the best informed and the chief executive should rely on this individual to have the requisite financial accounting experience. In addition, the independent auditor's role is vital.

\section{GASB Representative}

The chief executive of a government does not have to be an accountant in order to understand the implications of accounting and financial reporting. By the same token, they don't have to be social workers in order to understand their social services, or a former police officer to understand public safety. They higher people with the proper credentials and experience. Yet, it is still incumbent upon the chief executive, as the person ultimately responsible for the government and accountable to the citizenry, to be generally knowledgeable and aware. Some elected officials, executive and legislative both, are shockingly ill-informed about accounting. In summary, they don't have to be CPAs, but they should have a basic layperson's knowledge that allows them to oversee what is being done and take ultimately responsibility for it. 


\section{Question 03}

A municipal CFO may perceive him or herself as independent. But the reality of municipal hierarchy means they are subordinate to any of several actors in the system. If the CFO were to be suspicious that some irregularity involving a superior might need to be addressed, to whom might they turn? In answering this question, you should probably assume that only a handful of large municipalities would have an inspector general or similar office, and many CFO's may not be covered by laws that protect "whistle blowers." Could an independent audit committee serve this function?

\section{Practitioner - Large City, Florida}

I would have two suggestions. First, an independent audit committee would be a good place to discuss the issue. The audit committee could provide suggestions, ask questions, and provide direction. However, they have no enforcement or criminal investigative authority. The audit committee would be a good sounding board for direction. The second suggestion would be the City Attorney (legal council), and third, the government's external auditors. If this appears to be a criminal act, the person would be wise to speak to the State Attorney in the judicial circuit. The person would also be wise to speak to their own personal attorney first.

\section{Practitioner - Medium City, Ohio}

It could, but another elected official such as President of Council, etc. could also serve in that role.

\section{Practitioner-Medium City, Ohio}

Yes an audit committee could serve this purpose. However, good government and current auditors should insist on adopting a whistle blower policy

\section{Practitioner - Very Small City, Ohio}

An independent audit committee would definitely serve this purpose if used in accordance with its full potential and also as long as it stays 'independent'. If, for example, the audit committee is appointed by the Mayor because of his personal relationship with the members appointed it may or may not achieve the purpose depending on how close the relationship is. On the other hand, if the audit committee in keeping with their responsibility could be held liable for malfeasance, misfeasance or maybe even gross misconduct maybe the relationships would not hamper the efficient functioning.

The CFO probably would have other options in addition to involving the Audit Committee. These would include, approaching the State Auditor or perhaps the County Prosecutor anonymously, if need be. 


\section{Academic}

The CFO could turn to the elected officials and/or outside legal counsel, but this may be difficult because of the vested interest and relationships. An independent audit committee might be very useful to avoid such conflicts in these situations.

\section{Practitioner - Large City, Florida}

Absolutely. The independent audit committee is the perfect solution to this case. I would also argue that there should be an independent audit function in any good size municipality as the cost of this area is well covered by the savings in audit findings and possible decrease in extensive external audit testing.

\section{GASB Representative}

As I understand the function of an independent audit committee, that is not really their function. However, it might be a possible avenue for the CFO, if it can be done discreetly and privately. Alternative, there is typically someone at the state level with oversight responsibility for local governments. That person or office might be the appropriate venue for raising potential irregularities.

\section{Academic}

I favor an audit committee for this purpose. 


\section{Question 04}

Many of our respondent expressed deep reservations about implementation of IAC. Their opposition was twofold: many believed that there would be few available to serve who had the requisite accounting background and knowledge of municipal operations. Others felt it could become politicized as a sort of de facto shadow government. Do you believe these concerns are legitimate? If so, why?

\section{Practitioner - Large City, Florida}

The comments have no validity at all. An audit committee is an excellent idea. I have worked with one for seven years and cannot imagine not having an audit committee. It provides credibility, provides oversight over the auditor, is involved in the selection of the external auditor, and accepts the CAFR. It promotes accountability. Those that are not in favor of an independent audit committee are not secure in themselves and appear they do not want to be held accountable.

\section{Practitioner-Medium City, Ohio}

Yes, I would be concerned - it may undermine the process - I think there is an alternative - an audit committe of the legislative body plus the ability to hire "experts" to help if they did not have knowledge themselves.

\section{Practitioner - Medium City, Ohio}

Yes, unfortunately this is true.

Our government created an IAC. Instead of creating it to enhance the independent oversight it became a political issue. The politicians didn't understand how it was to be used and solicited people to serve who wanted to do things such as review compensation of employees and critique economic development tools etc. Instead of asking for participants with some auditing/accounting knowledge it was stated publicly that "anyone with any background or training" could serve.

\section{Practitioner - Very Small City, Ohio}

To a certain extent they are legitimate. In a highly political environment it is feasible that the IAC could be used as a baton by either side, the current office holders or the potential ones. I do not however believe that it would be hard to find a couple of members in the community who would be willing and able to serve. Municipal operations is an acquired knowledge and can be taught without too many pitfalls. The IAC may not have the exact accounting background but is that a real requirement? The majority of the functions that include understanding and maybe providing input on internal policies and procedures and acting as a liason between the external auditors and the management could be accomplished. Governments have watch dogs and considering almost everything is 
public record it would be advisable to establish an IAC and a good way to dissuade the formation of a de facto shadow government.

\section{Academic}

Yes, I believe the concerns are legitimate. Both concerns could be addressed with a very clear charge to the independent audit committee. This would need to be followed up with continuing discussions about the purpose and charge for such a committee.

\section{Practitioner - Large City, Florida}

The "shadow government" argument is quite extreme, in my opinion. My experience with audit committees in government is that the individuals on the committees recognize their role as advisors and not substitutes for the elected officials. Some understanding of the extent of their role is needed as most professionals tend to advise more and not less. When an internal audit function is present, some accountability should align with the auditor with advise received from the audit committee.

Regarding the lack of expertise, this is indeed a problem and would be more of a problem in smaller governments. This can be counter-acted by allowing both residents and business professionals who have offices in the municipality. Also, university professors may be available.

\section{GASB Representative}

I can see why they would feel that way. There is an general resistance to transparency and accountability, such that any reform, including an IAC, would be viewed suspiciously. But IACs do not usually have any "powers." They can shed light on an issue, but don't have the authority to implement changes, at least as far as I understand them. Regarding the issue of finding qualified people to serve, I disagree. I believe it is easier than they think.

\section{Academic}

In most cities I would think that there are local CPAs, bankers, educators, and others who could serve on such a committee. I do not see this as a shadow government. 


\section{Question 05}

Only $29.5 \%$ of our respondents indicated their respective cities had audit committees? Do you feel this indicates an anti-audit bias in municipal governance?

\section{Practitioner - Large City, Florida}

It demonstrates an anti-accountability bias. It demonstrates they do not want to have someone from outside the government looking inside the government. A qualified audit committee can be a positive influence over the organizations system of internal control. It could be seen as a threat if the City internal auditor reports to the City Manager. The Manager may not feel comfortable with knowledgeable parties being that close to government.

\section{Practitioner - Medium City, Ohio}

No. It has just not been commonly used.

\section{Practitioner - Medium City, Ohio}

NO, I think it shows that municipal governance hasn't really thought of the value and that oversight needs are being met in other ways.

\section{Practitioner - Very Small City, Ohio}

No one wants to be audited. Especially Finance Directors! We know what we are doing. Right? Wrong! There are communities that dread the annual audits only because they have skated along for another year and have not acted on any of the citations or recommendations made by auditors in the previous year. So maybe there is some truth to the anti-audit bias but only from the ones that did not comply. On the other hand it is the most effective tool in proving their performance. So other than the fact that auditors do take up a lot of time and efforts, I believe most city officials accept it as a necessary tool to prove the efficacy of their policies and processes. I believe that the low percentage of communities that have audit committees indicates that since it is a recommendation and not a requirement it is another layer of meetings and bureaucracy that can be avoided.

\section{Academic}

No, I believe it suggests that the finance committee and/or the full board takes on this role

\section{Practitioner - Large City, Florida}

Not at all. I think it indicates a need for more information about the benefits of an internal audit function and an audit committee getting in front of elected officials. 


\section{GASB Representative}

No. I just think that in a lot of governments, little attention is paid to the audit. It's just something they have to do, usually because the state says so. I would not be surprised to learn that many city officials don't know what one is or what its potential benefits are. They are becoming better known, though. It would be interesting to know what that number would have been 10 years ago.

\section{Academic}

Given there is not a requirement, I thought nearly $30 \%$ was encouraging. 


\section{Question 06}

Over $90 \%$ of our respondents felt it was critically important for financial statements to help citizens better understand their governments. And, 57\% agreed that municipalities owe a greater responsibility to the average citizen to be "publicly accountable" than private enterprises owe to their investors.

On the face of it, these attitudes are laudable. But recent statements from our Federal Reserve Chairman, Ben Bernanke, as well as research from the AICPA, suggest that most Americans are so financially illiterate that they could not understand even the most rudimentary of financial statements - indeed, they have difficulty figuring out if they owe more than they own, or vice versa. Furthermore, research from the GASB itself suggests few citizens pay attention to government financial statements in the first place.

With that said, one could explain our findings in any of three ways:

d) Our respondents told us "what they think we wanted to hear" but felt otherwise;

e) Our respondents believe that the average citizen does deserve a clearer financial statement, but overcoming citizen financial illiteracy is not their responsibility.

f) Our respondents understand that their primary audience is not the general public, but informing other constituencies such as bond raters in a more transparent, accurate manner will ultimately benefit the average citizen.

Which of these interpretations makes the most sense to you and why?

\section{Practitioner - Large City, Florida}

If I had to choose, I would choose item C. Citizens need to be involved and informed about the financial affairs of their government. The more they are told the more they can hold elected officials accountable. If they do not understand, they will put trust in those they think does understand. That information could come for bond holders, the media, elected officials, or government auditors. Whether they use them or understand financial statements, government has a responsibility to report and be held accountable. Citizens have a responsibility to vote and to then hold those they vote for accountable.

\section{Practitioner - Medium City, Ohio}

Our respondents believe that the average citizen does deserve a clearer financial statement, but overcoming citizen financial illiteracy is not their responsibility, it is ours prepare financial reports that they can read - such as the popular financial report - is an overview, but keeps them informed.

\section{Practitioner - Medium City, Ohio}

I think respondents believe the average citizen does deserve a clearer financial statement but GASB 34 statements are not going to provide that. Most local governments rely on a 
budget document that is easier to explain.

Also, PAFRs are being used to try to explain government finances.

Like most local government communications, there is apathy in the public.

\section{Practitioner - Very Small City, Ohio}

I am with the $90 \%$ crowd. 'B' does sound like the one I would pick since going the extra step of making the statements more understandable for the lay person is one thing but then to conduct classes to educate people in reading these statements would be another. Its like the thing about taking the horse to the water....

\section{Academic}

c. the average citizen relies on others to monitor state and local governments -- e.g., the bond raters, watchdog groups, and the media.

\section{Practitioner - Large City, Florida}

I would say either b or $\mathrm{c}$.

The finance officials I encounter understand that the financial statements are meant to serve many readers and that the general public is lower on the list than bond raters, elected officials, and the audit community.

The effort necessary to revise the current financial model to a more user friendly end product is immense and could cost countless hours and dollars. It seems that the political will is not there for such an uphill battle and the public isn't clamoring for any change.

\section{GASB Representative}

It is probably a combination of the three. A lot of governments do make an attempt to communicate basic information in a meaningful way to the general public. What may be necessary is not only to provide the information, but also to provide some explanation that helps the citizen to make sense of what $\mathrm{s} / \mathrm{he}$ is seeing. The issue of who financial statements are intended to serve is a longstanding conundrum. Although conceptually financial reporting standards include citizens and their representatives as a key group intended to be served by financial statements, the vast majority of citizens and legislators never open a CAFR and wouldn't know what to make of one if they did. However, it is equally true that many citizens and legislators are end users of financial statement information without realizing it. They receive the information from intermediaries who are the direct users of the financial statements. These intermediaries take the financial statement information, process it, and then communicate it to others in a form that is meaningful. Intermediaries would include city council and state legislative staff, citizen and taxpayer groups, and analysts at mutual funds, just to name a few. 
Academic

(C) That is what I have heard for years. 


\section{Question 07}

One of the great contradictions of our finding is as follows. A sizable majority of our respondents agreed that since the implementation GASB 34, public sector financial reporting is becoming more private sector-like. Yet a similar majority felt this would not benefit the average citizen and that it was a step in the wrong direction?

How do you interpret this dichotomy? Do you feel this is in part residue over the conflict regarding asset depreciation and its recording?

\section{Practitioner - Large City, Florida}

GASB 34 was a step in the right direction. It focuses on interperiod equity ann intergenerational responsibility. The difficulty in terms of the public is that GASB 34 presents information two ways - fund basis and entity wide. It appears to the average taxpayer as keeping two sets of books - thereby adding to their confusion.

Depreciation is recognized in the private sector and has always been recognized in enterprise and internal service funds. It recognizes the using up of an asset and even in governmental type funds it is difficult to argue against.

\section{Practitioner-Medium City, Ohio}

a) It is true, our financial statements look more private like, but they are not being used that way. In addition, having three (in Ohio we do) different basis of accounting in the same financial statements makes confusion for everyone.

b) Somewhat, - especially when a reader sees this large value as an asset (infrastucture) but that is only a small part of it. The biggest problem is the different basis - they look at the "balance sheet" and do not realize it is different from the statement of net assets.

I have personal experience of a CPA misinterpreting the GASB 34 statements, including comparing expenses from the entity-wide to the total budget (cash basis) - and reaching the conclusion that we are horrible budgeters.

\section{Practitioner - Medium City, Ohio}

I think both of those things are true. However, GASB 34 statements are not easily readable. I've had private sector accountants ask for interpretations. Those of us using GASB 34 reporting have accepted depreciation. The statements are still different from private sector and questions always arise from layman as to what they mean. 


\section{Practitioner - Very Small City, Ohio}

GASB 34 was an attempt to make the statements more in line with the Normal'. However, the items being reported in the public sector do not compare equally with the standard items that one would see in a private sector financial report. Thus when we talk about assets such as infrastructure (including sewers, culverts, etc.) in the public sector it may be more difficult to understand then the assets one would see in a typical private company balance sheet.

\section{Academic}

The new financial statements are very lengthy and complex - reporting on both the funds and entity wide, and also using both modified accrual and full accrual measures. This has not made the financial statements more user-friendly! I do not believe that the recording of asset depreciation is overly complex and may be one item that is easier to understand and helpful to citizens, e.g., road conditions

\section{Practitioner - Large City, Florida}

I think that many finance professionals were simply content with the previous model and didn't want the extra effort needed to apply GASB 34.

I also think that GASB 34 did not address anything the "average citizen" may have wanted from a revised financial statement model. I imagine that the average citizen would want something more simple and basic, say a budget to actual statement.

\section{GASB Representative}

Part of the answer lies in the misconception that 34 was intended to make government reporting more "business-like." It's a red herring. In the sense that 34 requires accrual reporting for the government as a whole, it is similar to the private sector. But that's where the similarity ends. The financial statements are very different. Fund financial statements have been retained (whereas the FASB eliminated fund reporting for not-forprofits). The rules of recognition and measurement are very different and lean toward producing more accurate depictions of the cost of service, rather than toward net position in the balance sheets. Governmental reporting is far more comprehensive than private sector reporting in large part because of what I suspect lies beneath some of your respondents' feelings that governments need to be more accountable--because they are using resources, taxes, that are not surrendered voluntarily. The infrastructure asset issue, stoked by the misinformation promulgated by a major professional association, has colored opinions to a degree. When you don't know any better, and the head of the national organization you belong to lies to you about what 34 requires, what else will you think? But it has been my experience that even the most vocal opponents of 34 , once they found out what they were really required to do, admitted that it was not as bad as they thought. Further, I have observed that finance officers are coming more andmore to realize the value of 34 . Finally, how can one argue that MD\&A is not valuable to the 
average citizen? If a citizen with an interest and a willingness to read the MD\&A can't get something meaningful out of it, then perhaps the MD\&A is not well written. Some finance officers say that citizens can't understand their financial report, but they don't do anything to make it more understandable, accessible, and readable. There is nothing in GAAP that prevents governments from making their financial reports easier to use and understand.

\section{Academic}

a) In part, the attitude is resistance to change

b) probably so. 


\section{Question 08}

If the financial statements become more transparent and understandable to the public, do you think this would weaken or strengthen the power of the financial bureaucracy relative to elected officials or other stakeholders such as the media or public?

\section{Practitioner - Large City, Florida}

Transparency will increase stewardship and accountability. It will strengthen other stakeholders knowledge and increase their expectations.

\section{Practitioner - Medium City, Ohio}

Theoretically, it should weaken the power of the financial bureaucracy as more people would understand the processes and thus the results.

However, when the media is involved, all is unknown....

\section{Practitioner - Medium City, Ohio}

I would hope it would weaken it but after this election season, I hope little hope that the public would take the time to educate itself in order not to have to rely on the messages given from politicians.

\section{Practitioner - Very Small City, Ohio}

Making the financial statements more understandable should be the goal and whether it weakens or strengthens the power of the financial bureacracy is not something that should be a concern. Everything that is expensed by using tax dollars should be an open record and hopefully justifiable if and when questioned either by the media or the public. This will ultimately diminish the jaundiced eye of the general public towards the bureaucracy and provide for a more healthy climate and interaction between the elected and the electors. (Which world am I living in?)

\section{Academic}

No.

\section{Practitioner - Large City, Florida}

It can only strengthen the financial bureaucracy is the public is engaged in the process and understands its results. 


\section{GASB Representative}

I don't understand the question. It seems like you're alluding to the power of information-whoever possesses the information, holds the power. When financial statements become more transparent and understandable, then the public gets decision-useful information it didn't have before, allowing them to make better informed decisions. You could interpret that as empowering them. If you believe that relinquishing control over information means the finance officer is "weakened," then I guess the assertion is correct. But one could also view transparency and understandability as improving the finance officer's ability to demonstrate proper stewardship and accountability--they are tools for proving to the public that you have done a good job. The GASB is sometimes accused of trying to set policy through its standards. Some argued that 34 was an attempt to make governments invest more in infrastructure. Others have claimed that 43 and 45 were attempts to force governments to fund their retiree health insurance. That's just silly. If a standard provides the public new information it didn't have before, and as a result of having this new information the public communicates different priorities to the government officials, how is this GASB setting policy? It is more accurate to say, I think, that those officials got away with doing something the public didn't want it to do, because the public didn't know what was going on until the new standards required that information be reported.

\section{Academic}

Reducing information asymmetry is a good thing for the public and other stakeholders. The question is how to do so, GASB 34 probably is not the answer. 


\section{Question 09}

Assuming SOX-like provisions were adopted in local governments, "who" should impose them? It would seem the choice is either the individual states or a federal agency such as the Government Accountability Office (GAO). Please comment.

\section{Practitioner - Large City, Florida}

I do not think the GAO can impose accounting requirements. GAO imposes auditing requirements. OMB Circular A-123 (Sarbanes-Oxley equivalent at the federal level) is an $\mathrm{OMB}$ action - not GAO. This could be imposed through changes to OMB Circualr A133 for state and local governments receiving federal funds or it could be required by individual state governments. It is easier to mandate at the federal level for federal agencies - one federal government. It will much harder to require at the State level as there are 50 state governments with 90,000 local governments providing them input. For $\mathrm{OMB}$ to require this through $\mathrm{OMB}$ Circular $\mathrm{A}-133$ would result in an outcry from the states. I do not see this coming to the states in the near future.

\section{Practitioner - Medium City, Ohio}

It would probably have to come from the GAO or some other body (more likely the SEC relating to municipal bond issuers)

\section{Practitioner - Medium City, Ohio}

I think the State needs to oversee and determine the process within the State.

\section{Practitioner - Very Small City, Ohio}

The imposer could be the State or the Federal Govt. Of course, the closer the imposer is to the local government in level the better it is for communication and further action. The question is who will enforce it? If the State Auditor was given the responsibility of being the enforcer, then it makes sense to have the imposing authority as close in level to the State. It would complicate and delay action and reporting if the Federal Govt were the imposer.

\section{Academic}

State governments should impose SOX-like provisions for small governments. Those who fall under the single audit act could have provisions imposed by the federal government.

\section{Practitioner - Large City, Florida}

I think the current Comptroller General has the political will to take on such a project, but this is not a guaranteed in future appointees. Legislation is needed to ensure imposition of 
the provisions and I support this could be effective from either federal or state.

\section{GASB Representative}

Not sure GAO could, unless it was through the single audit requirements. I suppose it would be done on a state-by-state basis. Another option, that most governments probably would not find palatable, would be the SEC, though that would apply only to governments in the public credit markets.

\section{Academic}

State. 


\section{Question 10 Florida}

The advent of the internet makes the widespread dissemination of a government annual financial report to all citizens who request it quite simple and inexpensive. If local governments were required to undertake this, what would be the "shape and form" of this document? Would it be comprised primarily of financials, per a CAFR? Would it combine financials with SEA's (the direction taken by federal agencies)? Would it be required to show comparisons relative to peers or national standards?

\section{Practitioner - Large City, Florida}

The Office has a web-site that includes information about the city auditor, office, audit committee, and questions and answers to most frequently asked questions. Importantly, every audit we issue is on our web site in its entirety to include a summary.

\section{Academic}

A "popular report" which includes simplified financials and SEA data would be most useful with a link to a full set of financial statements and footnotes.

\section{Practitioner - Large City, Florida}

Each of these ideas have their own unique issues and concerns. The simplest answer is to simply post the Budget document and CAFR, which does not require any additional cost. The other two options are larger and more expensive undertakings.

\section{GASB Representative}

All very good questions. Many governments that prepare audited financial statements put them on their websites in pdf form. Few, if any, take advantage of the functionality of the Internet. There is no drill-down capacity, no linkage to other information, such as performance measures, bond documents, budgets, etc. If an XBRL taxonomy is ever developed for governments, it would be a boon to financial reporting, but I think it's a long way off. That is where comparability is going to come from. If the intention is to further the indoctrination of citizens, then the CAFR as a whole would probably not be the right document. Rather, it would be one of many documents and databases from which information would be drawn. There should probably be a central portal that allows the user to bring together information from disparate sources within and without the government.

\section{Academic}

There should be some flexibility but I believe that SEA and financial information is very useful as would be comparisons to cities of similar size and other features. 


\section{Question 10 Ohio}

The advent of the internet makes the widespread dissemination of a government annual financial report to all citizens who request it quite simple and inexpensive. In this regard, Ohio is one of the leading states in requiring that CAFRs be available at one central location. Do you think this has been of value? For example, does it seem that your citizens are using this website to obtain a copy of your CAFR? Has it lowered your cost of printing CAFRs for public dissemination? On the other hand, has having the CAFR so readily available created some unintended consequences?

\section{Practitioner-Medium City, Ohio}

Yes, it has helped - we link to the state auditors website for the CAFR and audit - and this helps show our openness and assurance (audit). And yes, we had unintended consequences - a local CPA got a copy of the CAFR and turned it into a political issue saying we had too much money - showing total fund balances as "surplus". This was a very big issue for the city to overcome - even a charter amendment was placed on the ballot to reduce property taxes because these "concerned citizens" took this guys word as gold and the city admin as "liars". The good news is the people looked at the facts, and made the correct decision - to not lower their taxes and keep excellent long term planning and great city services.

\section{Practitioner-Medium City, Ohio}

Having the CAFRs easily available does not really cost down on costs. We have saved producing one or two copies. However, it is valuable to have them available. It has created as much havoc as good since people read them and do not understand them or the differences between a CAFR and a budget.

\section{Practitioner - Very Small City, Ohio}

Availability at a central location is a great boon to the community since we can easily direct anyone looking for one to the site or send one to their email box. It has certainly lowered the cost of printing and mailings. It has not helped the average citizen in becoming more aware of the activities because having the report available on the web has not done anything to kindle the interest of the average citizen in the community's financials. Their interest gets peaked when the trash does not get picked up or the basement floods. It is the same apathy that most citizens display towards their state and the country. Everyone has an opinion but rarely has the time or inclination to get involved. 


\section{Question 11}

Based on your knowledge and experience in the field, what do you think a would-be promulgator of SOX-like standards such as POC and IAC would need to consider prior to implementation, and why?

\section{Practitioner-Large City, Florida}

Do they have the authority to promulgate. At the State and local government level, those bodies have significant authority over what the government does and does not do. The second consideration is whether the promulgation is really needed in the mind of hte public.

Third - is the promulgation going to be viewed as "generally accepted" by the profession.

\section{Practitioner - Medium City, Ohio}

There would have to be a huge default or scandal - such as with Enron - that would role these out.

\section{Practitioner - Medium City, Ohio}

Good thought reasoning and explanation as to what the purpose and goals of each because to avoid misconceptions of how and why they are being implemented.

\section{Practitioner - Very Small City, Ohio}

As mentioned in \#9, the promulgator should consider not only the standards but the consequences of non-compliance. To ensure widespread compliance, it would be beneficial to have proper reporting channels established so that the promulgator, imposer and the enforcer can work hand in hand to have quick turn around on any noncompliance of the standards and fast decisive action so as to keep all others 'on their toes'.

\section{Academic}

Cost to smaller governments and the ability to find citizen volunteers to serve.

\section{Practitioner-Large City, Florida}

COSTS! Any new idea has both hard and soft costs and many governments remain in a cost-cutting mode. An unfunded mandate to enhance financial reporting could lead to a backlash from professionals unless their is a funding mechanism.

\section{GASB Representative}

Cost-benefit concerns will be prominent, since we're talking about using tax dollars. There may need to be some consideration of what governments it would apply to. For instance, GAAP reporting requirements in some states apply only to governments over a 
certain population, or apply differently to smaller governments

Academic

Based on SOX, cost will be a significant factor to consider. In addition, what size entity should be required? Timing of implementation. 


\section{Question 12}

(If your city provides a Popular Annual Financial Report (PAFR), please comment on its usefulness in communicating with your citizens. - First two responses)

In addition, please provide any additional comments.

\section{Practitioner - Large City, Florida}

The City of XXXXX does not currently produce a PAR report. We issue a CAFR that has been recognized by GFOA for financial presentation and budget presentation. It is my intent to issue a PAR type report this year on my Office - the Office of the City Auditor.

In my view the CAFR needs to be supplemented by a report that identifies Service Efforts and Accomplishments.

Lastly, the City of XXXXXX has an excellent Audit Committee and I highly recommend its structure and operation to other local governments.

\section{Practitioner - Medium City, Ohio}

I believe the PAFR is the key to the citizen involvement in municipal finance - not the CAFR. The CAFR would be used as the base, but then user friendly information could be used from it - such as an annual company report to shareholders as compared with their 10K filings (compared to the CAFR in government)

\section{Practitioner-Medium City, Ohio}

No Comment

\section{Practitioner - Very Small City, Ohio}

No comment.

\section{Academic}

Good luck with your research project.

\section{Practitioner - Large City, Florida}

I think their is a need for a first step in increasing accountability that is less costly: advise governments to institute an internal audit program. This would not be mandated effort, and adding such professionals would enhance governance and accountability and if organized effectively could have significant financial benefits. Once these professionals are ingrained, create an oversight body such as an independent audit committee. These 
efforts - as at local level - not mandated by the federal or state government would increase controls and effectiveness and not be perceived as a top down approach to legislate improvements.

\section{GASB Representative}

No comment,

\section{Academic}

No comment. 
Appendix C - Comments Received on Survey Instrument 


\section{Survey Question}

Please provide below any concerns or objections you think might affect the proper implementation of either the "principal officer certification" or the "independent audit committee"

Responses

\section{Ohio}

We have a finance committee - 4 elected city officials and the finance director chartered-provision board of control 4 elected. finance committee members \& mayor, law director, service director, finance director. Did not want additional committee.

\section{Florida}

The city has resolutions/ordinances that make the administration and council members accountable for the city's financial disclosures and practices.

\section{Ohio}

Sections of Ohio revised code and municipal charters are substantially different in contractual authority or legislated power for Ohio state \& local gov'ts. The "SOX" implementation would follow St. 34 issues - further drives investment rating entities to comparability (does little for the public - like PAFRs). GASB $34 \&$ items like this will push SEA reporting.

\section{Florida}

Political \& personal agendas can easily cause detrimental results in small towns.

\section{Florida}

Principal officer certification- although in theory it makes them responsible, practically speaking, finance is responsible. Internal audit committee - protect from public criticism, fear is that members would have to be trained in finance.

\section{Forida}

These are solutions to problems that do not exist in most municipalities

\section{Florida}

Finding people to be on the independent audit committee would be a difficult task. You will find very few people who understand governmental accounting to begin with. My experience has been that you find a lot of self-employed men \& women who think they 
understand it and want to tell gov't how wrong we are. The majority of time would be spent training \& retraining them to communicate with our auditor. One more unnecessary hurdle.

\section{Ohio}

The city of XXXXX has operated extremely well with none of the above. Too much regulation and requirements only hamper small towns. We just don't do unnecessary regulations. So why bother requiring them.

\section{Ohio}

We currently have an audit committee, however, since it is comprised of council members there is no true ability for them to function in the proper role. We are also at the mercy of the state auditors to determine who will perform our audit.

\section{Florida}

Many of our residents who qualify as "audit committee" members do not want to volunteer do to the litigious nature of public service. They fell even a "perceived" violation of sunshine laws or any rule or regulation could be harmful to there profpersonal reputation. We contend with groups of "disgruntled" residents who often threaten both elected and appointed officials with lawsuits.

\section{Ohio}

Independent audit committees in the governmental arena could potentially lead to political manipulation due to the sometimes sensitive nature of the information that is received by the committee. We already have too many committees, boards $\&$ commissions.

\section{Ohio}

They don't have clue about the financial records \& CAFR now. And the certainly wouldn't have with the implementation of SOX.

\section{Florida}

It would be difficult for a medium sized or small city to staff an audit committee with qualified members (other than the elected officials serving in that capacity).

\section{Florida}

I believe we can comply easily, however i do not see a big benefit with competent staff who do a good job or are regarded as professional. 


\section{Florida}

Overkill - how many municipalities have been accused or convicted of serious defalcations similar to the Enrons, Worldcoms, etc of the world.

\section{Ohio}

Municipalities are different "animals" than the private sector. There is no motivation for a municipality to "cook the books" or attempt to show a "paper profit". We are already audited annually, and hold to a very different standard than our counterparts in the private sector.

\section{Florida}

The city has had a citizens finance committee that reviewed the budget, financial advisor recommendations, and most other financial contracts for independent citizens input. Can't get volunteers.

\section{Ohio}

Under current state law the chief fiscal officer is already covered as the principal officer certification and this be another burden. No problem with the audit committee.

\section{Florida}

We may have the most qualified 3 person audit committee in the nation. Excellent, qualified, committed.

\section{Florida}

Can be done given sufficient time and proper attention to the" need"

\section{Ohio}

In a small community we would not find individuals willing to serve this capacity.

\section{Ohio}

No additional dollars are available for developing, implementing, nor maintaining additional policies, controls, or procedures.

\section{Ohio}

CAFR is too complicated for average citizen 


\section{Ohio}

The political implications with respect to "independent" auditors could pose a problem as those interested in serving on the committee could have political aspirations. 
VITA

DOUGLAS RAY FINK

Born, Dayton, Ohio

1968

B.S.B.A., Business Economics

Wright State University

Dayton, Ohio

1972

Masters of Business Administration

Wright State University

Dayton, Ohio

$1972-1973$

Accountant

Ernst \& Young, CPAs

Dayton, Ohio

$1973-1977$

Treasurer and Assistant to the President

Rieck Mechanical Services, Inc.

Dayton, Ohio

1976

Certified Public Accountant

State of Ohio

(non-active status)

$1978-1981$

Assistant Professor (Accountancy)

Wright State University

Dayton, Ohio

$1978-1981$

Leading Partner

Fink, Jeffcott, \& Crabtree, CPAs

Centerville, Ohio

$1981-1987$

Township Trustee

Washington Township

Montgomery County, Ohio

$1981-1987$

President

Ameripak, Inc.

Middletown, Ohio

1987-1991 President

Douglas R. Fink, Inc.

Washington Township, Ohio 


$$
\begin{array}{ll}
1990-1991 & \begin{array}{l}
\text { Instructor (Accountancy) } \\
1992-1993
\end{array} \\
\begin{array}{l}
\text { Wright State University } \\
\text { Dayton, Ohio }
\end{array} \\
2001-2004 & \begin{array}{l}
\text { Lecturer (Accountancy) } \\
\text { University of Dayton } \\
\text { Dayton, Ohio }
\end{array}
\end{array}
$$

\section{PUBLICATIONS AND PRESENTATIONS}

Fink, D.R., (1999). Activity Based Management for Local Governments. Paper presented at the Southeastern Conference on Public Administration meeting, Pensacola, Florida.

Fink D.R., (2003). Accounting Jeopardy: Novel Use of a Relational Database. Paper presented at the American Accounting Association Ohio Regional meeting, Columbus, Ohio.

Fink, D.R. (2005). Enhancing Accountability: Should Regulations Similar to Sarbanes-Oxley be Expanded to the Local Sector. Paper presented at the Southeastern Conference of Public Administration meeting, Little Rock, Arkansas.

Frank, H.A. and Fink, D.R. (Accepted 2006). Enhancing Accountability: Should Regulations Similar to Sarbanes-Oxley be Expanded to the Local Sector? Journal of Public Budgeting, Accounting \& Financial Management, In Press. 